\title{
Synthesis of deoxymannojirimycin using a Ruthenium-catalysed hydrogen borrowing reaction
}

\author{
Victoria Skinner \\ A thesis submitted to Victoria University of Wellington in partial fulfilment of the \\ requirements for the degree of Master in Drug Discovery and Development
}

Victoria University of Wellington

2017 


\section{ABSTRACT}

1-Deoxymannojirimycin (DMJ) has been investigated as a potential anti-cancer therapy due to its specific inhibition of class I $\alpha$-mannosidase enzymes, which has been shown to trigger ER stress and the Unfolded Protein Response (UPR) pathway, leading to apoptosis in human hepatocarcinoma cells.

Current methods for the synthesis of DMJ consist of multiple steps and often result in poor yields. The objectives of this research project were to develop a scale-up suitable synthesis of deoxymannojirimycin (DMJ), and to assess the feasibility of telescoping key-reactions to reduce the number of unit operations.

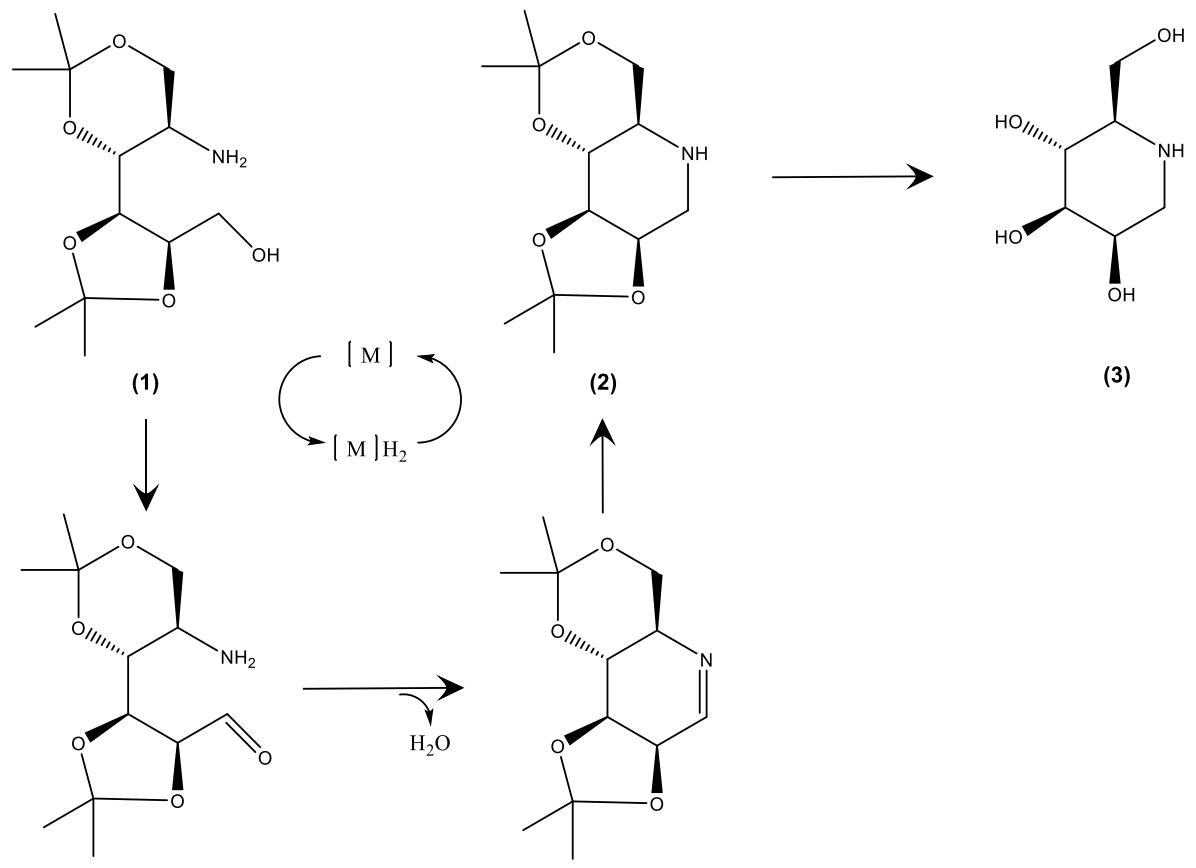

Synthetic efforts focused on the key conversion of 1 to 2 have previously involved separate oxidation and reduction steps. In our laboratory; attempts to use hydrogenborrowing chemistry had taken $>48 \mathrm{hr}$ and not been achieved in high yield. The highlights of this work were that this conversion was ultimately realised in $95 \%$ yield in $24 \mathrm{hr}$, and that the final deprotection of (2) could be telescoped into the process removing reactionworkup and chromatographic steps.

The ruthenium catalyst used in the hydrogen borrowing reaction was found to be extremely air-sensitive, with reactions taking place in carefully prepared reaction vessels under an atmosphere of dry argon gas. The catalyst was also found to exhibit sensitivities 
to materials such as metal needles and polymer tubing, preventing sampling and monitoring of the reaction during synthesis.

This study demonstrated that a one-pot synthesis is feasible, compressing the final steps in the synthesis of DMJ in excellent yield. The difficulty arises from the sensitive nature of the ruthenium catalyst, and the extreme care required in the preparation of the glassware and reagents used in synthesis. Many aspects of this development require further investigation, including the sampling, monitoring and quality control of each synthetic step. 


\section{DECLARATION AND COPYRIGHT}

The Copyright of this thesis resides with the author. The work in this thesis was completed by the author at the Ferrier Research Institute, Victoria University of Wellington in conjunction with GlycoSyn, Callaghan Innovation. No portion of this work has been reportedly previously. 


\section{ACKNOWLEDGEMENTS}

Thank you to Dr Scott Cameron and Dr Martyn Coles for your invaluable assistance with running and reporting my x-ray crystallography samples. Thanks also to Dr Tanzeel Arif for running my samples on the LCMS when I had all but given up and just about run out of time. The data you obtained was extremely valuable and went a long way to explaining my puzzling HPLC-CAD results.

Thank you to Dr Derek Watt for providing me with the starting material I needed and for your guidance as my project progressed. Without your knowledge, I would not have been able to achieve these results.

My sincerest and heartfelt thanks to my supervisor, Dr Simon Hinkley. Thank you for putting up with my attitude and quirks, for steering me back to sanity every time I went off the rails, for being my advocate and my guide. Thank you for your patience, for teaching me many new skills, and for sticking with me throughout this whole process. Absolutely none of this would have been possible without you, and I promise there will be cookies. My thanks also go to my colleagues and fellow students, for your support and assistance. Thank you to Assoc. Prof Peter Northcote and to Dr Lawrence Harris for your advice, and particularly your help with TLC. Special thanks to Norman for your help with everything, from teaching me to use Chromeleon to helping me find lab equipment. Thanks also to Dan for your guidance on HPLC method development and software use.

Special thanks also must go to my friends and family, especially to Ash and Hamish for keeping me happy and sufficiently sane. You are incredible people. 


\section{Table of Contents}

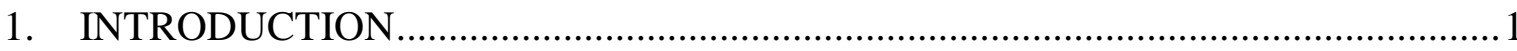

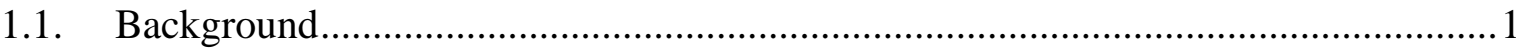

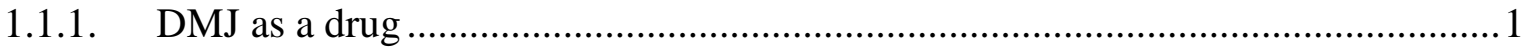

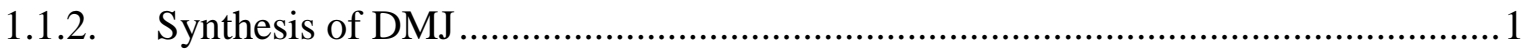

1.1.3. Borrowing Hydrogen Catalysis ("Hydrogen Borrowing") ...................................

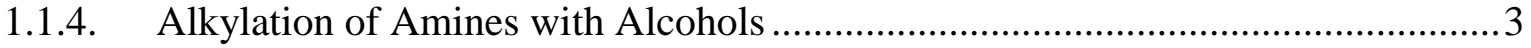

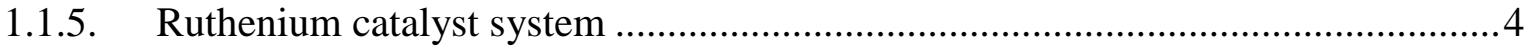

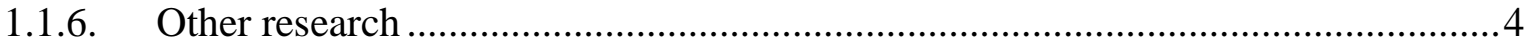

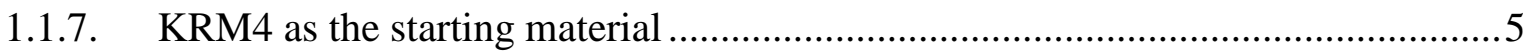

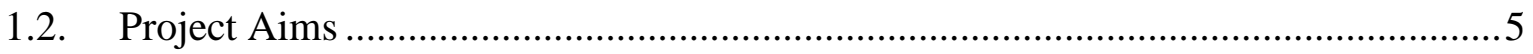

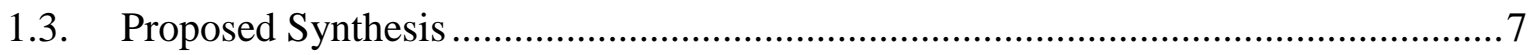

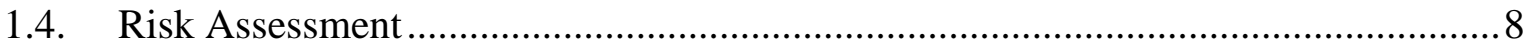

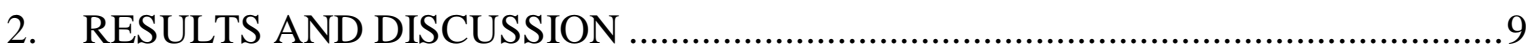

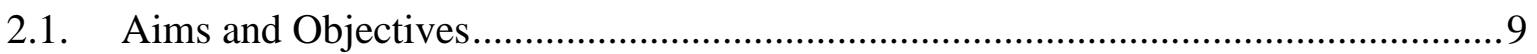

2.2. Purification and characterisation of KRM4 (1) .................................................... 9

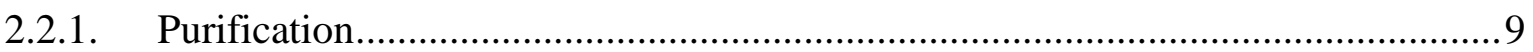

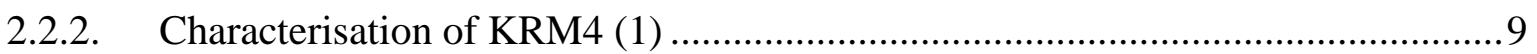

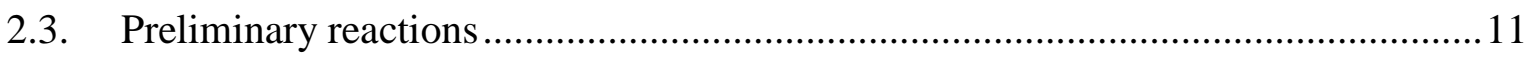

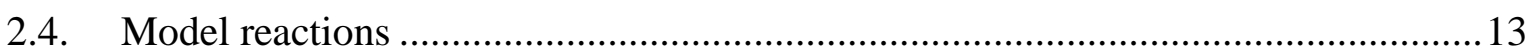

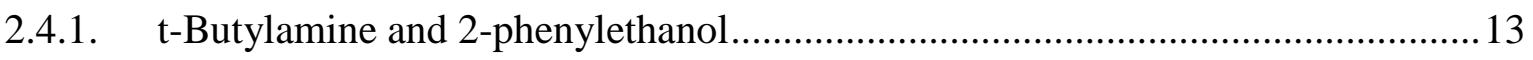

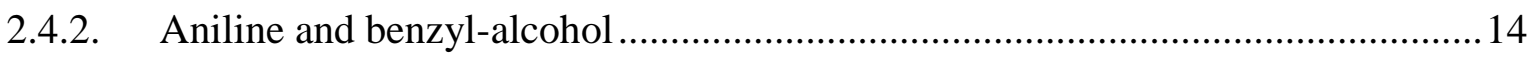

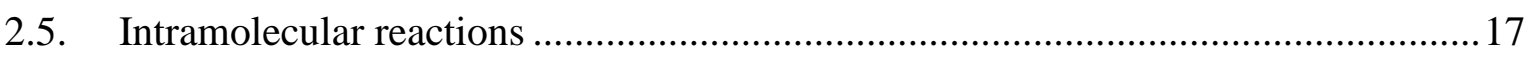

2.5.1. Synthesis of 1,3 -4,5-di-isopropylidene deoxymannojirimycin (2) ...................... 17

2.5.2. Purification of 1,3 -4,5-di-isopropylidene deoxymannojirimycin (2) .................. 19

2.5.3. Characterisation of $1,3-4,5$-di-isopropylidene deoxymannojirimycin (2) ...........21

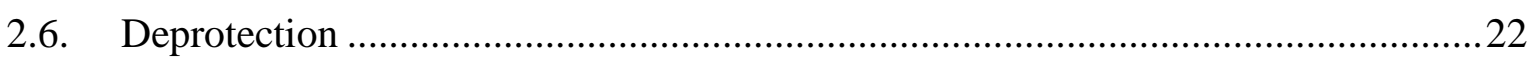

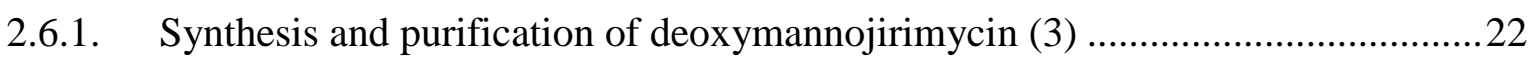

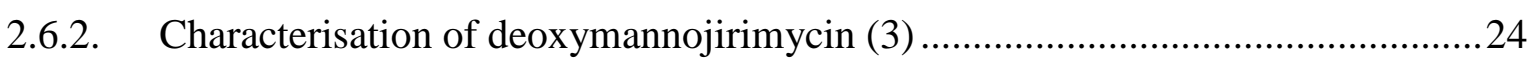

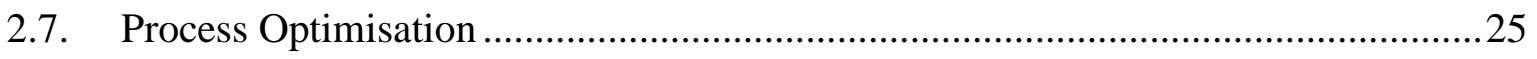

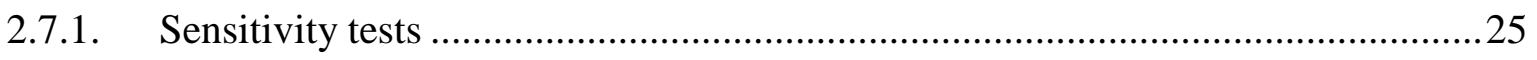

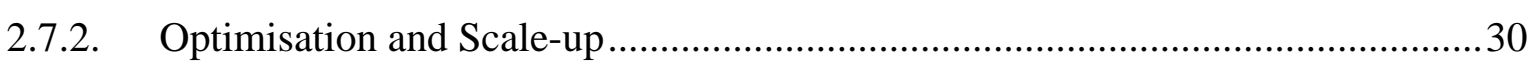

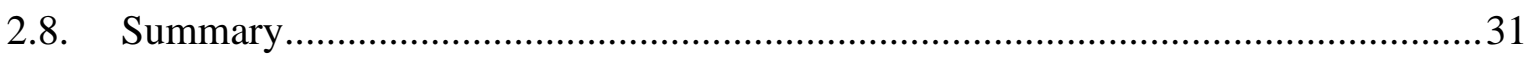

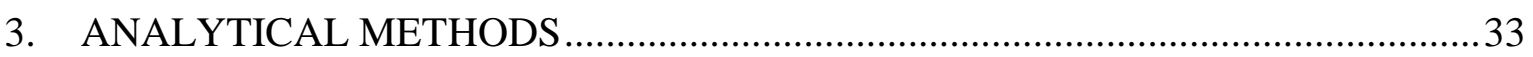




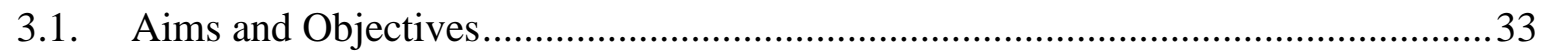

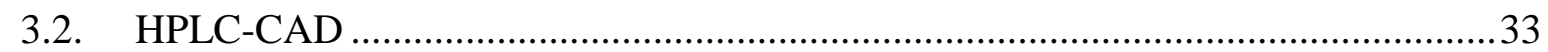

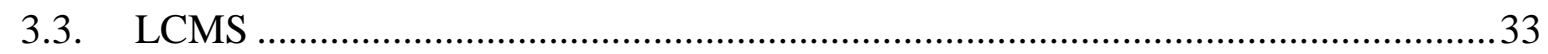

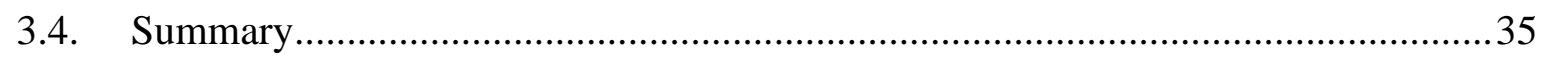

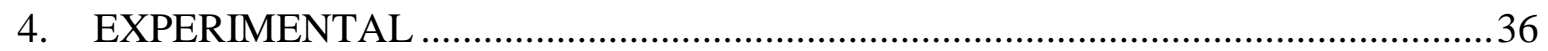

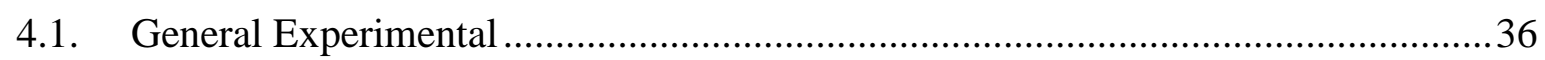

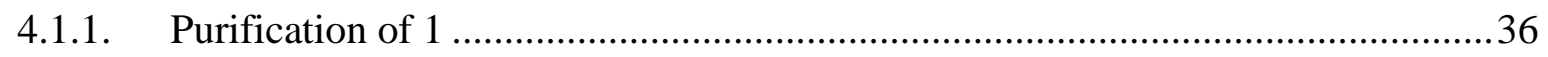

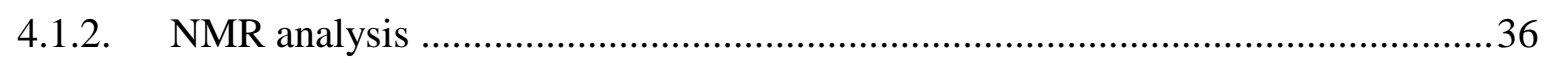

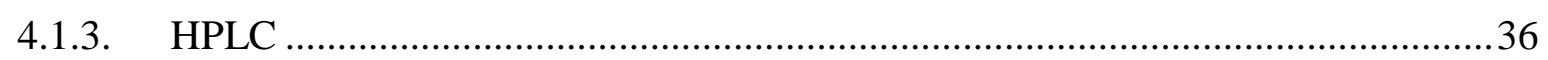

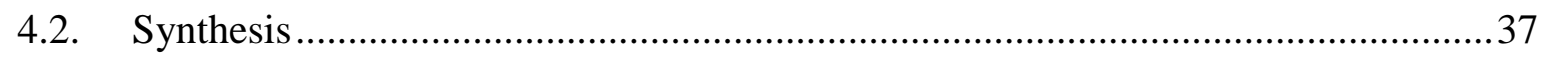

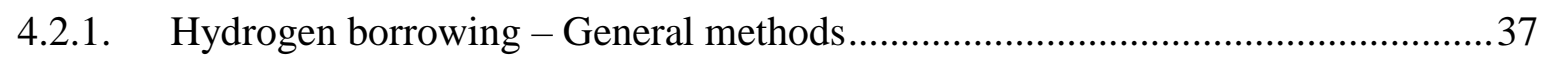

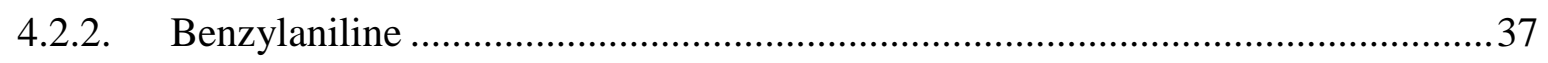

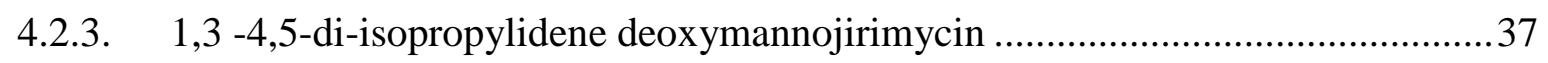

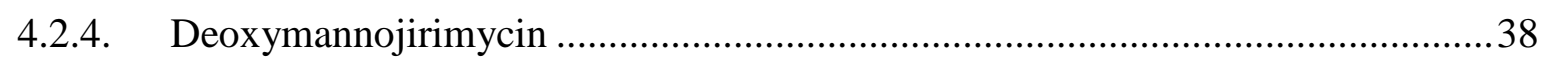

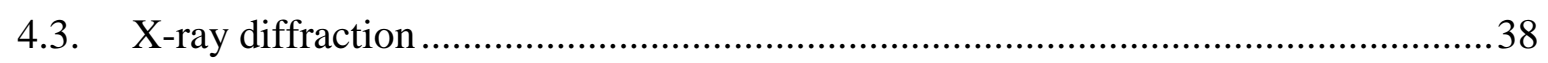

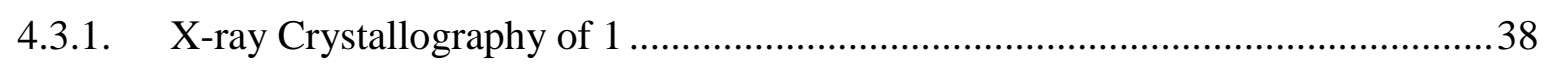

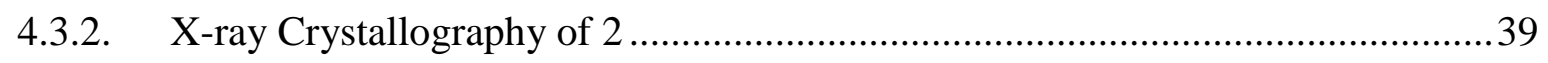

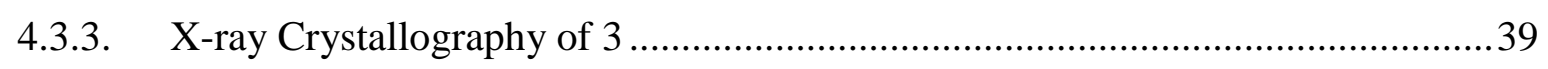

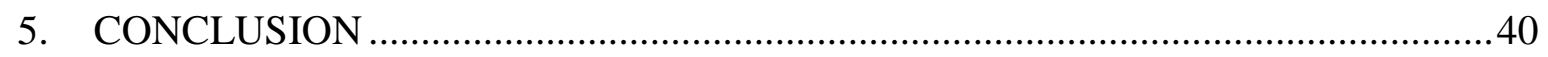

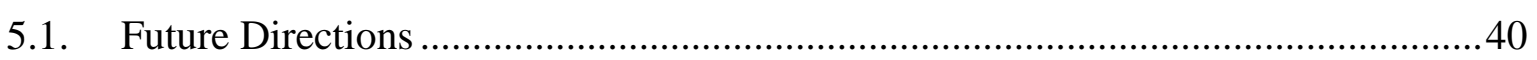

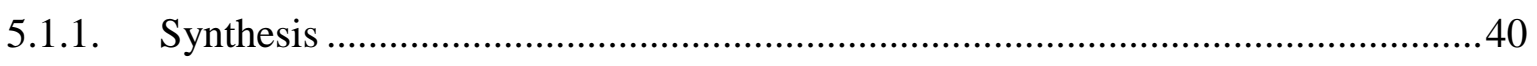

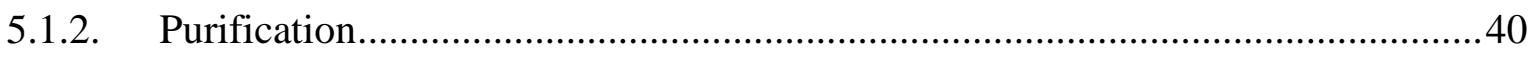

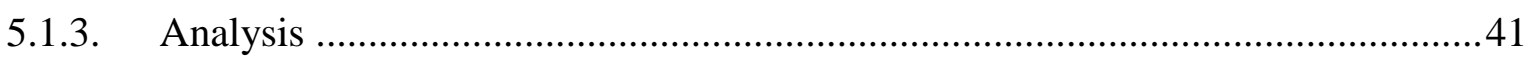

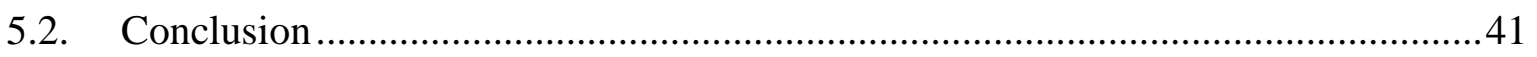

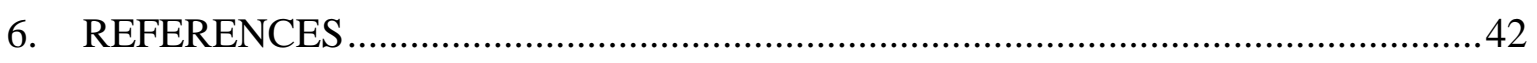

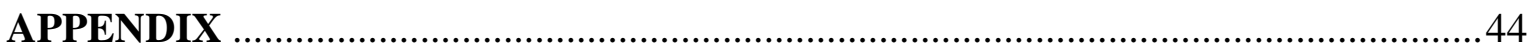




\section{ABBREVIATION LIST}

${ }^{1} \mathrm{H}$ NMR Proton nuclear magnetic resonance

${ }^{13} \mathrm{C}$ NMR Carbon-13 nuclear magnetic resonance

$\Delta$

CAD

COSY

$\mathrm{D}$

Dd

Ddd

Dt

DEPT-135

DPEPhos

$\mathrm{DPPF}$

DMJ

ER

HIV

HMBC

HPLC

HSQC

KRM4

$\mathrm{M}$

MBL

MS

ORTEP

PEEK

POV-Ray

S

$\mathrm{T}$

TEA

TLC

UPR
Chemical shift (ppm)

Charged Aerosol Detector

Homonuclear correlation spectroscopy

Doublet

Doublet of doublets

Doublet of doublets of doublets

Doublet of triplets

Distortionless Enhancement by Polarisation Transfer (135 $)$

bis[(2-diphenylphosphino) phenyl] ether

bis(diphenylphosphine)ferrocene

Deoxymannojirimycin

Endoplasmic reticulum

Human Immunodeficiency Virus

Heteronuclear multiple-bond correlation

High Performance Liquid Chromatography

Heteronuclear single quantum correlation

$(1,3)$-(4,6)-Di-isopropylidene-2-deoxy-2-aminomannitol

Multiplet

Mannose-binding Lectin

Mass Spectrometry

Oak Ridge Thermal Ellipsoid Plot Programme

Polyether ether ketone

The Persistence of Vision Ray Tracer (ray tracing programme)

Singlet

Triplet

Triethylamine

Thin-layer chromatography

Unfolded Protein Response pathway 


\section{INTRODUCTION}

\subsection{Background}

\subsubsection{DMJ as a drug}

1-Deoxymannojirimycin (DMJ, 3, Figure 1) has been investigated as a potential anti-cancer therapy due to its specific inhibition of class I $\alpha$-mannosidase enzymes. ${ }^{1}$ Alpha-mannosidases are involved in $\mathrm{N}$-glycan processing in the endoplasmic reticulum (ER) and Golgi apparatus. There is evidence to suggest that glycans play an important role in the correct folding and stabilisation of proteins. ${ }^{2}$ Inhibition of $\alpha$-mannosidases interferes with $N$-glycan processing and has been shown to trigger ER stress and the Unfolded Protein Response (UPR) pathway, leading to apoptosis in human hepatocarcinoma cells. ${ }^{1}$

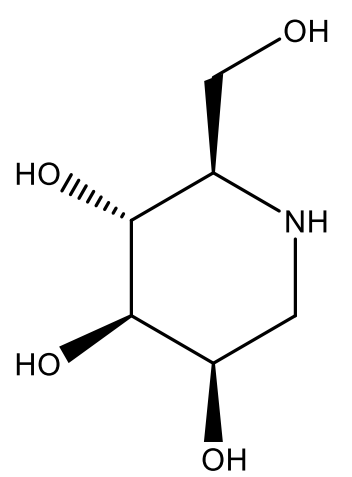

Figure 1. Deoxymannojirimycin (DMJ, 3)

DMJ also has applications in the treatment of Human Immunodeficiency Virus (HIV). Inhibition of $\alpha$-mannosidase has been shown to strengthen the interaction between HIV and Mannose-binding Lectin (MBL), and thus enhance deactivation of the virus via the lectin complement pathway. ${ }^{3}$ An effect was also seen on virus binding with monoclonal antibodies, potentially due to an increase in density of mannose residues on glycoprotein gp120.

\subsubsection{Synthesis of DMJ}

Several syntheses have been developed for the production of DMJ. Some of these methods are particularly relevant to this work as they considered synthesis at scale.

In 1989, a synthesis of DMJ from D-glucose was published. ${ }^{4}$ Already by this point there had been several reported syntheses, including a stereoselective synthesis from D-mannose, ${ }^{5}$ but there was a need for a viable method for production at a larger scale. The overall synthetic procedure involved joining of C-6 and C-2 with an amine linkage and reducing the aldehyde 
function at C-1 to an alcohol. This multi-step procedure reportedly resulted in an overall yield of 35\%. In an associated paper, Fleet et al. described the synthesis of DMJ from gulonolactone, involving the introduction of nitrogen with inversion at C-5 of Lgulonolactone. ${ }^{6}$ This provided an alternative synthetic route with an overall yield of $25 \%$.

In 2003, Knight and Tchabanenko reported a total synthesis of DMJ via carbonylation of 5vinyloxazolidin-2-ones. ${ }^{7}$ Vinyloxazolidinones were produced by converting D-serine into a protected aldehyde, to which vinyl magnesium bromide was added prior to treatment with potassium tert-butoxide. The resulting compounds were heated in ethanol under a carbon monoxide atmosphere with a bis(triphenylphosphine)palladium chloride catalyst, yielding the $\delta$-lactam, which was then epoxidised and treated with DBU to give the $\beta, \gamma$-unsaturated lactam (Figure 2Figure 2. ). Protection, dihydroxylation and reduction steps followed to give a piperidine compound that was then converted into DMJ with a $68 \%$ yield overall.
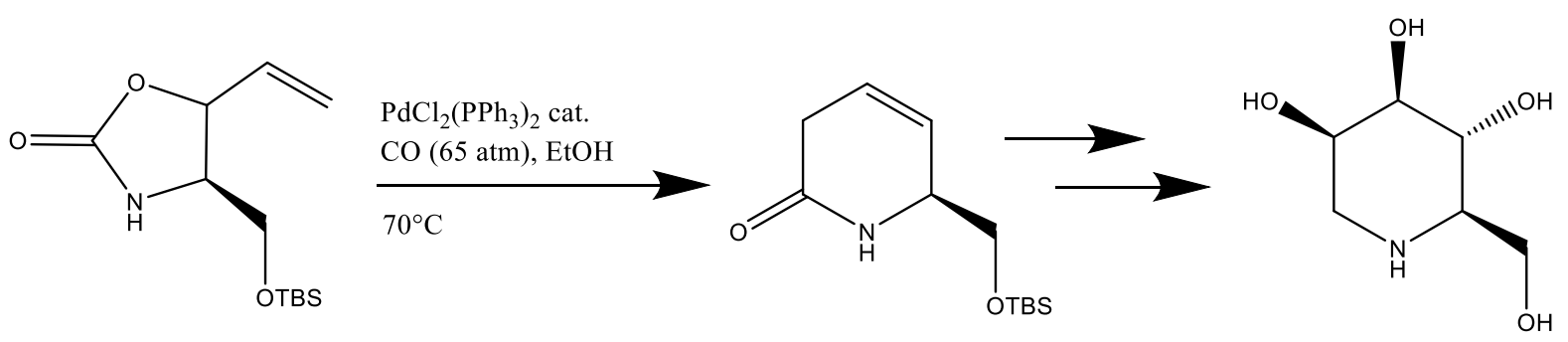

Figure 2. Knight and Tchabanenko synthetic route.

In 2009, Racine et al. reported a short synthesis of DMJ from D-fructose (Figure 3). ${ }^{8}$ The nitrone produced from D-fructose underwent a highly stereoselective reduction, with hydrogenation over $10 \% \mathrm{Pd} / \mathrm{C}$ affording DMJ.

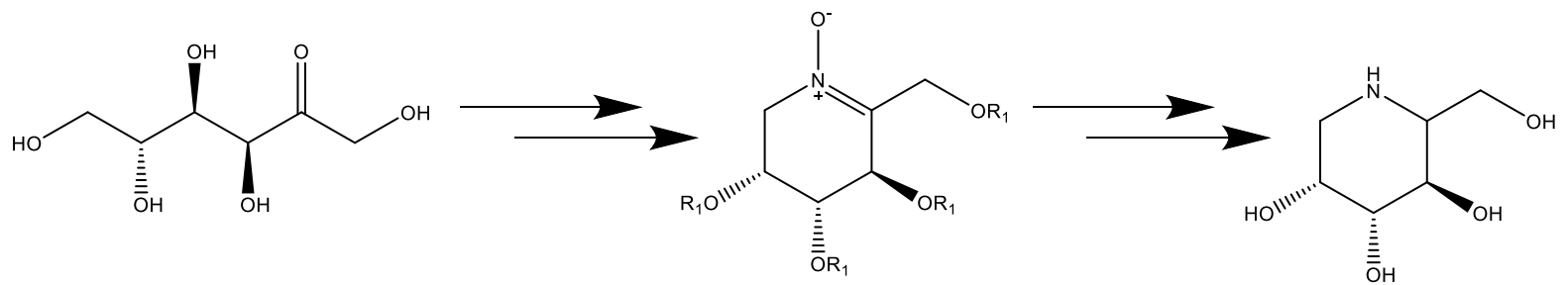

Figure 3. Synthesis from D-fructose (Racine et al.).

Current methods for the production of DMJ consist of multiple steps and often result in poor yields. For DMJ to be produced in a commercially viable manner, the number of steps must be reduced to minimise the time and cost required for production. To achieve this, a more efficient methodology is essential. 


\subsubsection{Borrowing Hydrogen Catalysis ("Hydrogen Borrowing”)}

Hydrogen borrowing (H-borrowing) reactions involve the use of a metal catalyst to activate an alcohol by temporary conversion to a carbonyl compound. ${ }^{9}$ These carbonyls then react to give a variety of compounds, including imines and alkenes. The catalyst then returns the "borrowed" hydrogen to the converted compound, finalising the process. This catalysis can be used to form N-C and C-C bonds using alcohols. ${ }^{9}$

Activation of alcohols is usually achieved by addition of a base or an acid. ${ }^{9}$ Treatment of the alcohol with a strong base, deprotonates the alcohol, resulting in a nucleophilic alkoxide, which is more readily able to react than its parent alcohol. This reduction step is often a lowyielding and slow process (solvent-dependent), forming by-products and requiring significant work-up prior to proceeding to the alkylation reaction. ${ }^{10}$

Hydrogen borrowing catalysis provides an alternative activation method, which comprises temporary removal of a hydrogen to oxidise the alcohol into an aldehyde or ketone. ${ }^{9}$ The hydrogen is later returned to the derivative compound, rendering the activation catalytic. This removes the need to pre-treat the alcohol, thus decreasing the complexity of the alkylation process.

\subsubsection{Alkylation of Amines with Alcohols}

$\mathrm{N}$-alkylation of amines is traditionally accomplished by reacting the amine with an alkyl halide. ${ }^{11}$ This is not ideal due to the toxicity of halide compounds and the production of halogenated waste. It is also suggested to be problematic due to the potential for overalkylation. ${ }^{11}$ Catalytic activation of an alcohol, to provide a carbonyl and an attractive electrophilic centre, provides an alternative $N$-alkylation pathway. In addition, this is overall a safer and fewer-step operation and produces only water as a by-product.

In the hydrogen borrowing method, the hydroxyl hydrogen is temporarily removed by the metal catalyst, resulting in conversion of the alcohol to an aldehyde or ketone (Figure 4). ${ }^{11}$ This carbonyl compound will then react with the amine in situ, forming an imine. Finally, the imine is reduced by return of the previously borrowed hydrogen to give the alkylated amine product. 


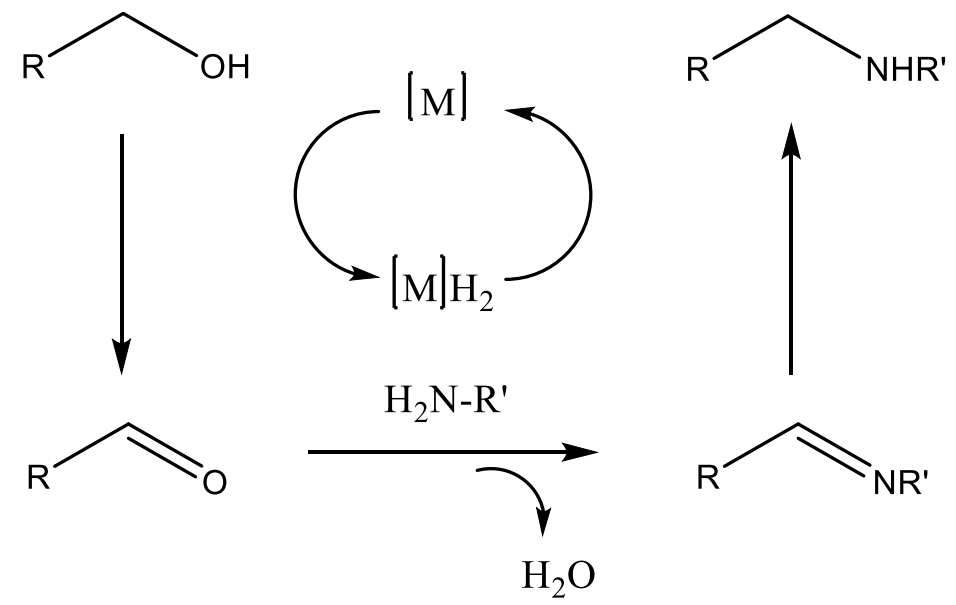

Figure 4. N-alkylation using borrowing hydrogen catalysis

\subsubsection{Ruthenium catalyst system}

Williams et al. performed a thorough investigation of potential catalyst/co-catalyst pairings for production of secondary and tertiary amines, heterocyclisation with diols, alkylation of sulfonamides and other species. ${ }^{11}$ The $\left[\mathrm{Ru}(p \text {-cymene }) \mathrm{Cl}_{2}\right]_{2}$ catalyst with bis(diphenylphosphine)ferrocene (DPPF) or bis[(2-diphenylphosphino)phenyl] ether (DPEPhos) as co-catalyst was shown to be very effective, resulting in high yields for most syntheses. Reactions were carried out under a nitrogen atmosphere in nitrogen-purged glassware using anhydrous techniques. This was a surprise, as it suggested that water may have been considered problematic for this type of reaction, yet is produced in a stoichiometric fashion.

\subsubsection{Other research}

Broomfield et al. investigated the use of a range of commercially available bisphosphine ligands as co-catalysts in borrowing hydrogen benzylation reactions. ${ }^{12}$ High yields were achieved when experiments were run in a sealed vessel under an argon atmosphere.

Leonard et al. considered the use of borrowing hydrogen catalysis as an alternative method for synthesis of a number of pharmaceutical intermediates. ${ }^{13}$ Difficulties were encountered when using this chemistry with complex polyfunctional molecules due to structural incompatibilities. It was noted that further research is required to develop more active catalysts. This research also highlighted some catalyst incompatibilities with heterocyclic structures rich in heteroatoms, which was demonstrated by spiking experiments. 


\subsubsection{KRM4 as the starting material}

KRM4 (1), or (1,3) -(4,6)-di-isopropylidene-2-deoxy-2-aminomannitol, is the proposed starting material for the synthesis of DMJ. It is obtained as an intermediate during the commercial synthesis of Kifunensine as completed under license by GlycoSyn (patented). ${ }^{14}$ This research thesis describes attempts to perform a ring-closing (intramolecular) $\mathrm{N}$ alkylation, coupling the alcohol carbon to the primary amine using the hydrogen borrowing reaction. This reaction pathway to DMJ is very attractive, as although there is a tremendous amount of literature and patented technology, the lack of a concise method is represented by the price point for DMJ.HCl at US\$ 4250/g (commercial price at time of reporting,

Carbosynth, Compton, UK). Thus, if this readily available (in Glycosyn) intermediate could be transformed efficiently, it would establish a commercially viable manufacturing method for DMJ, and a process that would likely be protected under trade-secret. A trial process has been attempted in Glycosyn, whereby the amine was protected as the carboxybenzyl carbamate, oxidation, imine formation and reduction, then deprotection yielding the desired product. This is not commercially viable due to the number of steps, series of workups, and potential issues with the aldehyde post-oxidation as a hold-point in a commercial process.

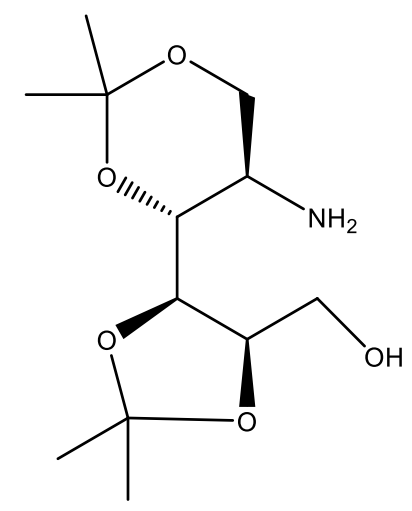

Figure 5. KRM4 (1)

\subsection{Project Aims}

The primary objective of this research project was to develop a scaleable synthesis of deoxymannojirimycin (DMJ) using a "hydrogen-borrowing" reaction. The second-objectives were to assess the feasibility of telescoping reactions to enable a one-pot multi-step synthesis, to optimise the yield, and to minimise reagent costs and by-products (scheme 1). 

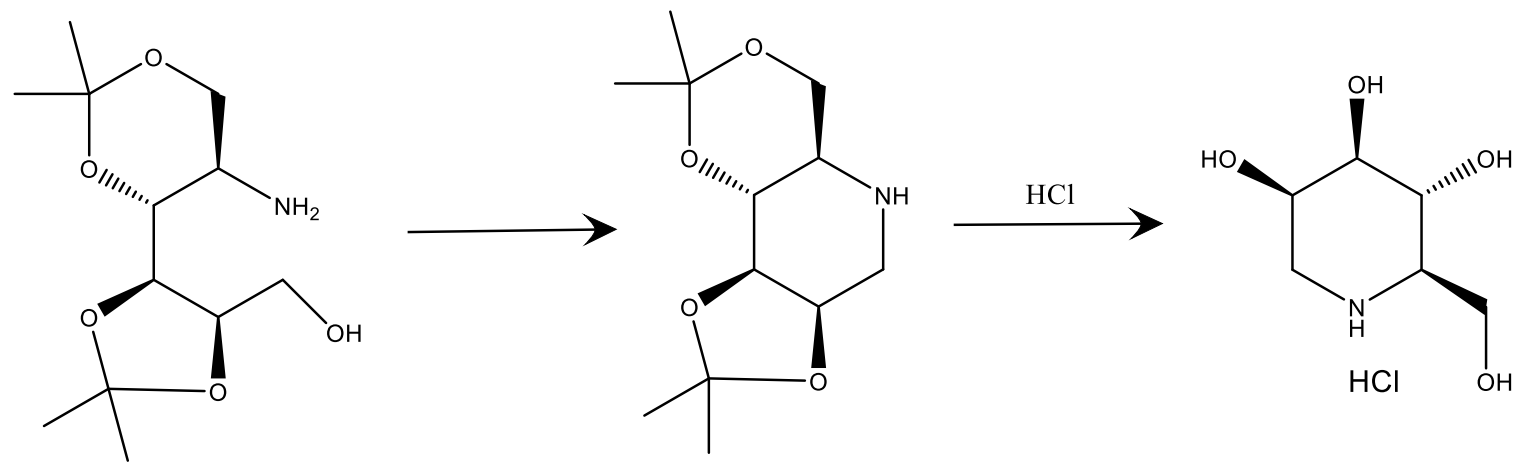

Scheme 1. Starting material KRM4 (1) converted to protected-DMJ (2), which is de-protected to give DMJ (3) as the final product

The first question to be answered during the course of this project was whether DMJ can be synthesised in this way. If so, the conditions required to drive the reaction and any reaction sensitivities would require investigation. One component of this study was to determine if and how the purity of the starting material affects the reaction, therefore development of a suitable purification method is important.

Clean up of the final product and removal of low level impurities is important to the success of this development process. Another aim was to develop a scalable purification process for the final product and a method for quality control. An analytical method to assess the product purity and enable monitoring of the product for long term stability was required. The overall goal for this project was to develop a reliable and commercially viable process for the production of DMJ from KRM4 at scale.

Elements of process design need to be considered to allow for translation from laboratory synthesis to large-scale production. This reaction requires careful preparation of glassware, therefore the size and type of glassware used for larger-scale synthesis must be taken into account. Other factors to be considered are means of stirring, heating, purging and drying glassware and solvents, sampling, and processing of product.

Factors that do not presented with difficulties at small scale may cause issues at a larger scale. It was considered that the water produced during the alkylation process could suppress the reaction in larger quantities and steps would to be taken to remove it from the reaction vessel. Following a step-wise approach to scale-up may aid the identification of issues such as this during the early stages of process development. 


\subsection{Proposed Synthesis}

The synthetic scheme proposed for the synthesis of DMJ involves the intramolecular alkylation of a protected precursor using a "hydrogen borrowing" reaction with a ruthenium catalyst system. The starting material $\mathbf{1}$ is obtained as an intermediate from the production of Kifunensine.
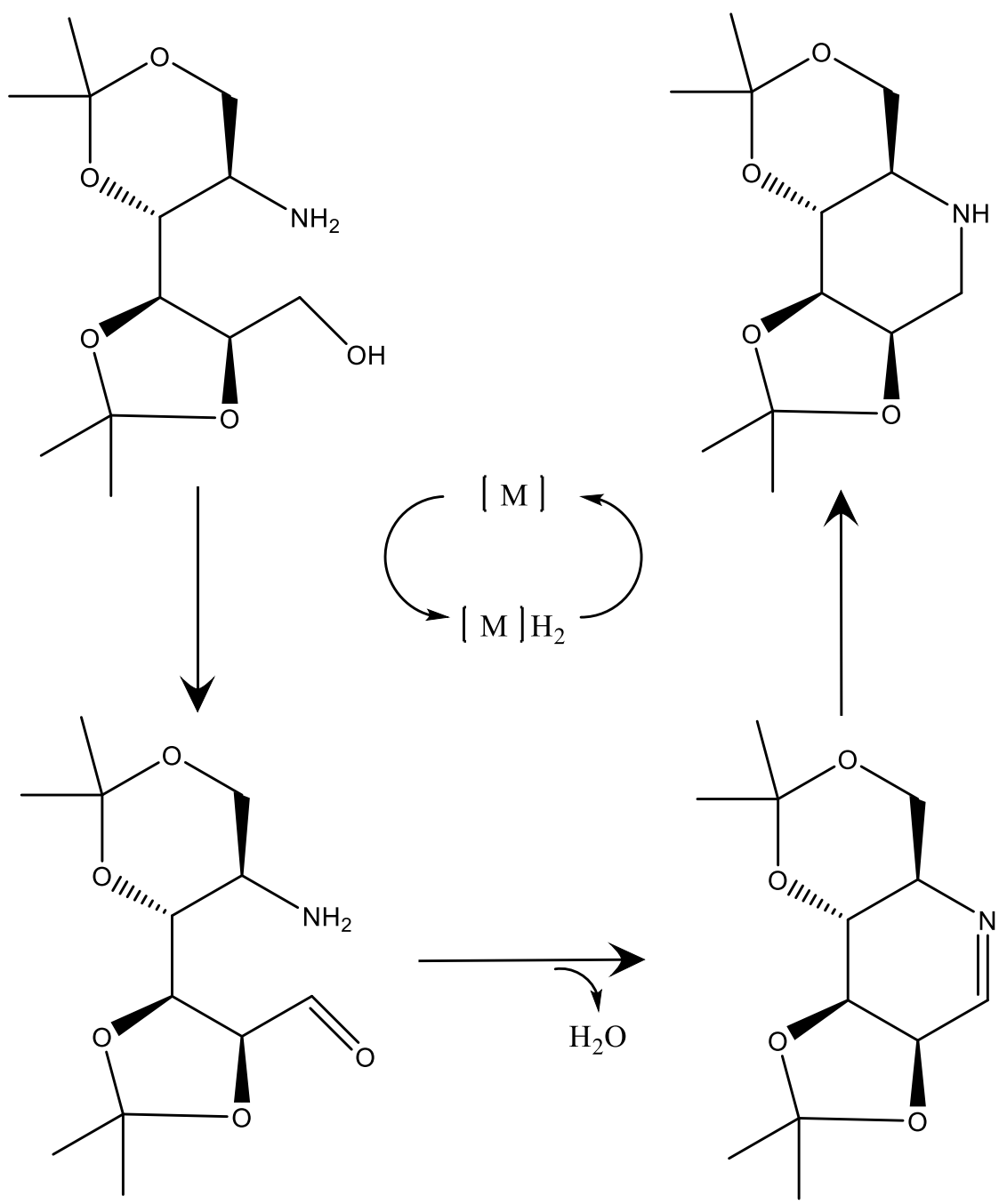

Scheme 2. The proposed hydrogen borrowing mechanism for the intramolecular alkylation of KRM4

The $N$-alkylated product, di-O-isopropylidene DMJ (2), is then hydrolysed to give the final product, DMJ (3). 


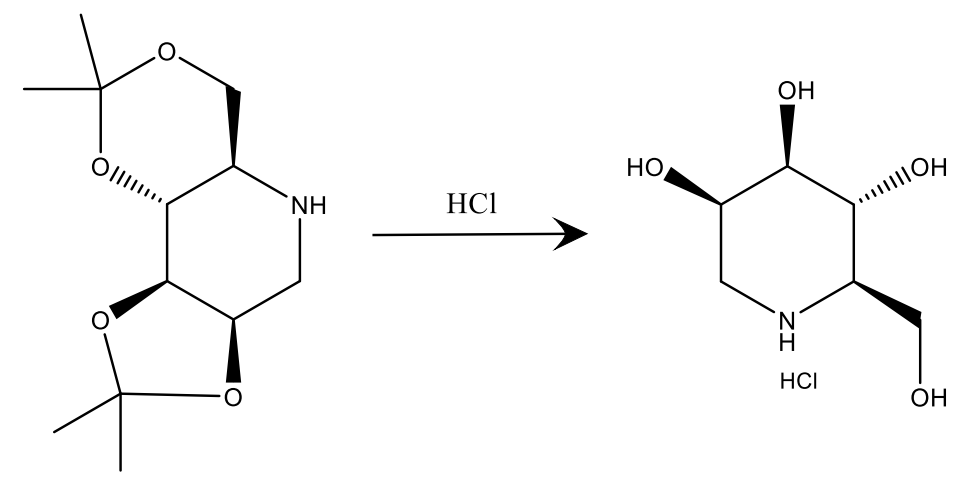

Scheme 3. Acid hydrolysis of di-O-isopropylidene DMJ

\subsection{Risk Assessment}

\section{Consideration of hazards}

Chemical hazards associated with planned experiments were assessed using Symyx

Notebook. Instruction were sought for use of gases, hazardous equipment, handling of liquid nitrogen and other cryogens. Potential risks associated with interactions between chemical species, solvent systems, workup procedures and equipment was considered prior to reaction set-up. This was particularly important during the scale-up phase of this project. The species under investigation in this project are primarily sugars with alcohol and amine functional groups. Toxicity was considered to be negligible. Standard safety protocols for handling of solvents were followed. Halogenated solvents were disposed of appropriately. Care was taken in the handling of powdered heavy-metal catalysts. 


\section{RESULTS AND DISCUSSION}

\subsection{Aims and Objectives}

The specific aims of the work discussed in this section are the manufacture of target compound 3, optimisation of its synthesis and production of a robust and simple synthetic method. Additional aims described include the purification and full characterisation of compounds $\mathbf{1}, \mathbf{2}$, and $\mathbf{3}$.

\subsection{Purification and characterisation of KRM4 (1)}

\subsubsection{Purification}

The crude KRM4 (1) supplied had been produced as an intermediate during the commercial synthesis of Kifunensine. The impurity could be due to addition of barium hydroxide or sodium n-butoxide/n-butanol during the deprotection of the $\mathrm{OH}$ group at position C-6 (previously $O$-protected) in the step that yields KRM4.

Crude starting material, KRM4 (1,3 -4,5-di-isopropylidene-2-deoxy-2-aminomannitol, 1), supplied from Glycosyn, was a crumbly yellow/orange solid. Silica flash chromatography yielded a pale, yellow oil. When left to stand, it crystallised, forming pure white, needles in an overall yield of $96 \%$. The purified KRM4 was dried under vacuum, and X-ray crystallographic analysis delivered the molecular arrangement as depicted (Figure 6). Full characterisation of the starting material was performed to provide further chemical characterisation, and provide a baseline for monitoring the progress of synthesis.

\subsubsection{Characterisation of KRM4 (1)}

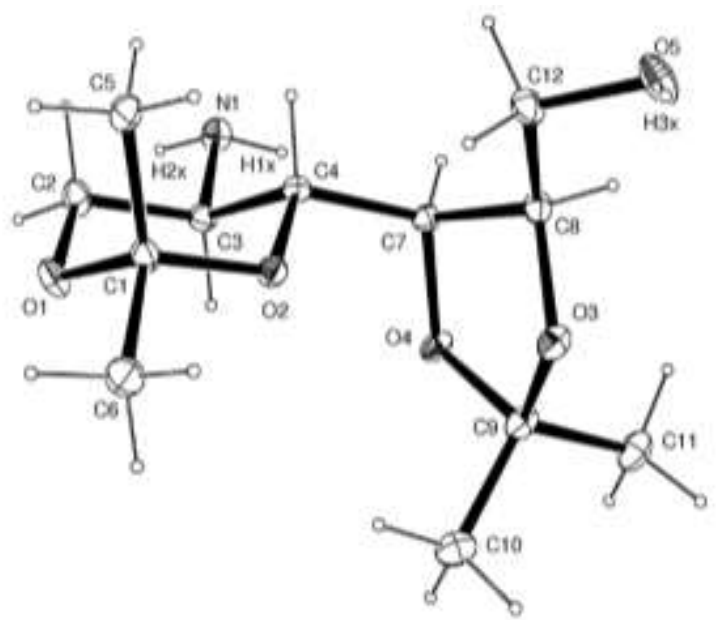

Figure 6. ORTEP image of KRM4 (1) (note that ORTEP numbering does not follow the system used in this thesis). 
NMR became an important tool in determining the outcome of each reaction. KRM4 (1) has not previously been characterised in full by NMR. ${ }^{1} \mathrm{H}$ and ${ }^{13} \mathrm{C}$ NMR were fully assigned with the assistance of ${ }^{13} \mathrm{C}$ NMR, DEPT-135, COSY, HSQC and HMBC experiments.

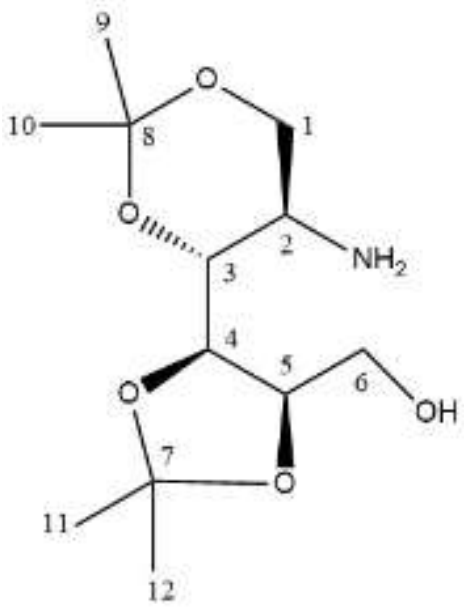

Figure 7. Structure of KRM4 (1)

\begin{tabular}{lllll}
\hline Position & $\boldsymbol{\delta}^{\mathbf{a}}, \mathbf{t y p e}$ & $\boldsymbol{\delta}_{\mathbf{H}} \mathbf{b}(\boldsymbol{J}$ in Hz$)$ & HMBC & COSY \\
\hline $1 \mathrm{a}$ & $66.2 \mathrm{CH}_{2}$ & $3.84, \mathrm{dd}(11.4,5.3)$ & $2,3,8$ & $1 \mathrm{~b}, 2$ \\
$1 \mathrm{~b}$ & & $3.44, \mathrm{dd}(11.4,2.1)$ & $2,3,8$ & $1 \mathrm{a}, 2$ \\
2 & $45.9 \mathrm{CH}$ & $3.07, \mathrm{ddd}(9.3,5.3)$ & 1,3 & $1 \mathrm{a}, 1 \mathrm{~b}, 3$ \\
3 & $73.9 \mathrm{CH}$ & $3.48, \mathrm{dd}(9.3,2.1)$ & 1,2 & 2,4 \\
4 & $74.6 \mathrm{CH}$ & $4.45, \mathrm{dd}(6.7,2.1)$ & $1,4,5,7$ & 3,5 \\
5 & $77.8 \mathrm{CH}$ & $4.25, \mathrm{dt}(6.7,4.8)$ & 3,7 & $4,6 \mathrm{a}, 6 \mathrm{~b}$ \\
$6 \mathrm{a}$ & $61.2 \mathrm{CH}_{2}$ & $3.78, \mathrm{dd}(12.0,5.0)$ & 4,5 & $6 \mathrm{~b}$ \\
$6 \mathrm{~b}$ & & $3.72, \mathrm{dd}(12.0,4.6)$ & $4,5$. & $5,6 \mathrm{a}$ \\
7 & $108.7 \mathrm{C}$ & & 11,12 & (none) \\
8 & $98.8 \mathrm{C}$ & & 9,10 & $($ none) \\
9 & $28.4 \mathrm{CH}_{3}$ & $1.38, \mathrm{~s}$ & 8,10 & 10 \\
10 & $19.2 \mathrm{CH}_{3}$ & $1.43, \mathrm{~s}$ & 8,9 & 9 \\
11 & $26.5 \mathrm{CH}_{3}$ & $1.49, \mathrm{~s}$ & 7,12 & 12 \\
12 & $25.6 \mathrm{CH}_{3}$ & $1.34, \mathrm{~s}$ & 7,11 & 11 \\
\hline
\end{tabular}

Table 1. NMR assignments for KRM4 (1). ${ }^{a} 125 \mathrm{MHz}$, Referenced to $\mathrm{CDCl}_{3}(\delta 77.00),{ }^{b} 500$ $\mathrm{MHz}$ Referenced to $\mathrm{CDCl}_{3}(\delta$ 7.26).

The ${ }^{13} \mathrm{C}$ NMR spectrum indicated the presence of 12 carbon environments, consistent with the structure 1. DEPT-135 indicated that two of these are $\mathrm{CH}_{2}$ groups, and eight are $\mathrm{CH}$ or $\mathrm{CH}_{3}$ groups. The four methyl groups $(\mathrm{C}-9-12)$ appear at $\delta 19.2-28.4 \mathrm{ppm}$, identified through using the DEPT-135 spectrum. The two quaternary carbons $(\mathrm{C}-7, \mathrm{C}-8)$ appear at $\delta$ 108.7 and 98.8 ppm, supported by the absence of those signals in the DEPT-135. The higher of the two shifts $(\delta 108.7 \mathrm{ppm})$ corresponds to the quaternary carbon of the five-membered 
ring, while the $\delta 98.8 \mathrm{ppm}$ signal corresponds to the quaternary carbon of the six-membered ring. This was supported by $\mathrm{HMBC}$ correlations that showed the $\mathrm{H}_{3}-11$ and $\mathrm{H}_{3}-12$ proton resonances correlate to $\mathrm{C}-7$, and $\mathrm{H}_{3}-9$ and $\mathrm{H}_{3}-10$ resonances to C8. HSQC and COSY were used to establish the proton signals associated with each methyl group (see Table 1).

The two $\mathrm{CH}_{2}$ groups appear at $\delta 61.2$ and $66.2 \mathrm{ppm}$. HSQC indicates that the $\delta 66.2 \mathrm{ppm}$ signal corresponds to two $d d$ signals at $\delta_{\mathrm{H}} 3.72$ and 3.78 on the ${ }^{1} \mathrm{H}$ NMR spectrum. These signals belong to the $\mathrm{CH}_{2}$ group at $\mathrm{C}-6$. The ${ }^{1} \mathrm{H}$ NMR signals were difficult to identify during analysis due to the low resolution of the two multiplets, which were initially thought to be one signal. The proton signals' similarity is due to the relatively free rotation of the $\mathrm{CH}_{2}$ group. The most important identifier for KRM4 (1) in ${ }^{13} \mathrm{C} \mathrm{NMR}$ is the $\mathrm{CH}_{2}$ peak for carbon 6 at $61.2 \mathrm{ppm}$, which shifts significantly after the intramolecular reaction is complete, and its $\mathrm{OH}$ group is lost.

HSQC and HMBC data allowed for the assignments of C-2 - 6, with further support from COSY. Carbons 3, 4 and 5 exist in similar environments, but were able to be assigned based on their 3-bond ${ }^{1} \mathrm{H}-{ }^{1} \mathrm{H}$ connectivities provided by COSY.

\subsection{Preliminary reactions}

Production of 2 requires a ring-closing $N$-alkylation, which can be effected by ruthenium catalysts. The metal catalyst "borrows" a hydrogen from the hydroxyl group on carbon 6 of $\mathbf{1}$, resulting in the formation of an aldehyde, the oxygen of which is ultimately lost as water when the $\mathrm{C}=\mathrm{N}$ (imine) bond is formed. Hydrogen is returned by the ruthenium catalyst to reduce the double bond, yielding 2 .

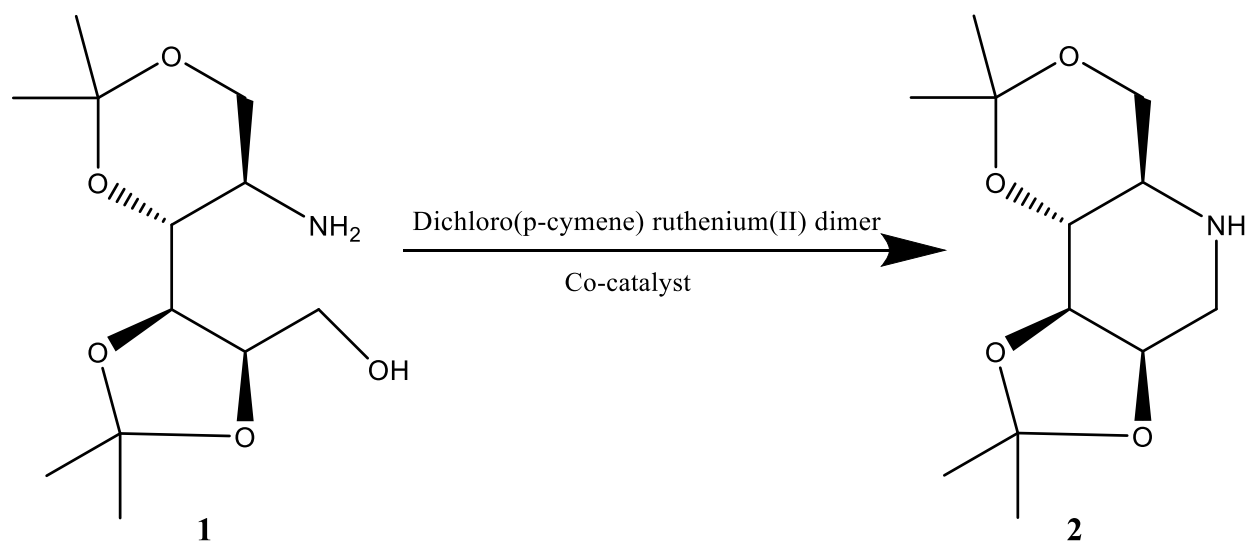

Figure 8. Intramolecular alkylation of 1 to produce 2 
All experiments were performed using KRM4 (1) as the precursor. This hydrogen borrowing reaction had been attempted in our laboratories, but to date only low yields over extended time had been achieved ( $<25 \%$ yield, $>48 \mathrm{hr}$ ). It was suggested that the reaction may be sensitive to water (and reported in the literature), which would pose a problem due to the production of water as a by-product of the reaction. Early experiments were performed in a round-bottom flask under an Argon atmosphere, with activated $4 \AA$ molecular sieves added to the mixture. The solvent (toluene) was degassed with Argon and stored on $4 \AA$ molecular sieves. The conditions were chosen based on the methodology described by Hamid et al. in their 2009 paper. $^{11}$

\begin{tabular}{|c|c|c|c|c|c|c|c|}
\hline \multicolumn{8}{|c|}{ Intramolecular $N$-alkylation of $\mathbf{1}$} \\
\hline & \multicolumn{3}{|c|}{$\mathrm{n}(\mathrm{mmol})$} & \multirow[b]{2}{*}{$\begin{array}{c}\text { Solvent } \\
\text { (vol / mL) }\end{array}$} & \multirow[b]{2}{*}{$\begin{array}{l}\mathrm{T} / \\
\left({ }^{\circ} \mathrm{C}\right)\end{array}$} & \multirow[b]{2}{*}{ Conditions } & \multirow[b]{2}{*}{ Result } \\
\hline Experiment & $\begin{array}{c}\text { KRM4 } \\
(\mathbf{1})\end{array}$ & Catalyst & $\begin{array}{c}\text { Co- } \\
\text { catalyst }\end{array}$ & & & & \\
\hline 1 & 0.19 & 0.0026 & 0.0045 & $\begin{array}{l}\text { Toluene } \\
\text { (3) }\end{array}$ & 110 & $\begin{array}{l}\text { Air, } 4 \AA \text { sieve, } \\
\text { sampling }\end{array}$ & No reaction \\
\hline 2 & 0.19 & 0.047 & 0.098 & $\begin{array}{l}\text { Toluene } \\
\text { (3) }\end{array}$ & 110 & $\begin{array}{l}\text { Air, } 4 \text { A sieve, } \\
\text { no sampling }\end{array}$ & No reaction \\
\hline
\end{tabular}

\section{Table 2. Experiment summary: Intramolecular $N$-alkylation, first attempts}

In both reactions, compound 1 , the catalyst (dichloro(p-cymene) ruthenium(II) dimer) and bis(diphenylphosphine) were added to the round-bottomed flask, which had been oven-dried and pressurised with Argon gas. Dry toluene ( $3 \mathrm{~mL}$ ) was added via syringe and needle through the rubber septum. The mixture was allowed to stir for 10 minutes at room temperature and then heated to $110^{\circ} \mathrm{C}$.

The first reaction was sampled in order to run thin layer chromatography analysis (TLC) after 42 minutes by drawing a small amount of the mixture into a syringe (with needle). At this stage, the reaction's sensitivity to sampling had not been considered. TLC showed no conversion after 42 minutes, or later after 24 hours.

The second reaction was not sampled, and a TLC was run after 72 hours. The TLC indicated total consumption of the starting material, but no product appeared to be present. The reaction mixture collected was run through a short silica column with the following solvent systems:

1. $40 \mathrm{~mL} 25 \%$ Ethyl acetate, $75 \%$ Petroleum ether

2. $40 \mathrm{~mL} 75 \%$ Ethyl acetate, $25 \%$ Petroleum ether

3. $40 \mathrm{~mL} 100 \%$ Ethyl acetate 
Fractions were collected $(7 \mathrm{~mL})$ and left to evaporate for $\sim 72$ hours. Fractions that had formed residue were individually evaporated and re-constituted in $\mathrm{CDCl}_{3}$ for ${ }^{1} \mathrm{H} \mathrm{NMR}$ analysis, which did not indicate the presence of a sugar in any sample. It is unclear what occurred in this case, but the result suggests a possible breakdown of $\mathbf{1}$. It is an important point for later findings to note that there was a distinct dark brown colour observed for the reaction mixture in both experiments.

As the second experiment also failed to yield any product, sampling was not thought to be the cause in this case, although it could not be ruled out as a contributing factor. No literature evidence of a similar successful intramolecular reaction could be found; therefore, the decision was made to attempt a model reaction with simpler reactants in order to identify the conditions necessary to affect the $N$-alkylation.

\subsection{Model reactions}

\subsection{1. t-Butylamine and 2-phenylethanol}

The first model reaction, between $t$-butylamine and 2-phenylethanol, was performed under the same conditions as the preceding attempts (Figure 9). A successful reaction could indicate the failures were due to a complication with the starting material or that the conditions were not appropriate for an intramolecular reaction. The model reaction was based on that of Hamid et al., without the presence of $\mathrm{K}_{2} \mathrm{CO}_{3}{ }^{11}$

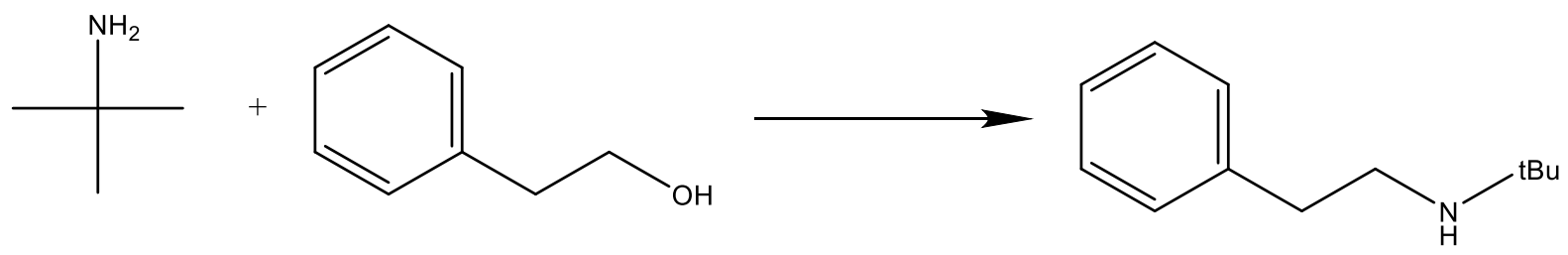

Figure 9. Reaction of t-Butylamine with 2-phenylethanol

The reactants were added to an oven-dried, argon/vacuum purged round-bottomed flask under an argon atmosphere, via pipette (as both are liquid). A sample was taken for TLC prior to heating (S1), and a second sample (S2) was taken one hour after commencing heating at $110^{\circ} \mathrm{C}$. After 24 hours, DPPF $(5 \mathrm{~mol} \%)$ and excess $t$-butylamine $(400 \mu \mathrm{L})$ were added. Further samples were taken for TLC and NMR, with no evidence of any reaction. After 48 hours, the temperature was increased to $145^{\circ} \mathrm{C}$ and the flask was covered with foil. Further toluene $(2 \mathrm{~mL})$ was added when the flask boiled dry. Fresh sieves were added, the 
temperature was reduced to $140^{\circ} \mathrm{C}$, and the foil was removed. The reaction was taken off after the $10^{\text {th }}$ day, chloroform was added, and the mixture was dried on a rotary evaporator. $\mathrm{NMR}$ in $\mathrm{CDCl}_{3}$ revealed only the presence of reactants, with no product formed.

It was recognised that the catalyst used could be sensitive to particular reagents. In this case, the t-butylamine was thought to be too sterically hindered to allow a hydrogen-borrowing reaction to take place. A second set of trial reactants were used.

\subsubsection{Aniline and benzyl-alcohol}<smiles>Nc1ccccc1</smiles><smiles>OCc1ccccc1</smiles>
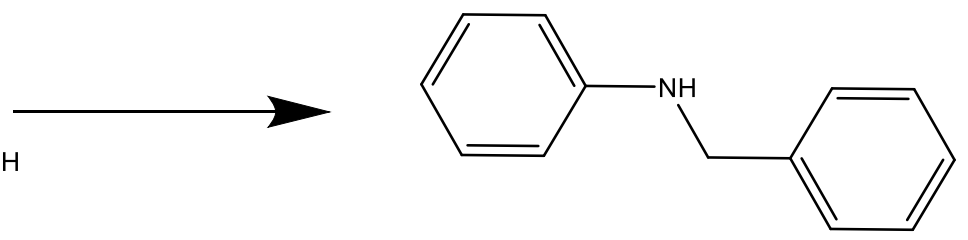

\section{Figure 10. Aniline and benzyl alcohol reaction}

Further review of the literature indicated a possible reaction sensitivity to air, rather than water as inferred from the methods of Hamid et al. A second model reaction using aniline and benzyl alcohol was prepared, based on the work of Broomfield, $\mathrm{Wu}$, Martin and Shafir. ${ }^{12}$ The co-catalyst was changed to DPPF, as it appeared to give improved results in the literature.

\begin{tabular}{|c|c|c|c|c|c|c|c|c|}
\hline \multicolumn{9}{|c|}{$\begin{array}{l}\text { Model reaction: Intermolecular } N \text {-alkylation of aniline with benzyl alcohol } \\
\qquad \mathrm{n} \text { (mmol) }\end{array}$} \\
\hline Exp. & Aniline & $\begin{array}{l}\text { Benzyl } \\
\text { alcohol }\end{array}$ & $\begin{array}{c}\text { Catalys } \\
\mathrm{t}\end{array}$ & $\begin{array}{c}\text { Co- } \\
\text { Catalyst } \\
\end{array}$ & $\begin{array}{c}\text { Solvent } \\
\text { (vol / mL) }\end{array}$ & $\begin{array}{l}\mathrm{T} / \\
\left({ }^{\circ} \mathrm{C}\right) \\
\end{array}$ & Conditions & Result \\
\hline 1 & 1.01 & 1.06 & 0.0075 & 0.017 & $\begin{array}{l}\text { Toluene } \\
\text { (1) }\end{array}$ & 120 & Argon & $\begin{array}{l}\text { High } \\
\text { conversion }\end{array}$ \\
\hline 2 & 1.01 & 1.06 & 0.0083 & 0.014 & $\begin{array}{l}\text { Toluene } \\
\text { (1) }\end{array}$ & 120 & $\begin{array}{l}\text { Argon, } \\
\text { sampling }\end{array}$ & No reaction \\
\hline 3 & 1.01 & 1.06 & 0.0073 & 0.014 & $\begin{array}{c}\text { Toluene } \\
\text { (1) }\end{array}$ & 120 & Argon & $\begin{array}{l}\text { High } \\
\text { conversion }\end{array}$ \\
\hline
\end{tabular}

\section{Table 3. Experiment summary: aniline/benzyl alcohol model reactions}

Calcium chloride and Drierite were oven-dried overnight, then flame-dried under high vacuum $(<4$ mbar). The dried beads were packed into a moisture trap, which was added to the argon gas line. The solvent (toluene) was degassed and purged with argon gas. The reaction vessel (Schlenk tube) was oven-dried, then flame-dried under vacuum. The vessel was purged with argon/vacuum three times, before being pressurised with argon and capped. The rubber bung was briefly removed for the addition of catalyst (4.6 mg, $0.75 \mathrm{~mol} \%)$, DPPF (9.3 mg, 
$1.68 \mathrm{~mol} \%$ ) and stir bar. Weighing was done as quickly and carefully as possible, to minimise any air getting into the vessel.

The Schlenk tube was purged again with argon/vacuum three times before adding $1 \mathrm{~mL}$ degassed toluene. Benzyl alcohol $(110 \mu \mathrm{L})$ and aniline $(92 \mu \mathrm{L})$ was drawn up under argon and added to the reaction vessel via syringe and needle through the rubber bung. The temperature was set to $120^{\circ} \mathrm{C}$, and the mixture was left to reflux for four days while stirring. After four days, the colour of the reaction mixture was orange/red, and moisture was observed on the inside of the Schlenk tube.

The reaction mixture was dried on a rotary evaporator and taken up in deuterated chloroform. NMR showed high conversion to the benzylaniline product. No starting material was present.

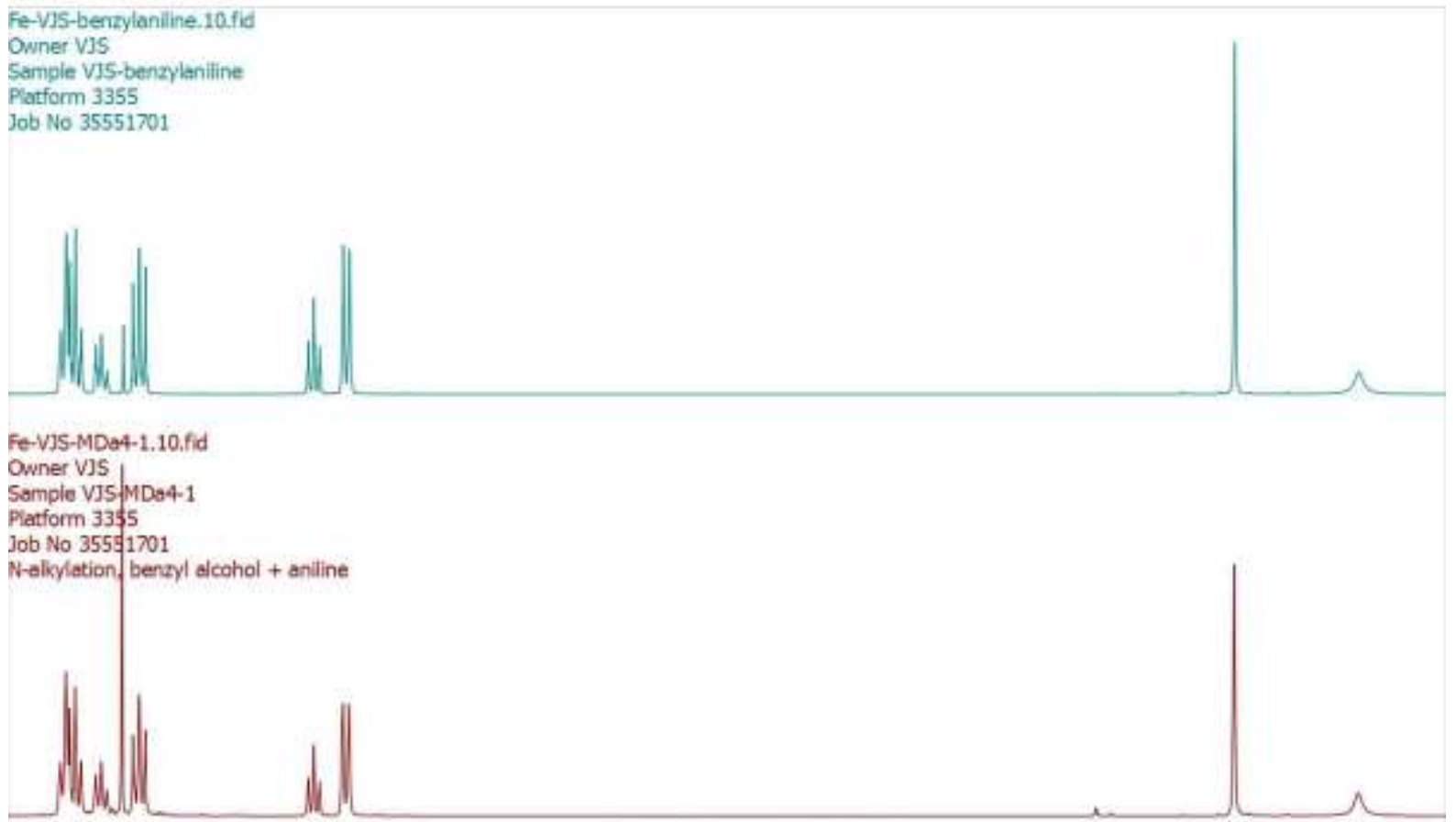

7.47 .37 .27 .17 .06 .96 .86 .76 .66 .56 .46 .36 .26 .16 .05 .95 .85 .75 .65 .55 .45 .35 .25 .15 .04 .94 .84 .74 .64 .54 .44 .34 .24 .14 .03 .93 .8 $\mathrm{f1}(\mathrm{ppm})$

Figure 11. ${ }^{1}$ H NMR comparison of benzylaniline reference (blue, top) and model reaction product (red, bottom)

The model reaction above was repeated under the same conditions, but with sampling at 10 , 30, 60 and 120 minutes. Sampling was performed using a syringe and needle to draw up a small volume of reaction mixture under argon gas. Each sample was dried on a rotary evaporator and taken up in deuterated chloroform for NMR analysis. The colour of the reaction mixture changed from red/orange at 0 minutes, to black/brown after 30 minutes. 
After four days, the mixture was black in colour. NMR showed no conversion to the benzylaniline product. This result indicated a strong likelihood that the reaction was very sensitive to contact with a metal needle.

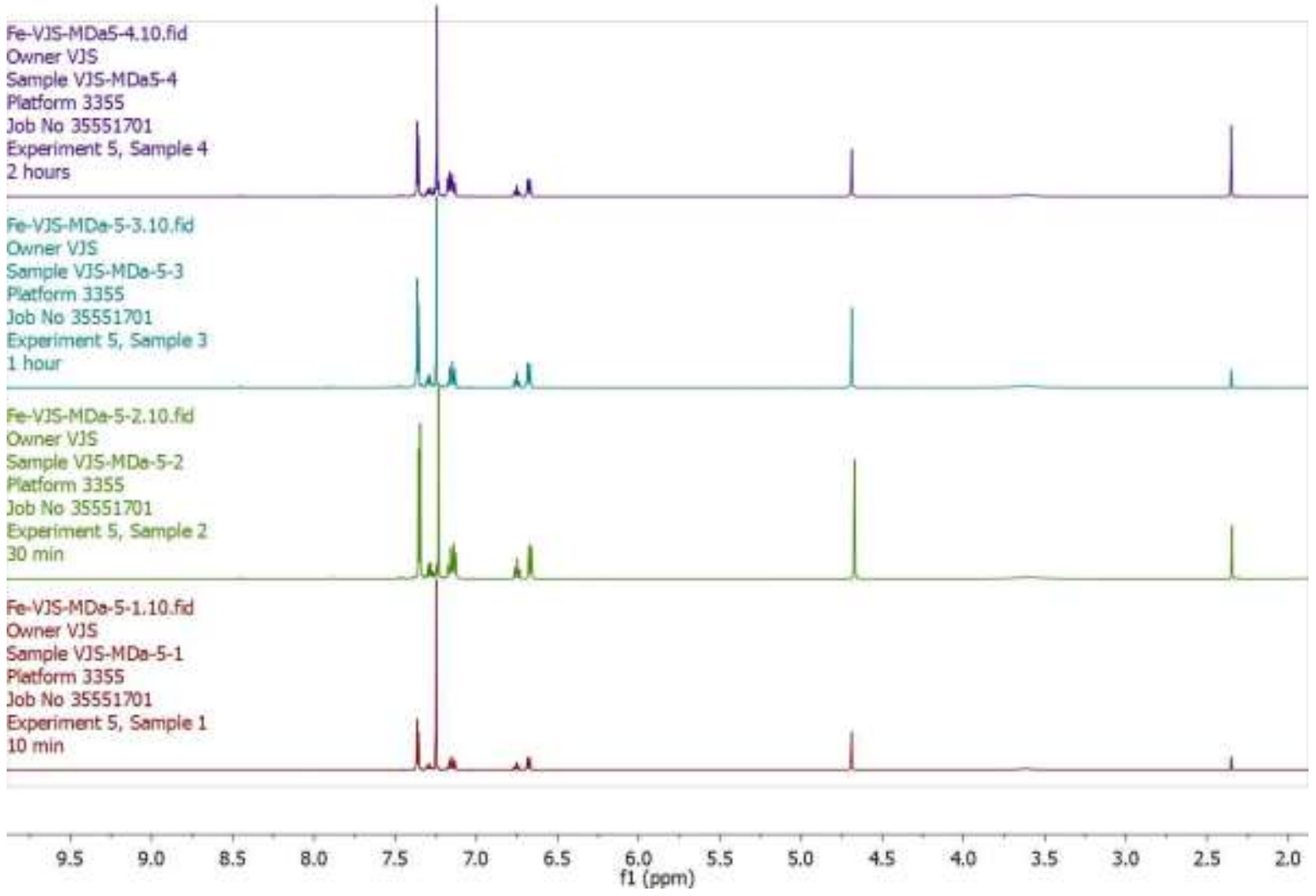

Figure 12. ${ }^{1}$ H NMR analysis of samples at 10, 30, 60 and 120 minutes (bottom to top)

To test whether sampling had caused the reaction to fail, the aniline/benzyl alcohol model reaction was repeated without sampling. The conditions were consistent with the first successful model reaction. After three days refluxing at $120^{\circ} \mathrm{C}$, the reaction mixture was an orange/red colour. NMR showed high conversion to the benzylaniline product.

The failure of the second reaction was likely due to poisoning of the ruthenium catalyst, caused by contact with the metal needle. The conditions under which the model reactions were performed were designed to eliminate air from the reaction vessel. The success of the experiments performed under these conditions supports the assumption that the reaction is air-sensitive. This assumption was carried through to future experiments.

The model reactions show potential poisoning of the catalyst by $\mathrm{O}_{2}$ and/or metal. The reaction only took place in the absence of air, and without contact with a metal needle. It is not likely that the catalyst is sensitive to water, as the reaction itself generates water as a by- 
product, and was successfully performed without the addition of activated molecular sieves. All further experiments were performed under the following assumptions:

1. The reaction is air-sensitive due to catalyst poisoning by $\mathrm{O}_{2}$.

2. The reaction is sensitive to metal ions and cannot be sampled with syringe and needle.

3. The reaction is not sensitive to water.

\subsection{Intramolecular reactions}

\subsubsection{Synthesis of 1,3 -4,5-di-isopropylidene deoxymannojirimycin (2)}

The conditions established in the model reactions above were used to perform the intramolecular reaction of KRM4 (1) to form di-isopropylidene deoxymannojirimycin (2). Catalyst (0.7 mol\%), DPPF (1 mol\%) and $1(263 \mathrm{mg})$ were added to a flame-dried, argon/vacuum purged Schlenk tube. The vessel was purged again three times with argon/vacuum prior to addition of $1 \mathrm{~mL}$ freshly degassed toluene (1 M KRM4 in toluene). The mixture was left to reflux at $120^{\circ} \mathrm{C}$ for 96 hours

\begin{tabular}{|c|c|c|c|c|c|c|c|}
\hline \multicolumn{8}{|c|}{ Intramolecular $N$-alkylation of $\mathbf{1}$} \\
\hline & \multicolumn{3}{|c|}{$\mathrm{n}(\mathrm{mmol})$} & & & & \\
\hline Experiment & $\begin{array}{c}\text { KRM4 } \\
\text { (1) }\end{array}$ & Catalyst & $\begin{array}{c}\text { Co- } \\
\text { catalyst }\end{array}$ & $\begin{array}{c}\text { Solvent } \\
\text { (vol / mL) }\end{array}$ & $\begin{array}{l}\mathrm{T} / \\
\left({ }^{\circ} \mathrm{C}\right)\end{array}$ & Conditions & Result \\
\hline 1 & 1.0 & 0.0069 & 0.014 & $\begin{array}{c}\text { Toluene, } \\
\text { (1) }\end{array}$ & 120 & Argon & $\begin{array}{l}\text { High } \\
\text { conversion }\end{array}$ \\
\hline 2 & 1.4 & 0.0098 & 0.021 & $\begin{array}{c}\text { Toluene, } \\
\text { (1) }\end{array}$ & 120 & Argon & $\begin{array}{l}\text { High } \\
\text { conversion }\end{array}$ \\
\hline
\end{tabular}

Table 4. Experiment summary: N-alkylation of KRM4 (1) under model reaction conditions

The reaction mixture was a deep red colour after 20 minutes. ${ }^{13} \mathrm{C}$ NMR showed high conversion of 1 to 2 , identified by the reduction of the $\mathrm{CH}_{2}$ peak at $61.2 \mathrm{ppm}$ and increase of the $\mathrm{CH}_{2}$ peak at $46.4 \mathrm{ppm}$, which corresponds to $\mathrm{C6}$ (Figure 13). 


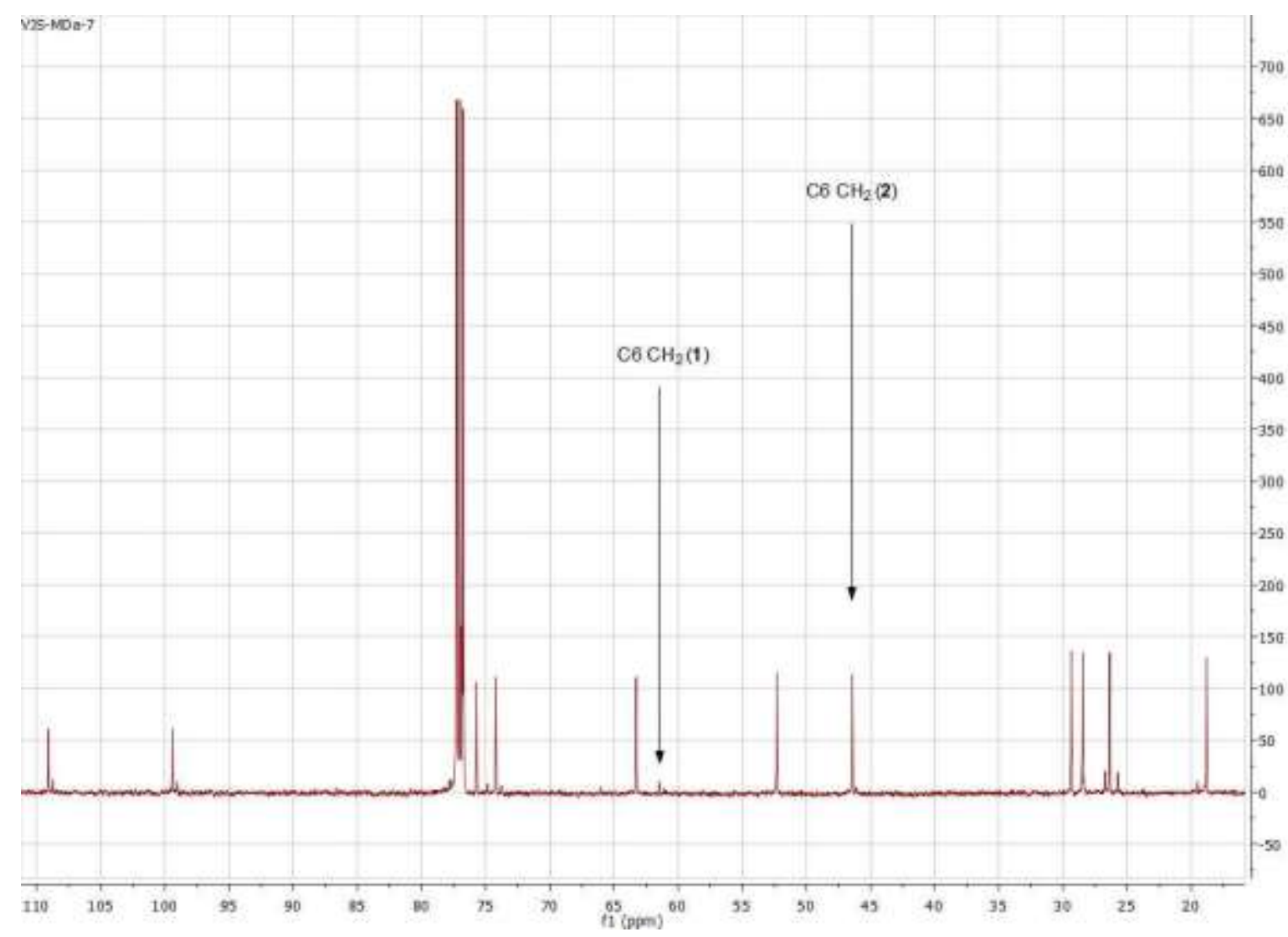

Figure 13. ${ }^{13} \mathrm{C}$ NMR spectrum of intramolecular reaction product. $125 \mathrm{MHz}$, Referenced to $\mathrm{CDCl}_{3}(\delta 77.00)$.

Due to the catalyst's sensitivity to metal, and with no suitable alternative sampling method at the time, the reaction was only monitored by ${ }^{13} \mathrm{C}$ NMR. ${ }^{1} \mathrm{H}$ NMR was earlier found to be unsuitable for monitoring, due to a significant change to the chemical shift in the spectrum that was concentration dependant (Figure 14). Thus ${ }^{1} \mathrm{H}$ NMR spectra were not consistent enough to use as a reliable measure of the reaction progress. 


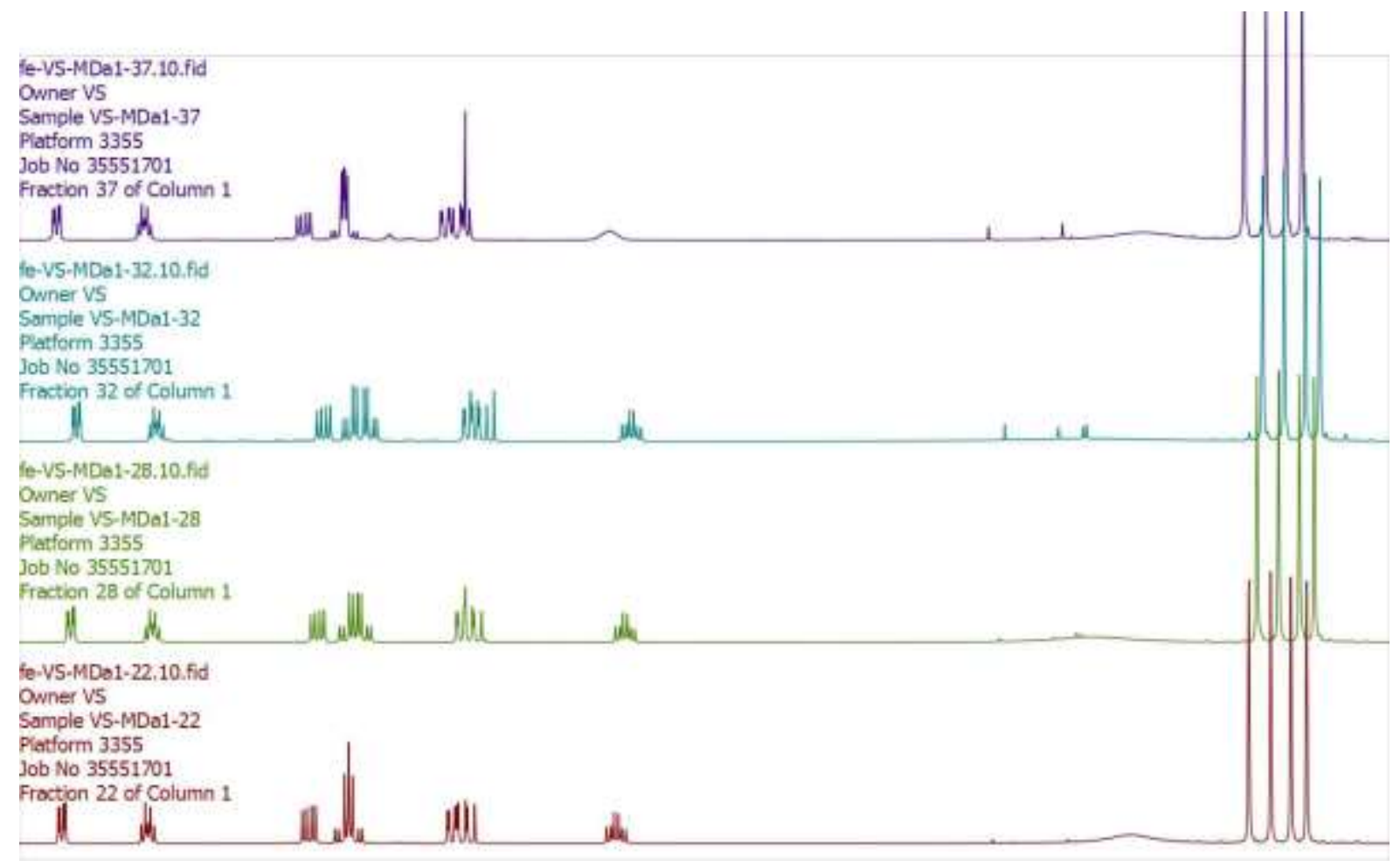

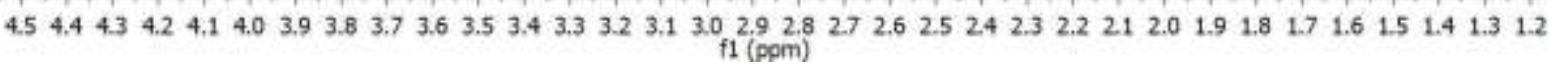

\section{Figure 14. ${ }^{1} \mathrm{H}$ NMR spectrum of KRM4 fractions $\left(500 \mathrm{MHz}, \mathrm{CDCl}_{3}\right)$}

The experiment was repeated to ensure reproducibility, with minor changes only to solvent volume, reaction concentration and reaction time. Catalyst (0.7 mol\%), DPPF (1.5 mol\%) and 1 (1.4 mmol) were added to a flame-dried, argon/vacuum purged Schlenk tube. The vessel was purged again three times with argon/vacuum prior to addition of $2 \mathrm{~mL}$ freshly degassed toluene. The mixture was left to reflux at $120^{\circ} \mathrm{C}$ for 69 hours. It was decided to reduce the overall reaction time. Previously a 96-hour reaction had demonstrated complete conversion, therefore a $30 \%$ reduction of reaction time was deemed appropriate. The reaction mixture was deep red in colour, and when dried, resulted in a tan-coloured solid (95\% mass recovered). ${ }^{13} \mathrm{C}$ NMR again showed high conversion of 1 to 2.

\subsubsection{Purification of 1,3 -4,5-di-isopropylidene deoxymannojirimycin (2)}

The reaction mixture was also sampled for TLC at the end of the 96-hour reaction time. The mixture was spotted on a $20 \times 100 \mathrm{~mm}$ aluminium-backed silica plate, and run in $\mathrm{CHCl}_{3}$ : $\mathrm{MeOH}$ : TEA (95: $5: 0.1)$. The spot could be identified by staining in vanillin or ninhydrin. The vanillin stain was most effective when the plate was dipped a second time after drying with a heat gun, as the spot became bright yellow in colour. Without the second dip, the spot 
appears as a white spot on the yellow stain background. Starting material remained close to the baseline, while 2 had a retention factor of approximately $0.3-0.4$.

Flash chromatography was used to purify 2 . The reaction mixture was dried on a rotary evaporator, taken up in chloroform and loaded onto a 25 x $60 \mathrm{~mm}$ silica column. The mobile phase used was the same as for TLC. Fractions were collected in $20 \mathrm{~mL}$ vials and sampled for TLC. Fractions containing 2 were pooled and dried on a rotary evaporator, yielding a pale, yellow oil which crystallised when left in the fridge overnight.

The product was re-dissolved in ethyl acetate. Petroleum ether was added until a white precipitate was observed. The solution was heated until the precipitate disappeared, and was left to cool to room temperature. The solution was placed in the fridge overnight, yielding a white crystalline solid ( $84 \%$ yield).

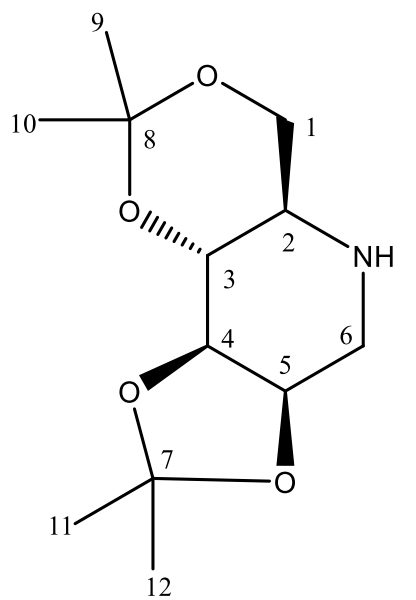

Figure 15. Structure of 1,3-4,5-Di-isopropylidene deoxymannojirimycin (2) 


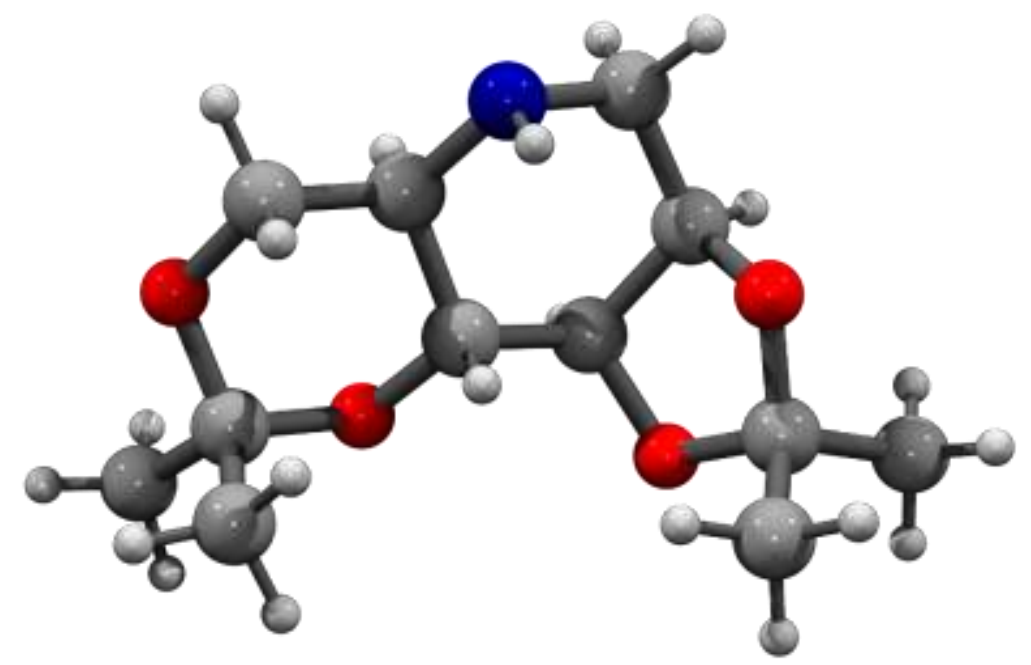

Figure 16. POV-Ray of Di-isopropylidene deoxymannojirimycin (2)

NMR Spectroscopy

\begin{tabular}{lllll}
\hline Position & $\boldsymbol{\delta c}^{\mathbf{a}}, \mathbf{t y p e}$ & $\boldsymbol{\delta} \mathbf{H}^{\mathbf{b}}(\boldsymbol{J}$ in Hz$)$ & HMBC & COSY \\
\hline $1 \mathrm{a}$ & $63.3 \mathrm{CH}_{2}$ & $3.86, \mathrm{dd}(11.1,5.3)$ & 2 & $1 \mathrm{~b}, 2$ \\
$1 \mathrm{~b}$ & & $3.56, \mathrm{~d}(10.9)$ & 2 & $1 \mathrm{a}, 2$ \\
2 & $52.3 \mathrm{CH}$ & $2.42, \mathrm{td}(10.5,5.3)$ & & $1 \mathrm{a}, 1 \mathrm{~b}, 3$ \\
3 & $75.7 \mathrm{CH}$ & $3.61, \mathrm{dd}(10.4,7.8)$ & 4,5 & 2,4 \\
4 & $76.8 \mathrm{CH}$ & $3.97, \mathrm{dd}(7.7,5.2)$ & 3 & 3,5 \\
5 & $74.2 \mathrm{CH}$ & $4.19, \mathrm{ddd}(7.2,3.2,1.2)$ & & $4,6 \mathrm{a}$ \\
$6 \mathrm{a}$ & $46.4 \mathrm{CH}_{2}$ & $3.04, \mathrm{dd}(15.0,3.1)$ & 2 & $4,6 \mathrm{~b}$ \\
$6 \mathrm{~b}$ & & $3.43, \mathrm{dd}(15.0,1.4)$ & 2 & $6 \mathrm{a}$ \\
7 & $109.1 \mathrm{C}$ & & 11,12 & (none) \\
8 & $99.4 \mathrm{C}$ & & 9,10 & (none) \\
9 & $29.3 \mathrm{CH}_{3}$ & $1.43, \mathrm{~s}$ & 10 & 10 \\
10 & $18.8 \mathrm{CH}_{3}$ & $1.49, \mathrm{~s}$ & 9 & 9 \\
11 & $28.5 \mathrm{CH}_{3}$ & $1.56, \mathrm{~s}$ & 12 & 12 \\
12 & $26.3 \mathrm{CH}_{3}$ & $1.37, \mathrm{~s}$ & 11 & 11 \\
\hline
\end{tabular}

Table 5. NMR assignments for Di-isopropylidene deoxymannojirimycin (2). ${ }^{a} 125 \mathrm{MHz}$, Referenced to $\mathrm{CDCl}_{3}\left(\delta\right.$ 77.00), ${ }^{b} 500 \mathrm{MHz}$ Referenced to $\mathrm{CDCl}_{3}(\delta$ 7.26).

The ${ }^{13} \mathrm{C}$ NMR spectrum of 2 showed the presence of 12 carbon environments, just as for compound 1. DEPT-135 indicated that two of these are $\mathrm{CH}_{2}$ groups. The four methyl groups (C-9-C-12) appear at $\delta 18.8-29.3 \mathrm{ppm}$, similar to those of $\mathbf{1}$. The two quaternary carbons (C-7, C-8) resonate at $\delta 109.1$ and $99.4 \mathrm{ppm}$, which is supported by the absence of those signals in the DEPT-135. The higher of the two shifts ( $\delta 109.1 \mathrm{ppm})$ corresponds to the quaternary carbon of the five-membered ring, while the $\delta 99.4 \mathrm{ppm}$ signal corresponds to the quaternary carbon of the six-membered ring. As for 1, HMBC showed a correlation of the 
$\mathrm{C} 11$ and $\mathrm{C} 12$ protons with $\mathrm{C} 7$, and of the $\mathrm{C} 9$ and C10 protons with C8. HSQC and COSY were used to establish the proton signals associated with each methyl group (see Table 5).

The two $\mathrm{CH}_{2}$ groups appear at $\delta 63.3$ and $46.4 \mathrm{ppm}$. HSQC indicated that the $\delta 46.4 \mathrm{ppm}$ signal corresponds to the two $d d$ proton signals at $\delta 3.04$ and $3.43 \mathrm{ppm}$, and is representative of C6. This signal becomes the most important in monitoring the conversion of $\mathbf{1}$ to $\mathbf{2}$, due to its significant and obvious shift from $\delta 61.2 \mathrm{ppm}$ to $46.4 \mathrm{ppm}$. The $\mathrm{C} 2 \mathrm{CH}$ signal is found at $\delta$ $52.3 \mathrm{ppm}$, which is also an important identifier for the presence of $\mathbf{2}$. The C2 peak of $\mathbf{1}$ occurs at $\delta 45.9 \mathrm{ppm}$.

\subsection{Deprotection}

\subsubsection{Synthesis and purification of deoxymannojirimycin (3)}

Compound $\mathbf{3}$ is produced by deprotection of $\mathbf{2}$.

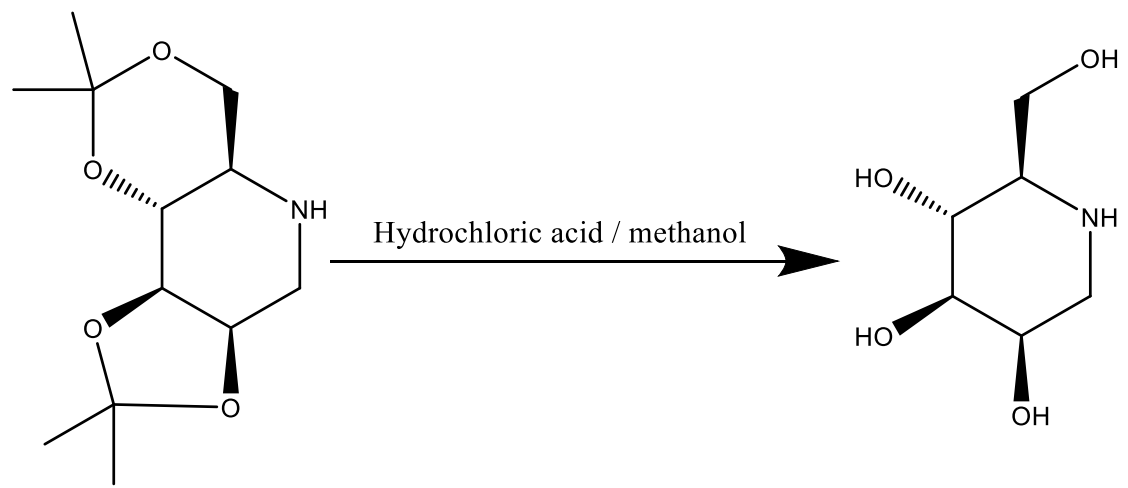

\section{Figure 17. Deprotection of 2 to produce 3}

Cleavage of acetonide protecting groups is commonly achieved by hydrolysis with $\mathrm{HCl}^{15}$. One objective of this research was to develop the synthesis of $\mathbf{3}$ in as simple a manner as possible. The simplest deprotection technique was to add an acidic solution and allow the mixture to stir at room temperature. For both experiments, methanolic hydrochloric acid was used (1 : 5 solution). DMJ (3) is known to be soluble in methanol, hence selection of this solvent for dilution of $\mathrm{HCl}$.

In the first experiment, purified $\mathbf{2}$ was used to rule out any potential interference from impurities. Methanolic $\mathrm{HCl}$ was added to $100 \mathrm{mg} 2$ dissolved in $1 \mathrm{~mL}$ methanol in a roundbottomed flask. The solution was left to stir at room temperature overnight. The acid/methanol mixture was dried on a rotary evaporator, leaving a cloudy, yellow oil. The oil was re-dissolved in methanol and dried again. The resulting oil was taken up deuterated methanol for NMR analysis. 
The solution was dried and dissolved in methanol. Ethanol was added until the solution was one part methanol to two parts ethanol, and the solution was left to stand, yielding a tancoloured solid. The solid was dissolved in methanol and ethanol was added until a white precipitate was observed. The solution was left to stand in the fridge overnight, but no crystals were formed. The mixture was dried on a rotary evaporator and re-dissolved in methanol three times. A further attempt was made to recrystallise from a solution of methanol/ethanol, this time yielding white, needle-shaped crystals (66\%).

In the second experiment, $400 \mu \mathrm{L}$ of crude reaction mixture, containing approximately 100 mg 2, was transferred to a round-bottomed flask with $400 \mu \mathrm{L}$ of methanolic $\mathrm{HCl}(1: 5$, as above). The solution was left to stir at room temperature overnight. It was uncertain whether the hydrolysis would be successful, given that the reaction mixture was largely comprised of xylene, which is immiscible with the aqueous acid.

The acid mixture was dried on a rotary evaporator, leaving a tan-coloured solid (73\%). The compound was washed with chloroform and dried again, leaving an off-white solid. It was taken up in deuterated methanol for NMR analysis, which showed high conversion to the DMJ (3) product. Further purification would have been possible using the recrystallisation method described for the first experiment, above.

\begin{tabular}{|c|c|c|c|}
\hline \multicolumn{4}{|r|}{ Deprotection of 2} \\
\hline Experiment & $2(\mathrm{mg})$ & $\begin{array}{l}\mathrm{HCl} / \mathrm{MeOH} \\
\quad(\mu \mathrm{L})\end{array}$ & Conditions \\
\hline 1 & 100 & 1200 & Purified 2 , stirred at room temperature overnight \\
\hline 2 & 100 & 400 & $\begin{array}{l}\text { Crude } 2 \text { reaction mixture, stirred at room temperature } \\
\text { overnight }\end{array}$ \\
\hline
\end{tabular}

\section{Table 6. Experiment summary: Deprotection of 2}

It is now known that purification of the intermediate, 2, is not required for successful hydrolysis to form $\mathbf{3}$. This would cut down production time significantly, and would mean $\mathbf{3}$ could be produced from $\mathbf{1}$ in a single reaction vessel. However, the quality of the DMJ (3) solid produced in this manner may be impacted. This requires further investigation. 
2.6.2. Characterisation of deoxymannojirimycin (3)<smiles>OC[C@H]1NC[C@@H](O)[C@H](O)[C@H]1O</smiles>

Figure 18. Structure of DMJ (3)

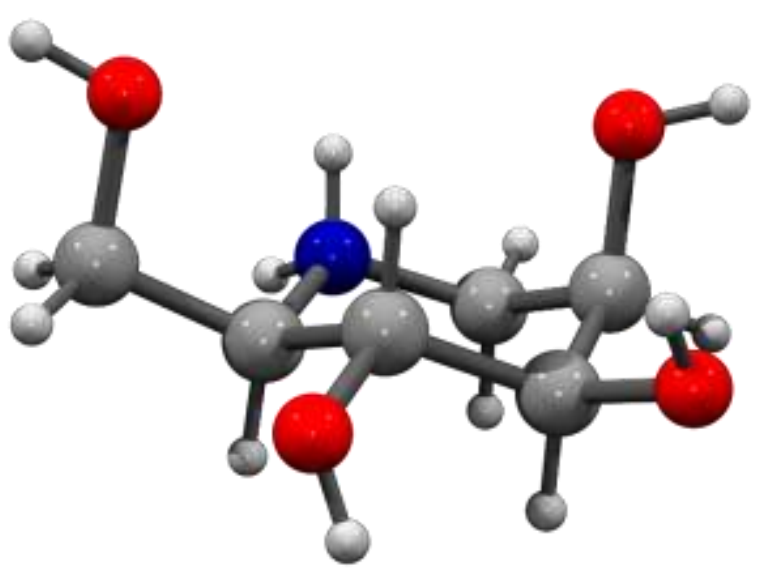

Figure 19. POV-Ray image of DMJ (3)

NMR Spectroscopy

\begin{tabular}{lllll}
\hline Position & $\boldsymbol{\delta}_{\mathbf{a}} \mathbf{a}$, type & $\boldsymbol{\delta}_{\mathbf{H}} \mathbf{b}(\boldsymbol{J}$ in Hz$)$ & HMBC & COSY \\
\hline $1 \mathrm{a}$ & $59.8 \mathrm{CH}_{2}$ & $3.95, \mathrm{dd}(11.9,3.3)$ & 2,3 & $1 \mathrm{~b}, 2$ \\
$1 \mathrm{~b}$ & & $3.74, \mathrm{~m}$ & 3 & $1 \mathrm{a}, 2$ \\
2 & $62.6 \mathrm{CH}$ & $3.00, \mathrm{dd}(14.6,7.2,3.1)$ & 3 & $1 \mathrm{a}, 1 \mathrm{~b}, 3$ \\
3 & $67.7 \mathrm{CH}$ & $3.78, \mathrm{~d}(9.6)$ & $1 \mathrm{a}, 1 \mathrm{~b}, 2,4,5$ & $1 \mathrm{a}, 2,5$ \\
4 & $67.6 \mathrm{CH}$ & $4.08, \mathrm{t}(2.8)$ & $6 \mathrm{~b}$ & $5,6 \mathrm{~b}$ \\
5 & $74.6 \mathrm{CH}$ & $3.52, \mathrm{dd}(9.2,2.7)$ & 3,4 & 3,4 \\
$6 \mathrm{a}$ & $49.0 \mathrm{CH}_{2}$ & $3.15, \mathrm{~d}(13.1)$ & 2 & $6 \mathrm{~b}$ \\
$6 \mathrm{~b}$ & & $3.27, \mathrm{~m}$ & 4 & $6 \mathrm{a}$ \\
\hline
\end{tabular}

Table 7. NMR assignments for deoxymannojirimycin (3). ${ }^{a} 500 \mathrm{MHz}$, Referenced to Methanol$d_{4}\left(\delta\right.$ 49.10), ${ }^{b} 125, \mathrm{MHz}$ Referenced to Methanol-d 4 ( $\delta$ 4.78).

The ${ }^{13} \mathrm{C}$ NMR spectrum of $\mathbf{3}$ indicates the presence of six carbon environments, which is consistent with the structure of DMJ (3) after the loss of the six acetonide carbons from 2 . All six signals can be seen in the ${ }^{13} \mathrm{C}$ NMR and DEPT-135 spectra, which provides further 
evidence for the loss of the acetonide groups. The DEPT-135 spectrum shows two $\mathrm{CH}_{2}$ signals at $\delta 49.0$ and 59.8 ppm, which correspond to C-6 and C-1 respectively. The C-6 signal experiences a 2.6 ppm upfield shift, while the C-1 signal shifts $3.5 \mathrm{ppm}$ downfield due to the loss of the protecting groups. C-2, C-3 and C-4 experience a significant upfield shift. The $\mathrm{CH}$ signals were assigned based on additional information provided by HSQC, HMBC and COSY.

The most obvious change to the ${ }^{1} \mathrm{H}$ NMR spectrum is the loss of the strong methyl singlets at $\delta 1.3-1.5 \mathrm{ppm}$. Mass spectral evidence of the product also supported the loss of the acetonide groups.

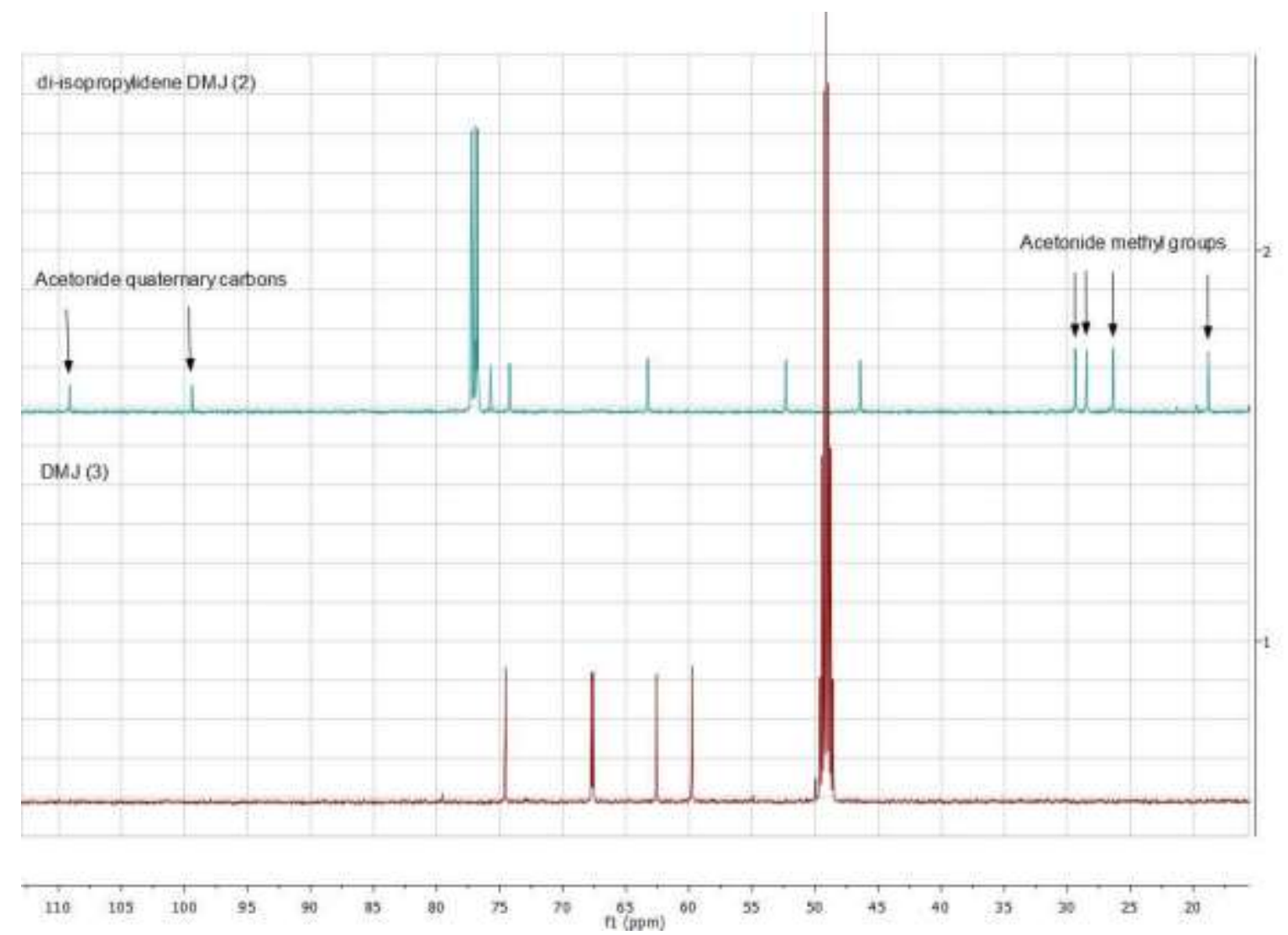

Figure 20. Comparison of $\mathbf{2}$ (top) and $\mathbf{3}$ (bottom) ${ }^{13} \mathrm{C} \mathrm{NMR}$ spectra (125 MHz)

\subsection{Process Optimisation}

\subsubsection{Sensitivity tests}

Several experiments were performed to investigate the catalyst sensitivity to a range of conditions and sampling methods, to determine where adjustments could be made in the preparation steps to make the process more efficient. 


\begin{tabular}{|c|c|c|c|c|c|c|c|}
\hline \multicolumn{8}{|c|}{$\begin{array}{c}\text { Intramolecular } N \text {-alkylation of } \mathbf{1} \\
\text { Sensitivity tests }\end{array}$} \\
\hline & \multicolumn{3}{|c|}{$\mathrm{n}(\mathrm{mmol})$} & \multirow[b]{2}{*}{$\begin{array}{c}\text { Solvent } \\
\text { (vol / mL) }\end{array}$} & \multirow[b]{2}{*}{$\begin{array}{l}\mathrm{T} / \\
\left({ }^{\circ} \mathrm{C}\right)\end{array}$} & \multirow[b]{2}{*}{ Conditions* } & \multirow[b]{2}{*}{ Result } \\
\hline Experiment & $\begin{array}{c}\text { KRM4 } \\
(\mathbf{1})\end{array}$ & Catalyst & $\begin{array}{c}\text { Co- } \\
\text { catalyst }\end{array}$ & & & & \\
\hline 1 & 3.8 & 0.030 & 0.047 & $\begin{array}{l}\text { Toluene } \\
\text { (6) }\end{array}$ & 120 & $\begin{array}{l}\text { Crude starting } \\
\text { material }\end{array}$ & No reaction \\
\hline 2 & 1.0 & 0.0065 & 0.014 & $\begin{array}{l}\text { Toluene } \\
\text { (6) }\end{array}$ & 120 & $\begin{array}{l}\text { Crude starting } \\
\text { material }\end{array}$ & $\begin{array}{l}\text { Poor } \\
\text { conversion }\end{array}$ \\
\hline 3 & 1.1 & 0.0077 & 0.015 & $\begin{array}{l}\text { Toluene } \\
\text { (2) }\end{array}$ & 120 & House vacuum & No reaction \\
\hline 4 & 1.1 & 0.0080 & 0.016 & $\begin{array}{l}\text { Xylene } \\
(2)\end{array}$ & 130 & House vacuum & No reaction \\
\hline 5 & 1.0 & 0.0059 & 0.015 & $\begin{array}{l}\text { Toluene } \\
\text { (2) }\end{array}$ & 120 & House vacuum & $\begin{array}{l}\text { High } \\
\text { conversion }\end{array}$ \\
\hline 6 & 0.99 & 0.0065 & 0.013 & $\begin{array}{l}\text { Xylene } \\
(2)\end{array}$ & 130 & House vacuum & No reaction \\
\hline 7 & 1.00 & 0.0064 & 0.013 & $\begin{array}{l}\text { Toluene } \\
\text { (2) }\end{array}$ & 120 & $\begin{array}{l}\text { Heat gun dried } \\
\text { reaction vessel }\end{array}$ & $\begin{array}{l}\text { Poor } \\
\text { conversion }\end{array}$ \\
\hline 8 & 0.81 & 0.0060 & 0.010 & $\begin{array}{l}\text { Xylene } \\
(2)\end{array}$ & 130 & Tefzel tubing & No reaction \\
\hline 9 & 0.79 & 0.0065 & 0.012 & $\begin{array}{l}\text { Xylene } \\
\text { (2) }\end{array}$ & 130 & PEEK tubing & $\begin{array}{l}\text { Moderate } \\
\text { conversion }\end{array}$ \\
\hline
\end{tabular}

*All reactions performed under an Argon atmosphere in flame-dried glassware purged with argon/vacuum, using degassed solvent. All reactions allowed to reflux for 72 hours with no sampling.

\section{Table 8. Experiment summary: sensitivity tests}

\section{Impurities}

The tolerance of the reaction to impurities was investigated by using crude starting material, in place of the purified KRM4 (1) used previously. The reaction was attempted twice, at the 1 mmol and $4 \mathrm{mmol}$ scale. All other reaction conditions were consistent with previous successful attempts. Each reaction was left to reflux at $120^{\circ} \mathrm{C}$ for 72 hours. NMR showed no conversion of starting material in the first reaction and very poor conversion in the second reaction. It is not clear what impurities were present in the crude starting material, but it should be noted that KRM4 (1) needs to be of high purity to support a reaction.

\section{Vacuum}

The second condition investigated was the strength of vacuum. In each previous reaction, the vessel was prepared by purging with dry argon gas and high vacuum ( $<1 \mathrm{mbar})$ using a vacuum pump and cold trap. To determine whether such a strong vacuum was required, a series of reactions were performed using standard laboratory ("house") vacuum of $\sim 10$ mbar for preparation of the reaction vessel. In theory, a 1 mbar pressure means $0.1 \%$ of the atmosphere remains, while 10 mbar is $1 \%$; thus, after three purges and evacuations the 
amount of residual atmosphere not displaced by the inert gas is minuscule (in both cases) and proposed to not be significant in the context of the proposed reaction. Each of the four reactions were performed at a $1 \mathrm{mmol}$ scale and left to reflux for 72 hours. Two reactions were performed with toluene at $120^{\circ} \mathrm{C}$, and two with xylene at $130^{\circ} \mathrm{C}$. Neither of the xylene experiments showed any evidence of conversion, while only one of the toluene experiments was successful.

The inconsistency of results highlights the importance of adequately preparing the reaction vessel. Whilst using a vacuum pump offers more consistent results, use of house vacuum is sufficient if appropriate care is taken. Flushing the reaction vessel over a longer period, or increasing the number of argon/vacuum flushes, could sufficiently compensate for the lesser vacuum strength. The method of preparation must be given due consideration, as this is important during scale-up and commercial development. The use of a vacuum pump and cold trap may not be feasible on a commercial manufacturing scale.

Drying of the reaction vessel

Another important step in the preparation of the reaction vessel is drying of the glassware under vacuum to expel any trapped moisture. In each successful experiment, the vessel was flame-dried using a propane torch. Whilst this is an appropriate method for bench-top reactions, it would not be feasible on a commercial scale. An alternative method would need to be investigated. For this reason, an alternative drying method was tested. The Schlenk tube was dried with a heat gun under vacuum. All other conditions were kept constant and the reaction was performed at the $1 \mathrm{mmol}$ scale in toluene. The reaction mixture was left to reflux at $120^{\circ} \mathrm{C}$ for 72 hours. NMR showed partial conversion of $\mathbf{1}$ to product $\mathbf{2}$. 


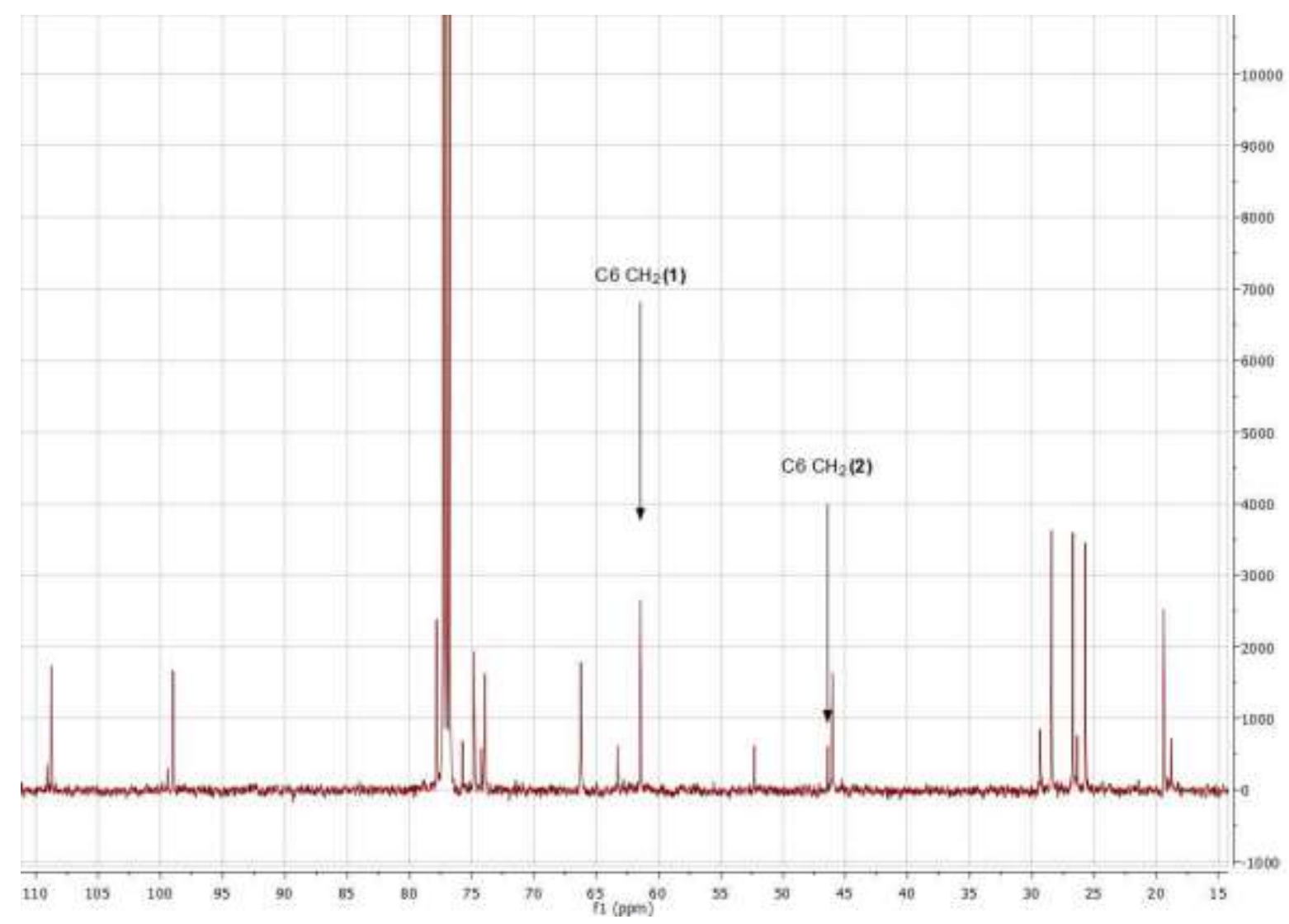

Figure 21. ${ }^{13} \mathrm{C}$ NMR spectrum of reaction product. $125 \mathrm{MHz}$, Referenced to $\mathrm{CDCl}_{3}$

\section{Sampling materials}

As concluded from earlier experiments, the reaction is not compatible with sampling via a metal needle. In the second aniline/benzyl alcohol model reaction, contact with the needle at 10 minutes appears to have prevented any conversion of starting material. All conditions in that experiment were consistent with that of the two successful model reactions, but for the introduction of sampling. Ideally, an appropriate sampling method could be developed to investigate reaction kinetics and provide a means of monitoring the progress of the synthesis.

Two materials were considered for use in sampling: Tefzel and PEEK tubing. Tefzel tubing is made from ethylene tetrafluoroethylene, a fluorine-based polymer. ${ }^{16}$ PEEK (polyether ether ketone) tubing is often used as an alternative to stainless steel tubing, and is commonly used with HPLC systems. ${ }^{17}$

Two experiments were set up to investigate the compatibility of each material with the reaction. In each case, the reaction vessel was prepared by flame drying under vacuum and 
flushing with argon/vacuum three times, as per previous experiments. Each vessel was pressurised with argon prior to addition of KRM4 (1), catalyst and DPPF. A small piece of PEEK tubing was added to one vessel, while Tefzel tubing was added to the other. Each reaction vessel was flushed again with argon/vacuum before addition of degassed xylene and mixing at $130^{\circ} \mathrm{C}$ for 24 hours.

The reaction performed in the presence of Tefzel tubing was not successful, with NMR showing no conversion. NMR for the reaction performed with PEEK tubing showed some conversion, but the reaction did not go to completion. The reduced reaction time from 72 to 24 hours was supported by prior experiments (discussed below) and was not the cause of the poor conversion. For the purpose of this project, the materials were deemed incompatible with the reaction and no sampling method was produced. Experiments were performed as "black box" reactions, monitored only by their output after the specified reaction time.

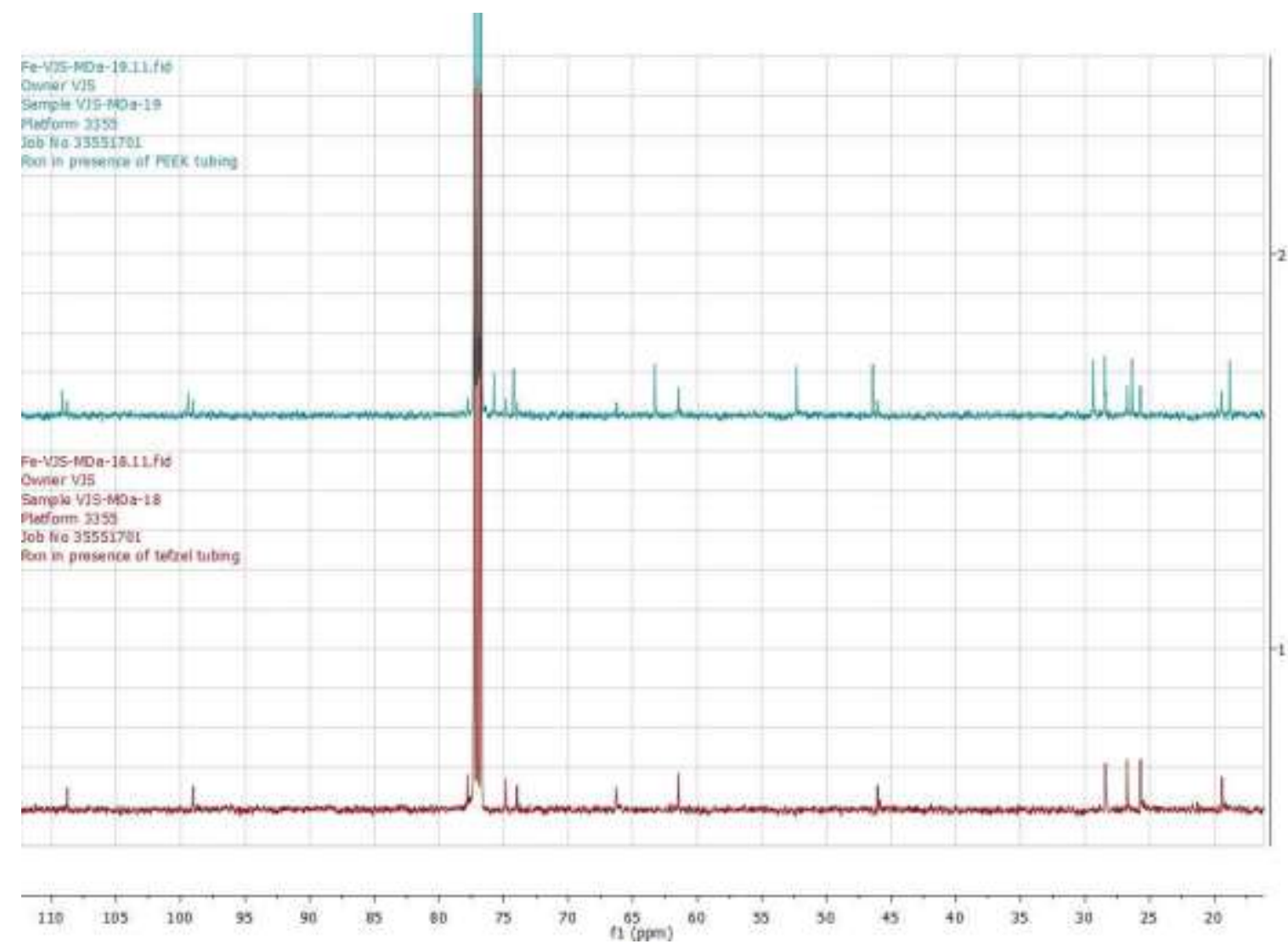

Figure 22. ${ }^{13} \mathrm{C}$ NMR spectra of reaction product - PEEK / Tefzel sensitivity tests. $125 \mathrm{MHz}$, $\mathrm{CDCl}_{3}$ 


\subsubsection{Optimisation and Scale-up}

\begin{tabular}{|c|c|c|c|c|c|c|c|}
\hline \multicolumn{8}{|c|}{ Intramolecular $N$-alkylation of $\mathbf{1}$} \\
\hline & \multicolumn{3}{|c|}{$\mathrm{n}(\mathrm{mmol})$} & \multirow[b]{2}{*}{ Solvent } & \multirow[b]{2}{*}{$\mathrm{T} /\left({ }^{\circ} \mathrm{C}\right)$} & \multirow[b]{2}{*}{ Conditions } & \multirow[b]{2}{*}{ Result } \\
\hline Exp. & $\begin{array}{l}\text { KRM4 } \\
\text { (1) }\end{array}$ & Catalyst & $\begin{array}{c}\text { Co- } \\
\text { catalyst }\end{array}$ & & & & \\
\hline 1 & 1.03 & 0.0069 & 0.016 & Xylene & 130 & $\begin{array}{l}22 \text { hours, } 0.67 \mathrm{~mol} \% \\
\text { catalyst }\end{array}$ & $\begin{array}{l}\text { High } \\
\text { conversion }\end{array}$ \\
\hline 2 & 1.91 & 0.0103 & 0.019 & Xylene & 130 & $\begin{array}{l}22 \text { hours, } 0.54 \mathrm{~mol} \% \\
\text { catalyst, } 125 \mathrm{mg} / \mathrm{mL}\end{array}$ & $\begin{array}{l}\text { High } \\
\text { conversion }\end{array}$ \\
\hline 3 & 3.86 & 0.0199 & 0.043 & Xylene & 130 & $\begin{array}{l}18 \text { hours, } 0.52 \mathrm{~mol} \% \\
\text { catalyst, } 250 \mathrm{mg} / \mathrm{mL}\end{array}$ & $\begin{array}{l}\text { High } \\
\text { conversion }\end{array}$ \\
\hline
\end{tabular}

Table 9. Experiment summary: optimisation and scale-up

The first experiment was designed to formally investigate the use of xylene as the reaction solvent, which had been used in several prior experiments (see table 7). The higher boiling point of xylene compared with toluene allowed for the mixture to be heated to a higher temperature $\left(130^{\circ} \mathrm{C}\right)$, which could effectively reduce the reaction time. The issue with testing this hypothesis, was that the lack of an appropriate in-process sampling method that prevented the monitoring of the reaction. Instead, whether product had formed or not was estimated qualitatively based on the colour of the reaction mixture. It was noted in early experiments that a failed reaction was a brown-black in colour, whereas a successful reaction was a deep red. In this experiment, the colour change was noted the morning after the reaction was put on heat. ${ }^{13} \mathrm{C}$ NMR analysis of the reaction mixture at 22 hours showed a high conversion to 2 .

Two conditions were altered in the second experiment. The scale was increased to $500 \mathrm{mg}$ and the catalyst loading was reduced from $\sim 0.7 \mathrm{~mol} \%$ to $\sim 0.5 \mathrm{~mol} \%$. These conditions would be investigated individually if the reaction was unsuccessful. After 22 hours, ${ }^{13} \mathrm{C}$ NMR analysis indicated a high conversion to $\mathbf{2}$. The reaction had been performed in xylene at a concentration of approximately $125 \mathrm{mg} / \mathrm{mL}$.

The third experiment focused on a scale-up to $1000 \mathrm{mg} \mathbf{1}$ in the same volume of xylene (4 $\mathrm{mL}$ ), resulting in a concentration of $250 \mathrm{mg} / \mathrm{mL}$. The catalyst loading was the same as for the previous experiment. After 18 hours, ${ }^{13} \mathrm{C}$ NMR showed a high conversion to 2 .

These experiments have shown that the reaction can be performed successfully at the 1000 mg scale, with no changes to preparation and reaction time. The high concentration allows for a low-volume synthesis, which means that larger scale production may be performed using 
standard laboratory glassware. The catalyst loading in the initial experiments was $1.25 \mathrm{~mol} \%$ of the ruthenium dimer and $2.50 \mathrm{~mol} \%$ of the co-catalyst, DPPF. The optimisation experiments have showed the same results can be obtained with a loading of $0.5 \mathrm{~mol} \%$ ruthenium and $1.0 \mathrm{~mol} \% \mathrm{DPPF}$, which would reduce the overall cost of production.

\subsection{Summary}

DMJ (3) was successfully produced in a two-step, one-pot synthesis, with excellent yields. Successful production of $\mathbf{2}$ using hydrogen borrowing methodology supports the broad application of the technique, and shows its ability to be used for intramolecular $N$-alkylation, as well as intermolecular small-molecule reactions. This alternative to conventional alkylation methods is a positive step in the development of waste-efficient commercial production.

Investigation and optimisation of the hydrogen borrowing reaction shed light on the limits and sensitivities of the chemistry. Beyond the trial reactions, no attempt was made to control catalyst exposure to water, which is generated as a by-product of the reaction. The success of the experiments in the absence of these controls indicate that the catalyst is not watersensitive. It was discovered, however, that the catalyst possesses a range of other sensitivities, some of which were difficult to control.

For a successful reaction, the glassware had to have been thoroughly dried and purged effectively with dry argon and a strong vacuum to eliminate any air in the vessel. If any part of the preparation procedure was relaxed, the yield of $\mathbf{2}$ was affected. This included the use of house vacuum instead of vacuum pump, and the use of a heat gun instead of a propane torch. It will be more difficult to ensure an oxygen-free environment during large-scale, commercial production. Preparation procedures will have to be carefully developed. It is also important to note that the system has a low tolerance for impurities, hence the purification of $\mathbf{1}$ is an important prefatory step. The flash chromatography method described is efficient and produces a high quality white solid in excellent yields.

It should be noted that in the hands of other operators this exact conversion often results in the recovery of only starting material. This may suggest the reaction is sensitive to the procedure followed and warrants further investigation.

Further investigation is also required into the reaction kinetics, to further optimise reaction time. The difficulty is developing an appropriate sampling method without compromising the 
reaction. It was found that contact of the catalyst in solution with foreign materials, such as needles and polymer tubing, adversely affected the yield of product. Sensitivity testing of a wider range of materials is required.

It was determined that the deprotection reaction could be performed in the same reaction vessel, without any isolation of intermediate 2 . Further work is required to optimise this step of the reaction. It is likely that the reaction time could be significantly reduced by performing this step at temperature.

The synthetic method described provides a simple and robust alternative to previously reported syntheses. Purification methods have been developed for each of the three compounds, but require further work to increase efficiency and recovery. All three compounds have been fully characterised. 


\section{ANALYTICAL METHODS}

\subsection{Aims and Objectives}

The specific aim of the work discussed in this section was to investigate the use of High Performance Liquid Chromatography (HPLC) for the purity and identity testing of $\mathbf{1}, \mathbf{2}$ and $\mathbf{3}$. An analytical method is required for the quality control testing of $\mathbf{3}$, which should be capable of quantifying the purity of the compound.

\section{RESULTS AND DISCUSSION}

\subsection{HPLC-CAD}

Initial attempts to analyse the three compounds were made using a reverse phased C18 column and Charged Aerosol Detector (CAD). The detector works by converting the analyte into dry particles, which are then charged by collision with a stream of positively charged $\operatorname{gas}^{18}$. Larger particles receive a greater charge. The particles are then directed to a collector, where an electrometer is used to measure their charge. A signal is produced, which is proportional to the amount of analyte present in the sample.

Each compound was dissolved in HPLC grade methanol at a concentration of $1 \mathrm{mg} / \mathrm{mL}$. An initial run was performed for each solution, with $5 \mu \mathrm{L}$ injections and an isocratic solvent system of $100 \%$ acetonitrile for 10 minutes. For 1, no peaks were identified except for the solvent front at $\sim 2$ minutes. Compounds $\mathbf{2}$ and $\mathbf{3}$ appeared to contain some impurities, which produced small peaks later in the run, but there were no strong signals to indicate elution of the target compound. Running for 30 minutes at $100 \%, 80 \%$ and $60 \%$ acetonitrile respectively did not produce different results.

A gradient method was prepared, starting at 5\% acetonitrile (95\% water) and increasing to $100 \%$ over 30 minutes. Compound 1 showed a peak at 2.4 minutes, immediately to the right of the solvent front. Compounds $\mathbf{2}$ and $\mathbf{3}$ did not appear to elute. If $\mathbf{1}$ was eluting so quickly, it was assumed that $\mathbf{3}$ was not being retained on the column at all. A mixture of all three compounds in methanol was run using the same method, but the chromatogram showed only elution of 1 .

\subsection{LCMS}

The compounds were run on an LCMS to identify the retention times of $\mathbf{2}$ and $\mathbf{3}$. A gradient method was used, starting at $5 \%$ methanol and increasing to $100 \%$ over 10 minutes, then 
holding for two minutes at $100 \%$. A $0.05 \% \mathrm{v} / \mathrm{v}$ solution of formic acid was run with the mobile phase.

\section{Compound 1}

The Total Ion Count (TIC) indicated a peak at 2.6 minutes, which was not observed with the Diode Array Detector (DAD). The peak was selected for analysis by mass spectrometry, which identified a reference peak at $262.1 \mathrm{Da}$, which is the expected $\mathrm{m} / \mathrm{z}$ for compound $\mathbf{1}$, which has a molecular weight of $261.32 \mathrm{~g} / \mathrm{mol}$.

\section{Compound 2}

TIC presented a peak at 2.48 minutes, which was very similar to the retention time of compound 1. This peak corresponded to an ion at $244.1 \mathrm{Da}$, which is consistent with compound 2, which has a molecular weight of $243.30 \mathrm{~g} / \mathrm{mol}$. This compound was expected to be retained on the column longer than compound $\mathbf{1}$, as it was thought to be more non-polar. Interestingly, the retention times were very similar, which would lead to difficulties in distinguishing them in a mixture using this method.

Impurities were seen at 9.6 and 11.2 minutes. These peaks are likely due to ruthenium complexes remaining in the sample. Further analysis is required to identify these impurities.

\section{Compound 3}

TIC showed a peak at 0.47 minutes. This peak corresponded to a peak at $164.1 \mathrm{Da}$, which is consistent with compound 3 , which has a molecular weight of $163.17 \mathrm{~g} / \mathrm{mol}$. This compound was expected to have a lower retention time than compounds $\mathbf{1}$ and $\mathbf{2}$. It's position in the chromatogram indicates that the peak was likely masked by the solvent front in HPLC-CAD. This poses significant issues for analysis.

Impurities were seen at 9.6, 11.1 and 11.2 minutes, which is consistent with the peaks observed for compound 2 .

\section{Mixture of compounds 1, 2 and 3}

LCMS revealed peaks at $0.47,2.55$, and 2.70 minutes. These peaks correspond to compounds 3, 2 and 1 respectively. Compounds $\mathbf{1}$ and $\mathbf{2}$ are poorly resolved, and further work is required to develop an appropriate chromatographic method. Compound $\mathbf{3}$ is barely retained on the column at all. Alternative chromatography methods may need to be investigated for analysis of this compound. 


\subsection{Summary}

The LCMS data provides a starting point for the development of analytical methods. It is important to note that chemical identity testing can be performed by ${ }^{13} \mathrm{C} N \mathrm{NR}$, which also provides some information as to the compound's purity. At this point, HPLC is not able to be used to quantify each compound without the use of mass spectrometry. It is recommended that a quantitative MS method be developed for testing of chemical purity.

The mass spectrometry data provides further evidence for the identity of compounds $\mathbf{1}, \mathbf{2}$, and 3, characterised earlier in this report. 


\section{EXPERIMENTAL}

\subsection{General Experimental}

\subsubsection{Purification of 1}

Purification was achieved using flash column chromatography. Columns were packed using silica 60 (silica gel, $40-60 \mu \mathrm{m}), 60 \times 100 \mathrm{~mm}, \mathrm{~m}\left(\mathrm{SiO}_{2}\right)=112.6 \mathrm{~g}$. Isocratic operation using $5: 0.5: 0.1, \mathrm{CHCl}_{3}: \mathrm{MeOH}: \mathrm{NH}_{4} \mathrm{OH}(25 \%$, aq.).

${ }^{1} \mathrm{H}$ NMR $\left(500 \mathrm{MHz}, \mathrm{CDCl}_{3}\right): \delta 4.45(\mathrm{dd}, J=6.7,2.1 \mathrm{~Hz}, 1 \mathrm{H}, \mathrm{H} 3), 4.25(\mathrm{dt}, J=6.7,4.8 \mathrm{~Hz}$, 1H, H2), 3.84 (dd, $J=11.4,5.3 \mathrm{~Hz}, 1 \mathrm{H}, \mathrm{H} 6 \mathrm{a}), 3.78$ (dd, $J=12.0,5.0 \mathrm{~Hz}, 1 \mathrm{H}, \mathrm{H} 1 \mathrm{a}), 3.72$ (dd, $J=12.0,4.6 \mathrm{~Hz}, 1 \mathrm{H}, \mathrm{H} 1 \mathrm{~b}), 3.48$ (dd, $J=9.3,2.1 \mathrm{~Hz}, 1 \mathrm{H}, \mathrm{H} 4), 3.44(\mathrm{dd}, J=11.4,2.1 \mathrm{~Hz}, 1 \mathrm{H}$, H6b), 3.07 (ddd, $J=9.3,5.3 \mathrm{~Hz}, 1 \mathrm{H}, \mathrm{H} 5), 1.49$ (s, 3H, H11), 1.43 (s, 3H, H10), 1.38 (s, 3H, H9), 1.34 (s, 3H, H12); ${ }^{13} \mathrm{C}$ NMR (125 MHz, CDCl 3 ): $\delta 108.7$ (C, C-7), 98.8 (C, C-8), 77.8 $(\mathrm{CH}, \mathrm{C}-2), 74.6(\mathrm{CH}, \mathrm{C}-3), 73.9(\mathrm{CH}, \mathrm{C}-4), 66.2\left(\mathrm{CH}_{2}, \mathrm{C}-6\right), 61.2\left(\mathrm{CH}_{2}, \mathrm{C}-1\right), 45.9(\mathrm{CH}, \mathrm{C}-$ 5), $28.4\left(\mathrm{CH}_{3}, \mathrm{C}-9\right), 26.5\left(\mathrm{CH}_{3}, \mathrm{C}-11\right), 25.6\left(\mathrm{CH}_{3}, \mathrm{C}-12\right), 19.2\left(\mathrm{CH}_{3}, \mathrm{C}-10\right)$.

\subsubsection{NMR analysis}

Spectra were collected at $30{ }^{\circ} \mathrm{C}$. Compounds $\mathbf{1}$ and $\mathbf{2}$ were dissolved in $\mathrm{CDCl}_{3}$ and compound 3 was dissolved in methanol-d $\mathrm{d}_{4}$. Chemical shifts were referenced to solvent peaks at ${ }^{1} \mathrm{H} \delta 7.26$ ppm and ${ }^{13} \mathrm{C} \delta 77.00$ ppm for chloroform, and to ${ }^{1} \mathrm{H} \delta 3.31 \mathrm{ppm}$ and ${ }^{13} \mathrm{C} \delta 49.10 \mathrm{ppm}$ for methanol-d 4 .

NMR spectra were recorded on two instruments:

1) An Agilent MR600 with a ${ }^{13} \mathrm{C} /{ }^{1} \mathrm{H}$ optimized OneProbe.

2) A three-channel Bruker Avance III 500.

Spectra were processed using MestReNova software, version 11.0.4- 18998 ID. NMR resonances were assigned based on COSY, HSQC and HMBC 2D experiments.

\subsubsection{HPLC}

Samples were dissolved in HPLC grade methanol at $1 \mathrm{mg} / \mathrm{mL}$, and run on a Phenomenex Kinetex $2.6 \mu \mathrm{m} \mathrm{C18} 100 \AA$ A column (100 x 3 mm) using a ThermoFisher UltiMate uHPLC system. A gradient method was used, starting at 5\% acetonitrile (95\% water, $0.05 \mathrm{M}$ formic acid) and increasing to $100 \%$ acetonitrile over 30 minutes, with a 5-minute hold at $100 \%$ and return to starting conditions over two minutes. 
The same samples were run on an Agilent HPLC-MS system using a C18 reverse phased column. A gradient method was used, starting at 5\% methanol (95\% water, $0.05 \mathrm{M}$ formic acid) and increasing to $100 \%$ methanol over 10 minutes, with a 2 -minute hold at $100 \%$.

\subsection{Synthesis}

\subsubsection{Hydrogen borrowing - General methods}

Unless otherwise stated, all reactions were conducted under an atmosphere of dry argon, in flame-dried glassware (Schlenk tube) with degassed HPLC grade solvents. Xylene and toluene were stored over activated $4 \AA$ molecular sieves and pressurised with argon. Prior to addition of 1, catalyst and co-catalyst, the reaction vessel was flame dried under vacuum and purged with argon/vacuum three times. A further argon/vacuum purge was performed prior to addition of the freshly degassed solvent. Reactions were stirred at reflux for the specified reaction time. For each reaction, the catalyst used was dichloro(p-cymene) ruthenium(II) dimer and the co-catalyst was 1,1'-bis(diphenylphosphino)ferrocene (DPPF). Reaction progress was not monitored, but the outcome of each reaction was assessed at its conclusion by ${ }^{13} \mathrm{C}$ NMR spectroscopy (details below).

\subsubsection{Benzylaniline}

To a Schlenk tube, catalyst $(4.6 \mathrm{mg}, 0.0075 \mathrm{mmol})$ and co-catalyst DPPF (9.3 mg, 0.017 mmol) were added. After purging with argon/vacuum, $1 \mathrm{~mL}$ degassed toluene was added and the mixture was stirred at room temperature for 10 minutes. Benzyl alcohol $(110 \mu \mathrm{L}, 1 \mathrm{mmol})$ and aniline ( $92 \mu \mathrm{L}, 1 \mathrm{mmol})$ were drawn up under argon and added to the reaction vessel. The reaction was heated to $120^{\circ} \mathrm{C}$ and left to stir for 72 hours. The solution was then concentrated in vacuo to provide the crude product. No purification was performed. Spectral data matched literature values. ${ }^{19}$

\subsection{3. $1,3-4,5$-di-isopropylidene deoxymannojirimycin}

To a Schlenk tube, 1 (1008.3 mg, $3.86 \mathrm{mmol})$, catalyst (12.2 mg, $0.0199 \mathrm{mmol})$ and cocatalyst (23.6 mg, $0.43 \mathrm{mmol}$ ) were added. After purging with argon/vacuum, $4 \mathrm{~mL}$ degassed xylene was added. The reaction was then heated to $130^{\circ} \mathrm{C}$ and left to stir for 18 hours. The solution was then concentrated in vacuo to provide the crude product (95\%). Purification was achieved using flash column chromatography using silica 60 (silica gel, $40-60 \mu \mathrm{m}$ ), and run using the eluent indicated in the discussion. The solution was concentrated in vacuo to afford a tan coloured solid. The solid was recrystallised from ethyl acetate and petroleum ether. The 
solution was decanted and the solid dried under vacuum to afford white, needle-shaped crystals $(2,87 \%)$.

${ }^{1} \mathrm{H}$ NMR (500 MHz, $\mathrm{CDCl}_{3}$ ): $\delta 4.19$ (ddd, $\left.J=7.2,3.2,1.2 \mathrm{~Hz}, 1 \mathrm{H}, \mathrm{H} 5\right), 3.97$ (dd, $J=7.7,5.2$ Hz, 1H, H4), 3.86 (dd, $J=11.1,5.3 \mathrm{~Hz}, 1 \mathrm{H}, \mathrm{H1a}), 3.61$ (dd, $J=10.4,7.8 \mathrm{~Hz}, 1 \mathrm{H}, \mathrm{H} 3$ ), 3.56 (d, $J=10.9,1 \mathrm{H} \mathrm{Hz}, \mathrm{H} 1 \mathrm{~b}$ ), 3.43 (dd, $J=15.0,1.4 \mathrm{~Hz}, 1 \mathrm{H}, \mathrm{H} 6 \mathrm{~b}), 3.04$ (dd, $J=15.0,3.1 \mathrm{~Hz}$, 1H, H6a), 2.42 (td, J = 10.5, 5.3 Hz, 1H, H2), 1.56 (s, 3H, H11), 1.49 (s, 3H, H10), 1.43 (s, 3H, H9), 1.37 (s, 3H, H12); ${ }^{13} \mathrm{C}$ NMR (125 MHz, CDCl 3 ): $\delta 109.1$ (C, C-7), 99.4 (C, C-8), 76.8 (CH, C-4), 75.7 (CH, C-3), $74.2(\mathrm{CH}, \mathrm{C}-5), 63.3\left(\mathrm{CH}_{2}, \mathrm{C}-1\right), 52.3(\mathrm{CH}, \mathrm{C}-2), 46.4\left(\mathrm{CH}_{2}\right.$, C-6), $29.3\left(\mathrm{CH}_{3}, \mathrm{C}-9\right), 28.5\left(\mathrm{CH}_{3}, \mathrm{C}-11\right), 26.3\left(\mathrm{CH}_{3}, \mathrm{C}-12\right), 18.8\left(\mathrm{CH}_{3}, \mathrm{C}-10\right)$.

\subsubsection{Deoxymannojirimycin}

To $400 \mu \mathrm{L}$ of crude reaction mixture (containing $100 \mathrm{mg} 2$ in xylene), a solution of methanolic $\mathrm{HCl}(400 \mu \mathrm{L}, 1: 5)$ was added. The solution was left to stir at room temperature overnight. The solution was concentrated in vacuo to give the crude product (73\%).

Purification was achieved by dissolving in methanol and concentrating under vacuum three times, and recrystallising from a 2:1 solution of ethanol/methanol to yield an off-white solid $(66 \%)$.

${ }^{1} \mathrm{H}$ NMR (500 MHz, $\left.\mathrm{CDCl}_{3}\right): \delta 4.08(\mathrm{t}, J=2.8 \mathrm{~Hz}, 1 \mathrm{H}, \mathrm{H} 4), 3.95(\mathrm{dd}, J=11.9,3.3 \mathrm{~Hz}, 1 \mathrm{H}$, H1a), 3.78 (d, $J=9.6 \mathrm{~Hz}, 1 \mathrm{H}, \mathrm{H} 3), 3.74$ (m, 1H, H1b), 3.52 (dd, $J=9.2,2.7 \mathrm{~Hz}, 1 \mathrm{H}, \mathrm{H} 5)$, 3.27 (m, 1H, H6b), 3.15 (d, $J=13.1 \mathrm{~Hz}, 1 \mathrm{H}, \mathrm{H} 6 \mathrm{a}), 3.00$ (dd, $J=14.6,7.2 \mathrm{~Hz}, 1 \mathrm{H}, \mathrm{H} 2) ;{ }^{13} \mathrm{C}$ NMR (125 MHz, CDCl $)$ ): $\delta 74.6(\mathrm{CH}, \mathrm{C}-5), 67.7(\mathrm{CH}, \mathrm{C}-3), 67.6(\mathrm{CH}, \mathrm{C}-4), 62.6(\mathrm{CH}, \mathrm{C}-2)$, $59.8\left(\mathrm{CH}_{2}, \mathrm{C}-1\right), 49.0\left(\mathrm{CH}_{2}, \mathrm{C}-6\right)$.

\subsection{X-ray diffraction}

\subsubsection{X-ray Crystallography of 1}

A sample of crystalline KRM4 was mounted on an Agilent SuperNova diffractometer fitted with an Eos S2 CCD detector. Data was collected at 120.0 K using Cu radiation at $1.5418 \AA$. The structure was refined with SHELXL-2013, implemented within WinGX, and drawing using ORTEP-3 for Windows.

The data indicated an orthorhombic crystal system, within the $P 2{ }_{1} 2_{1} 2_{1}$ (No. 19) space group. There are two molecules present in the crystal structure. Hydrogen bonding interactions are 
present. $\mathrm{H}$-atoms on $\mathrm{OH}$ and $\mathrm{NH}_{2}$ groups were located on the difference map and freely refined; all others were placed in calculated positions and refined as a riding model.

\subsubsection{X-ray Crystallography of 2}

A sample of crystalline $\mathbf{2}$ was mounted on an Agilent SuperNova diffractometer fitted with an Eos S2 CCD detector. Data was collected at $120.2 \mathrm{~K}$ using $\mathrm{Cu}$ radiation at $1.5418 \AA$. The structure was refined with SHELXL-2013, implemented within WinGX, and modeled using POVRAY.

The data indicated a monoclinic crystal system, within the $P 2_{1}$ space group.

\subsubsection{X-ray Crystallography of 3}

A sample of crystalline $\mathbf{3}$ was mounted on an Agilent SuperNova diffractometer fitted with an Eos S2 CCD detector. Data was collected at $120.2 \mathrm{~K}$ using Cu radiation at $1.5418 \AA$. The structure was refined with SHELXL-2013, implemented within WinGX, and modeled using POVRAY.

The data indicated an orthorhombic crystal system, within the $P 2{ }_{1}{ }_{1}{ }_{2}{ }_{1}$ (No. 19) space group. 


\section{CONCLUSION}

\subsection{Future Directions}

\subsubsection{Synthesis}

The use of hydrogen borrowing methodology in the synthesis of DMJ was explored in this project, however there is much still to be investigated. At the conclusion of this project, the synthesis of DMJ was completed in two steps, $<48$ hours, $>70 \%$ yield. The hydrogen borrowing step underwent significant optimisation, but it is likely the reaction time and catalyst loading could be further improved.

The catalyst system employed in this project were based on prior work by Broomfield et al. ${ }^{12}$ Alternative ruthenium-based catalysts are available and could give improved results.

Likewise, only two co-catalysts were utilised in this project, but neither were thoroughly investigated.

For further study of the hydrogen borrowing reaction in this context, a sampling method will need to be developed, without risking catalyst poisoning. In this system, the catalyst displayed incompatibilities with a range of materials which were considered for sampling. It is possible that sampling could be performed with a glass or ceramic needle, but these were not available for testing during this research. Monitoring the reaction at regular intervals would give important information about reaction kinetics, which would allow for further optimisation.

\subsubsection{Purification}

Limited investigation of purification methods was performed. The purification of KRM4 (1) involves simple flash chromatography, which was found to be suitable for batches up to 10 grams. Further work is required to develop a purification process suitable for commercial scale.

Purification of $\mathbf{2}$ required flash chromatography, followed by recrystallisation. This method would be difficult to perform at scale, although purification of $\mathbf{2}$ was not found to be required for successful production of $\mathbf{3}$.

An adequate purification of $\mathbf{3}$ was not developed in this project. As the final product, purity and quality are of high importance. Further work is required to develop a scale-up suitable 
method, which yields a highly pure solid, free of heavy metal impurities and residual solvents.

\subsubsection{Analysis}

A robust analytical method is still required for the quality control of DMJ and the monitoring of its synthesis. During this project, HPLC-CAD and LCMS were used for a preliminary assessment of compounds 1, 2 and 3. Difficulties arose with the HPLC method utilised, with all three compounds eluting from the column extremely quickly, with compound $\mathbf{3}$ not able to be distinguished from the solvent front. Compounds $\mathbf{1}$ and $\mathbf{2}$ were poorly resolved, so cannot be properly quantified in solution. Further development will possibly require chromatography on a normal phased column. Development of a quantitative LCMS method is recommended for monitoring chemical purity.

Impurity peaks were noted in the LCMS chromatograms. Further work is required to identify and quantify these impurities.

\subsection{Conclusion}

The primary objective of this research project was to develop a scale-up suitable synthesis of DMJ using hydrogen borrowing alkylation. The hydrogen borrowing reaction was successfully used for the intramolecular $N$-alkylation of KRM4 (1) up to a scale of $1000 \mathrm{mg}$. The conditions required for a successful reaction were investigated, along with any significant sensitivities and incompatibilities. It was found that the reaction required an oxygen-free atmosphere and highly pure reactants. As the system was not compatible with crude starting material, a suitable purification method was developed.

The second objective was to assess the feasibility of telescoping reactions to enable a one-pot multi-step synthesis. It was found that intermediate $\mathbf{2}$ did not need to be purified before deprotection, and this final step could be completed in the same reaction vessel as the hydrogen borrowing alkylation reaction.

The synthetic method described in this work provides a simple and robust alternative to previously reported syntheses. Further work is required in the purification of the final product (DMJ) and the development of a suitable analytical method, but the use of hydrogen borrowing methodology in the large-scale production of DMJ is a promising alternative to previous methods. 


\section{REFERENCES}

1. Lu, Y., Xu, Y.Y., Fan, K.Y. \& Shen, Z.H. 1-Deoxymannojirimycin, the alpha1,2mannosidase inhibitor, induced cellular endoplasmic reticulum stress in human hepatocarcinoma cell 7721. Biochemical and biophysical research communications $\mathbf{3 4 4}, 221$ 225 (2006).

2. Shental-Bechor, D. \& Levy, Y. Effect of glycosylation on protein folding: A close look at thermodynamic stabilization. Proceedings of the National Academy of Sciences 105, 8256-8261 (2008).

3. Hart, M.L., Saifuddin, M. \& Spear, G.T. Glycosylation inhibitors and neuraminidase enhance human immunodeficiency virus type 1 binding and neutralization by mannosebinding lectin. Journal of General Virology 84, 353-360 (2003).

4. Fleet, G.W.J., Ramsden, N.G. \& Witty, D.R. A practical synthesis of deoxymannojirimycin and of (2s,3R,4R,5R)-3,4,5-trihydroxypipecolic acid from D-glucose. Tetrahedron 45, 327-336 (1989).

5. Setoi, H., Takeno, H. \& Hashimoto, M. Synthesis of 1-deoxynojirimycin and 1deoxymannojirimycin. Chemical and Pharmaceutical Bulletin 34, 2642-2645 (1986).

6. Fleet, G.W.J., Ramsden, N.G. \& Witty, D.R. Practical synthesis of deoxymannojirimycin and mannonolactam from L-gulonolactone.: Synthesis of Ldeoxymannojirimycin and L-mannonolactam from D-gulonolactone. Tetrahedron 45, 319326 (1989).

7. Knight, J.G. \& Tchabanenko, K. Total synthesis of deoxymannojirimycin and dmannolactam via carbonylation of 5-vinyloxazolidin-2-ones. Tetrahedron 59, 281-286 (2003).

8. Racine, E., Bello, C., Gerber-Lemaire, S., Vogel, P. \& Py, S. A Short and Convenient Synthesis of 1-Deoxymannojirimycin and N-Oxy Analogues from d-Fructose. The Journal of Organic Chemistry 74, 1766-1769 (2009).

9. Hamid, M.H.S.A., Slatford, P.A. \& Williams, J.M.J. Borrowing Hydrogen in the Activation of Alcohols. Advanced Synthesis \& Catalysis 349, 1555-1575 (2007).

10. Smith, R.G., Vanterpool, A. \& Kulak, H.J. Dimethyl sulfoxide as a solvent in the Williamson ether synthesis. Canadian Journal of Chemistry 47, 2015-2019 (1969). 
11. Hamid, M.H.S.A., et al. Ruthenium-Catalyzed N-Alkylation of Amines and Sulfonamides Using Borrowing Hydrogen Methodology. Journal of the American Chemical Society 131, 1766-1774 (2009).

12. Broomfield, L.M., Wu, Y., Martin, E. \& Shafir, A. Phosphino-amine (PN) Ligands for Rapid Catalyst Discovery in Ruthenium-Catalyzed Hydrogen-Borrowing Alkylation of Anilines: A Proof of Principle. Advanced Synthesis \& Catalysis 357, 3538-3548 (2015).

13. Leonard, J., et al. A Survey of the Borrowing Hydrogen Approach to the Synthesis of some Pharmaceutically Relevant Intermediates. Organic Process Research \& Development 19, 1400-1410 (2015).

14. Benjes, P.A., et al. Process for preparing kifunensine (cyclic oxamide derivative of 1amino-mannojirimycin) intermediate and kifunensine therefrom. (ed. Office, N.Z.I.P.) (Industrial Research Ltd, New Zealand, 2004).

15. Greene, T. \& Wuts, P. Protective Groups in Organic Synthesis, (John Wiley \& Sons, Inc., USA, 1991).

16. Tefzel ETFE fluoropolymer resin. 2017 (DuPont, 2010).

17. IDEX. PEEK Tubing. 2017 (IDEX Health \& Science, 2016).

18. Charged Aerosol Detection for Liquid Chromatography. 2017 (ThermoFisher Scientific).

19. Xu, H. \& Wolf, C. Copper catalyzed coupling of aryl chlorides, bromides and iodides with amines and amides. Chemical Communications, 1715-1717 (2009). 


\section{APPENDIX}

\section{Spectra}

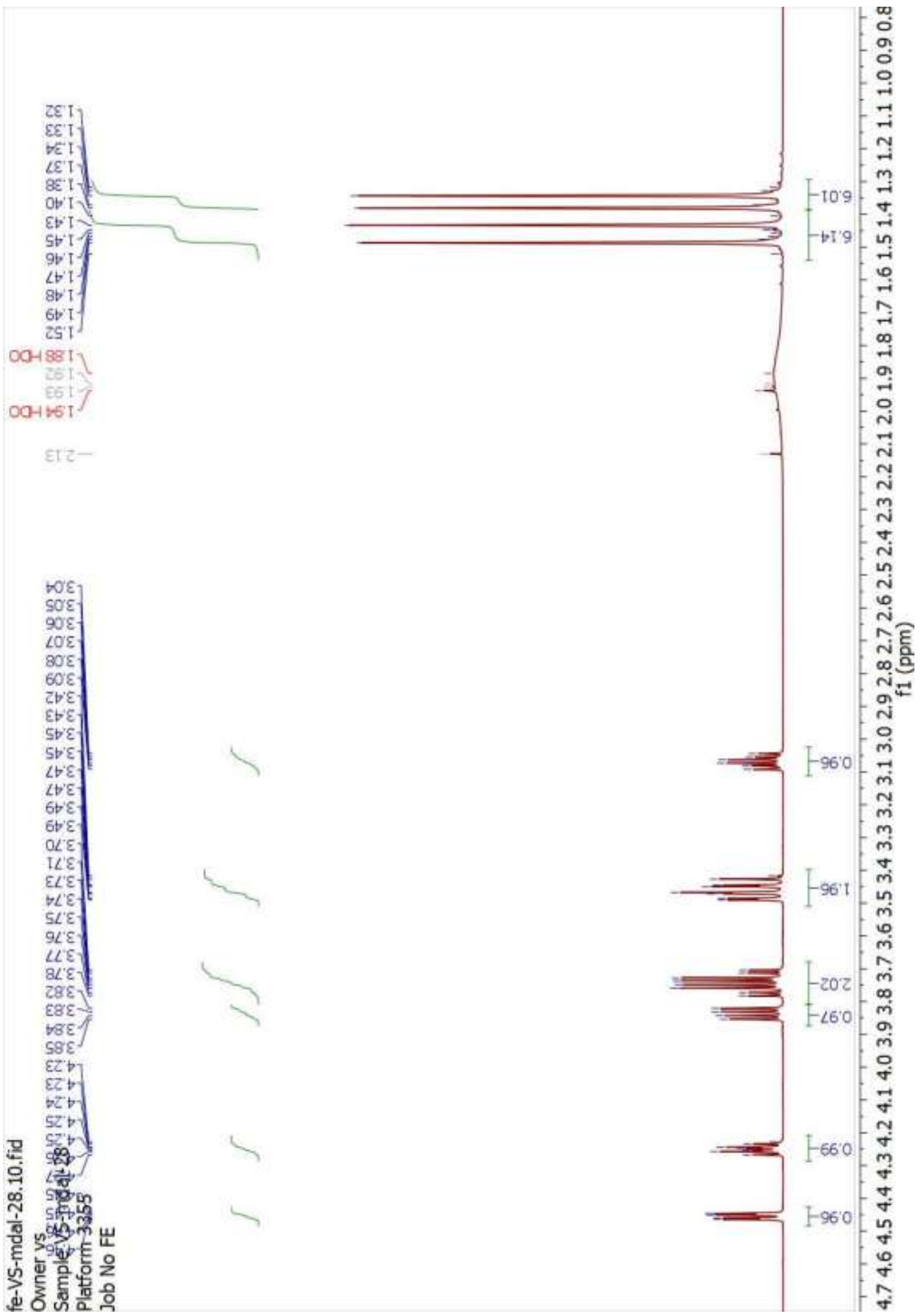

${ }^{1} \mathrm{H}$ NMR spectrum of starting material $1\left(500 \mathrm{MHz}, \mathrm{CDCl}_{3}\right)$ 


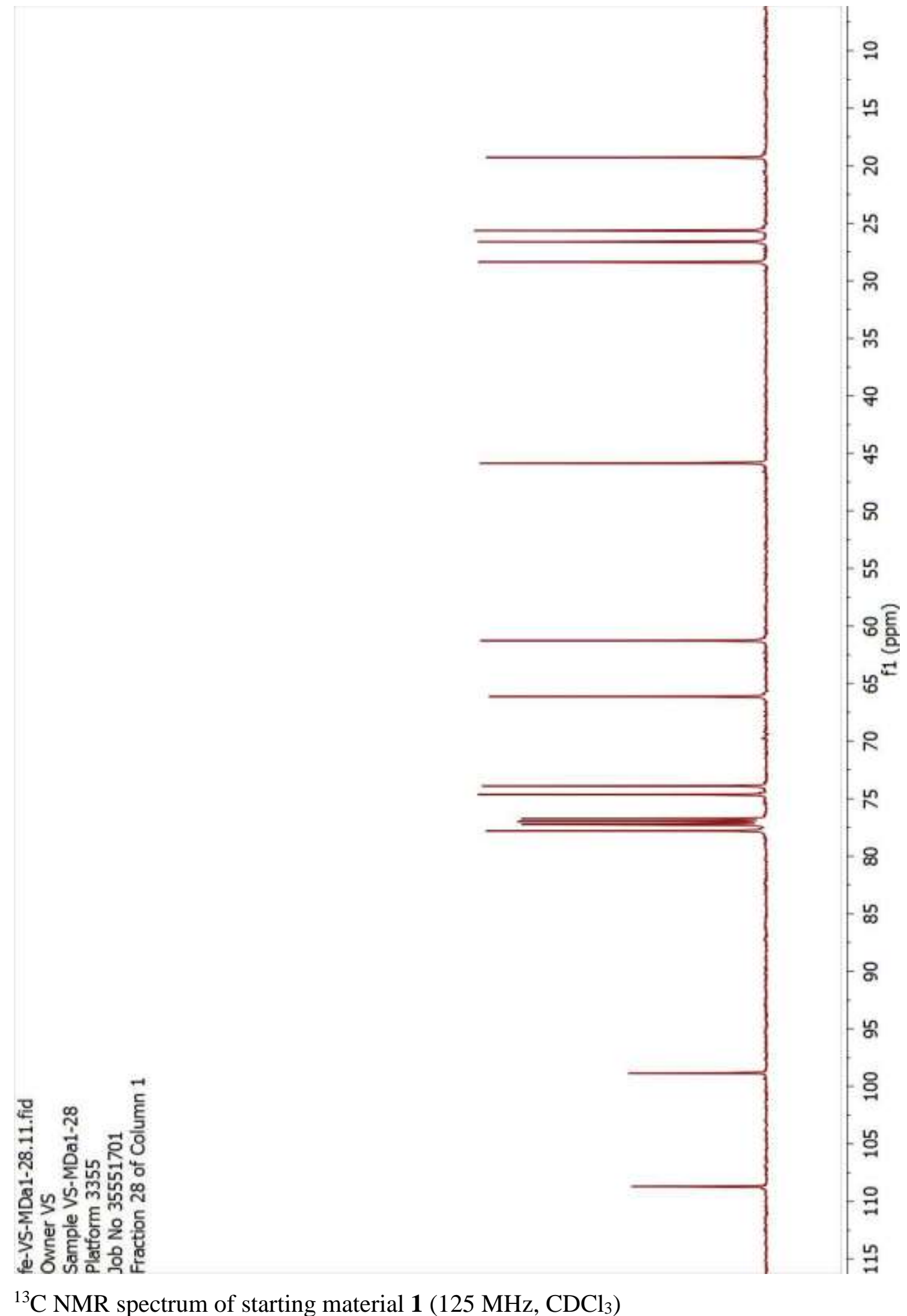




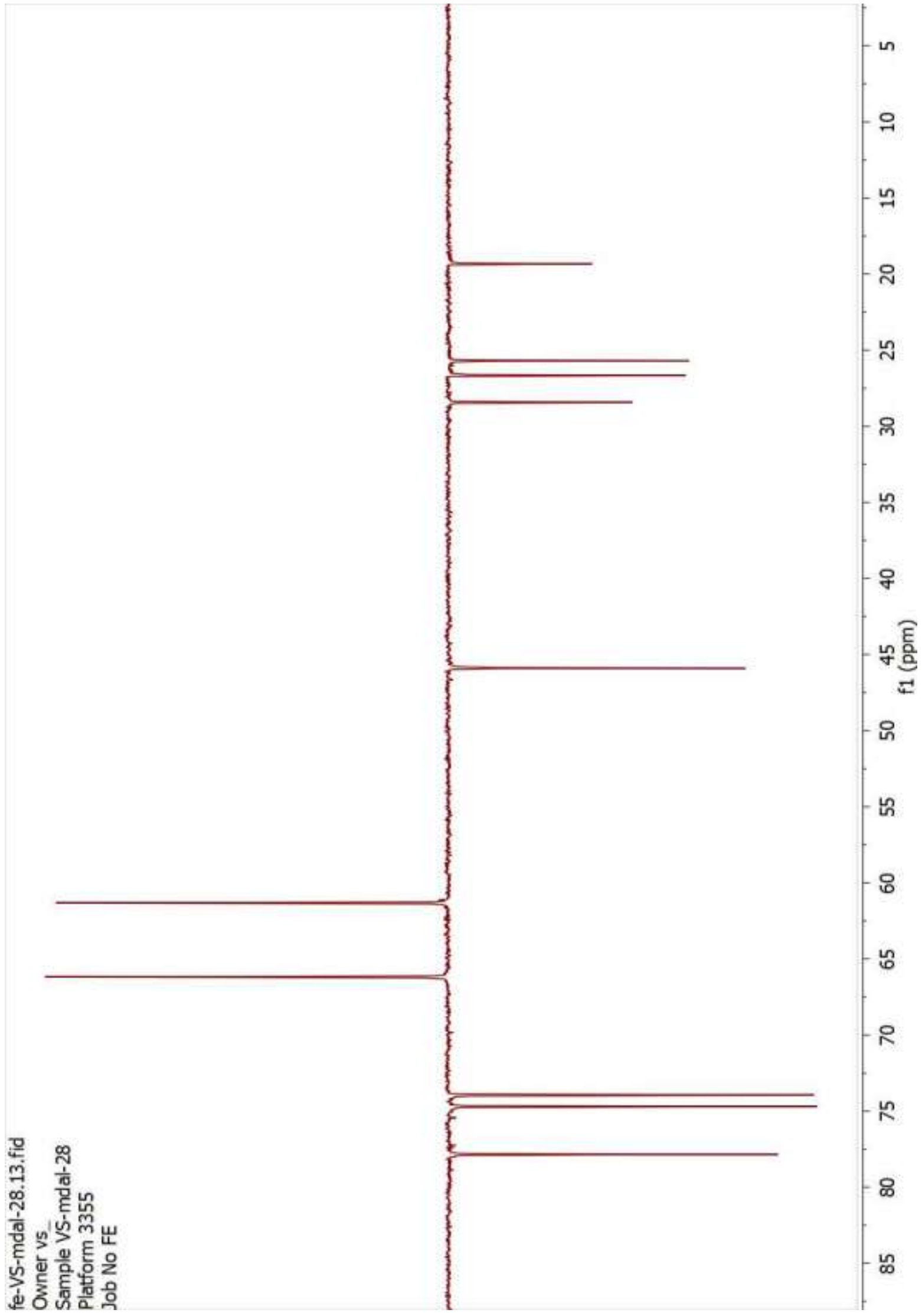

DEPT-135 spectrum of starting material $1\left(125 \mathrm{MHz}, \mathrm{CDCl}_{3}\right)$ 
(wdd) Tt

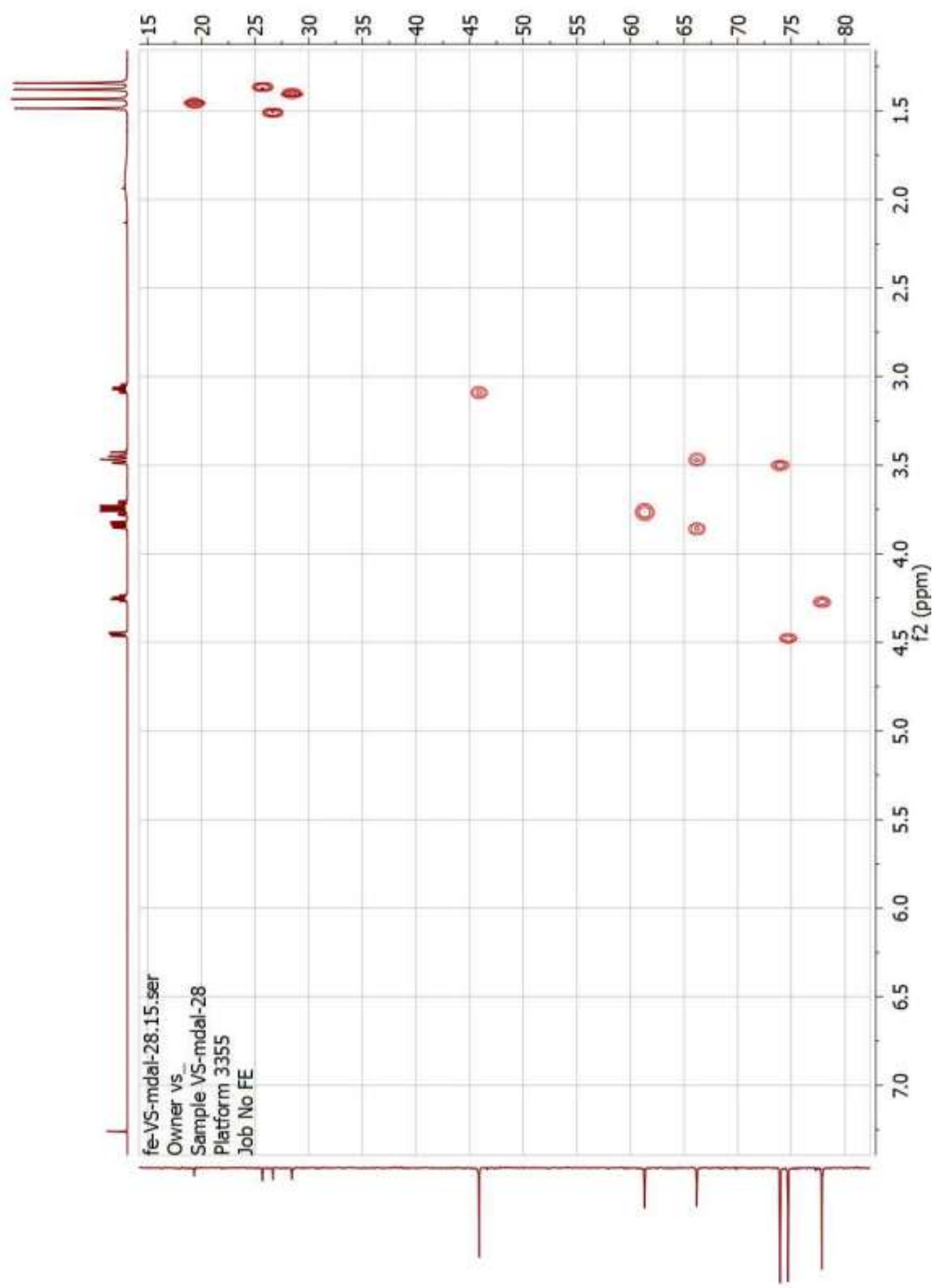

HSQC spectrum of starting material $1\left(500 \mathrm{MHz}, \mathrm{CDCl}_{3}\right)$ 
(wdd) If

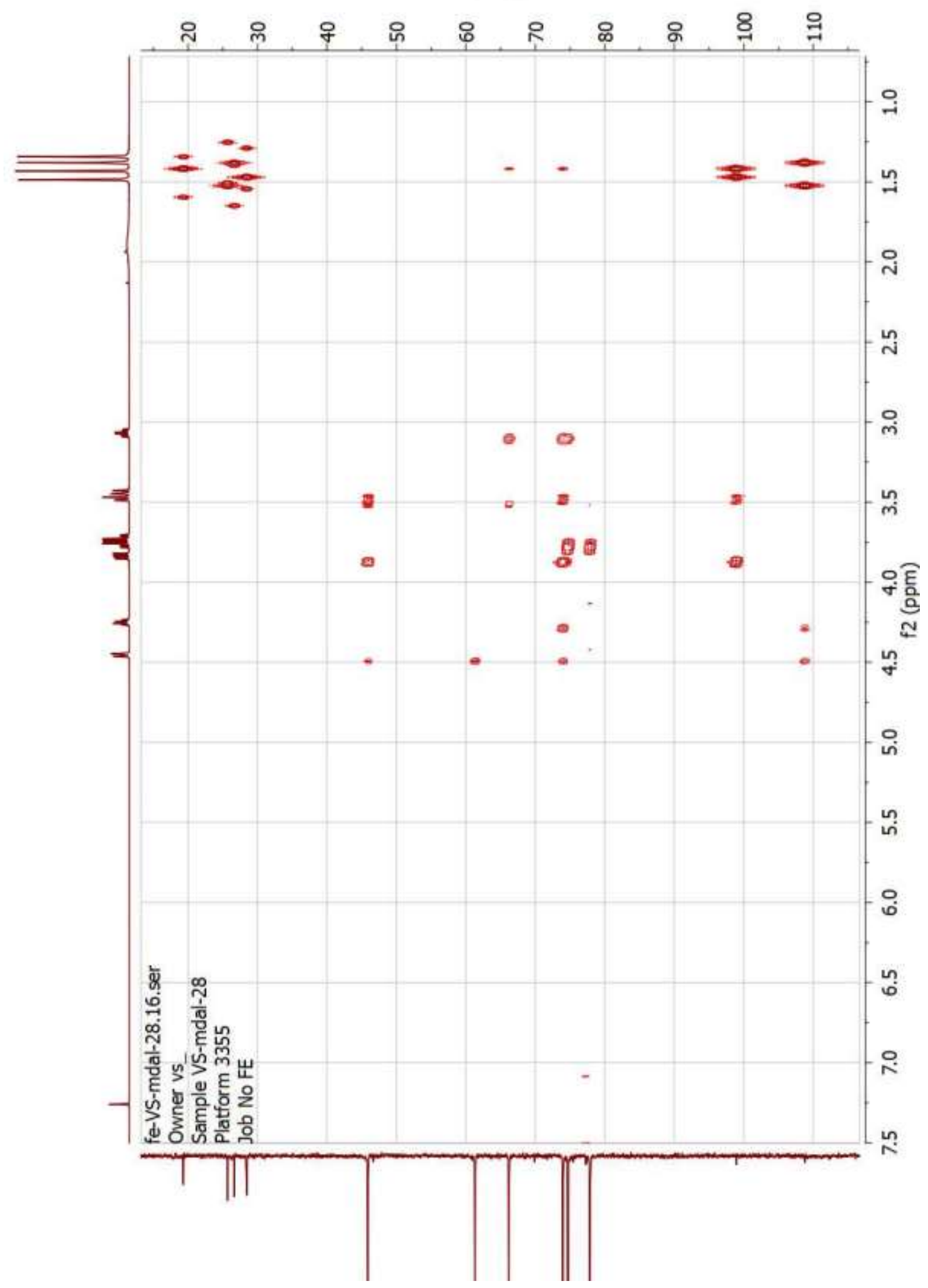

$\mathrm{HMBC}$ spectrum of starting material $1\left(500 \mathrm{MHz}, \mathrm{CDCl}_{3}\right)$ 
(widd) tis

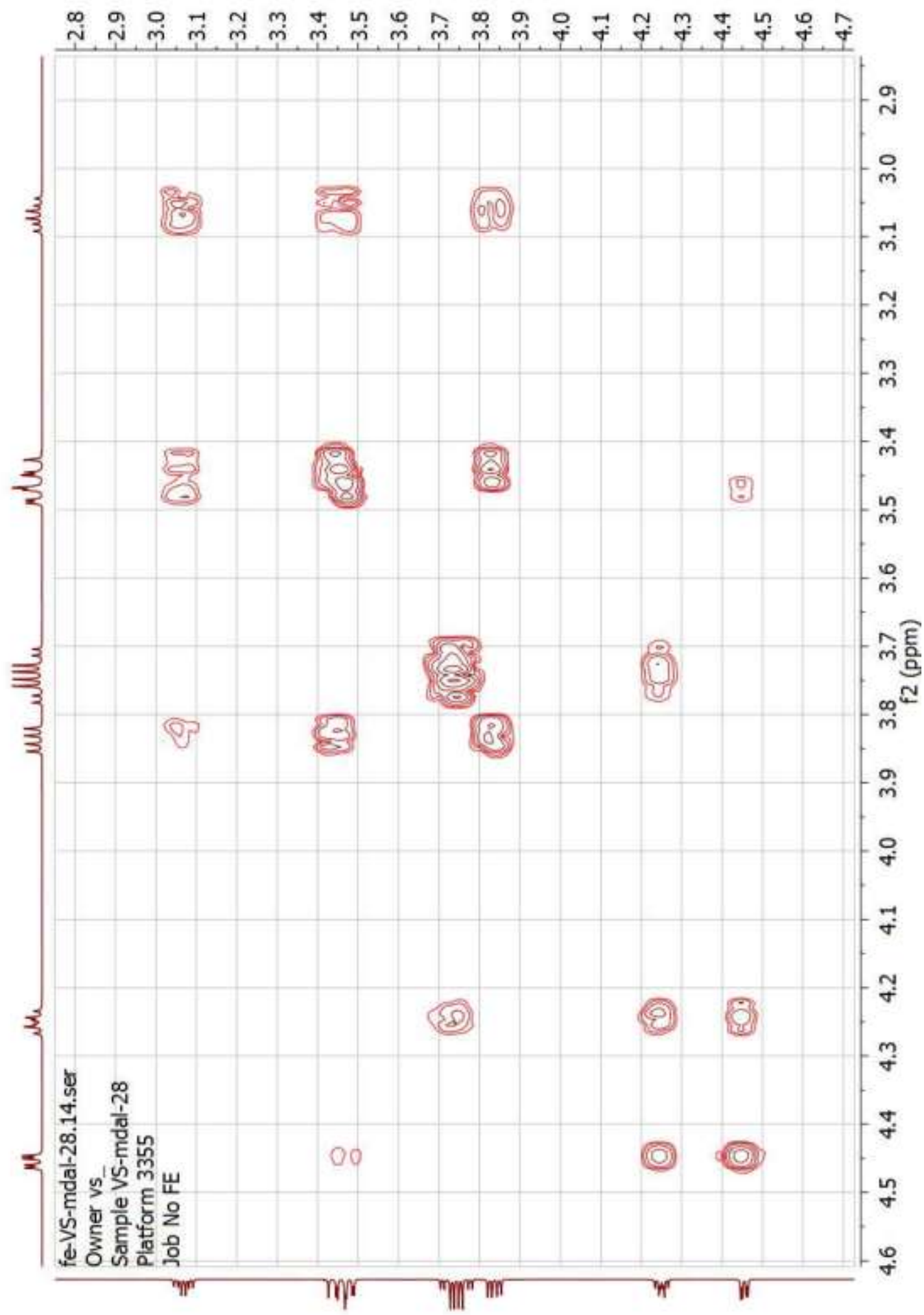

COSY spectrum of starting material $1\left(500 \mathrm{MHz}, \mathrm{CDCl}_{3}\right)$ 


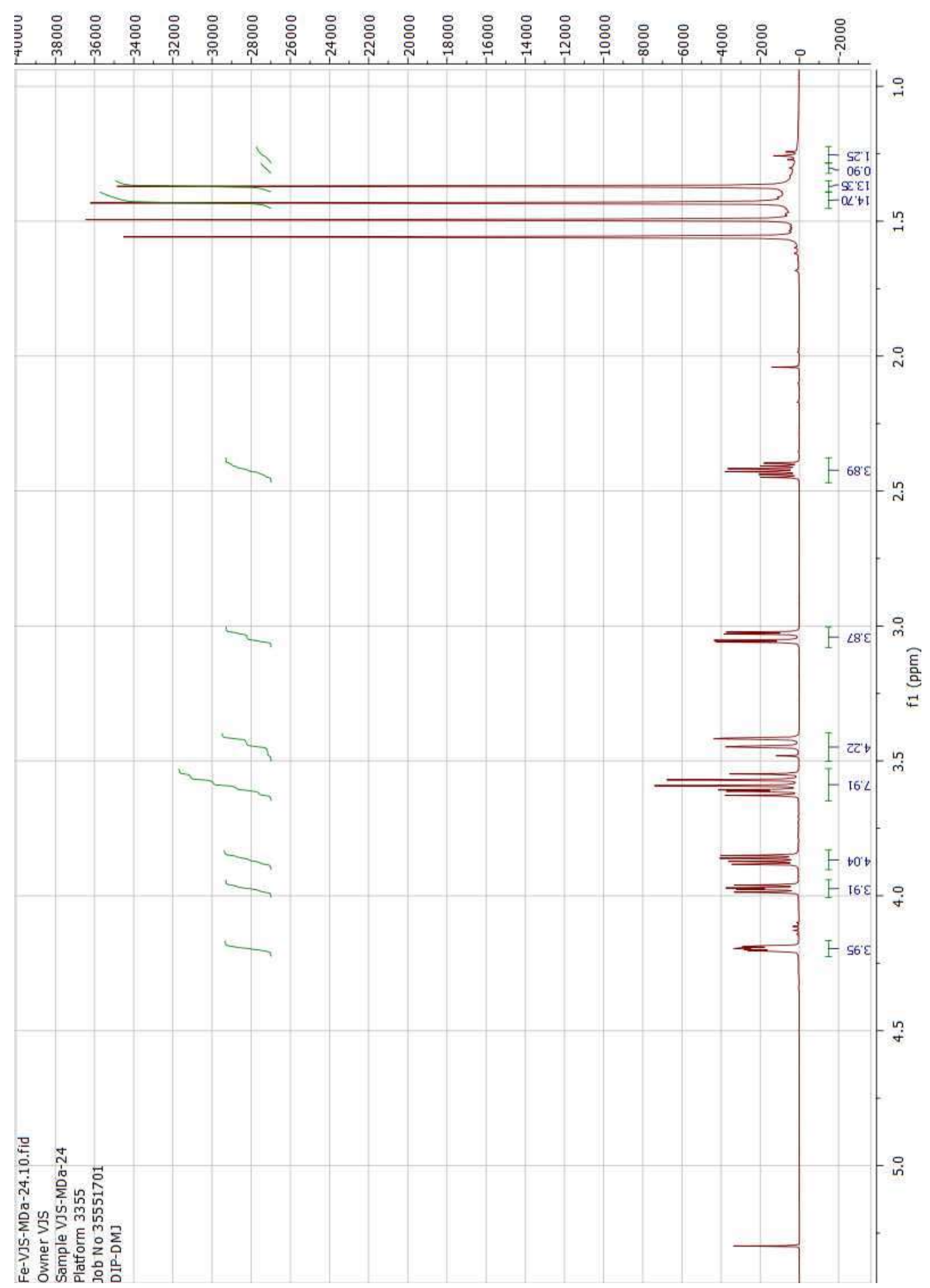

${ }^{1} \mathrm{H}$ NMR spectrum of $2\left(500 \mathrm{MHz}, \mathrm{CDCl}_{3}\right)$ 


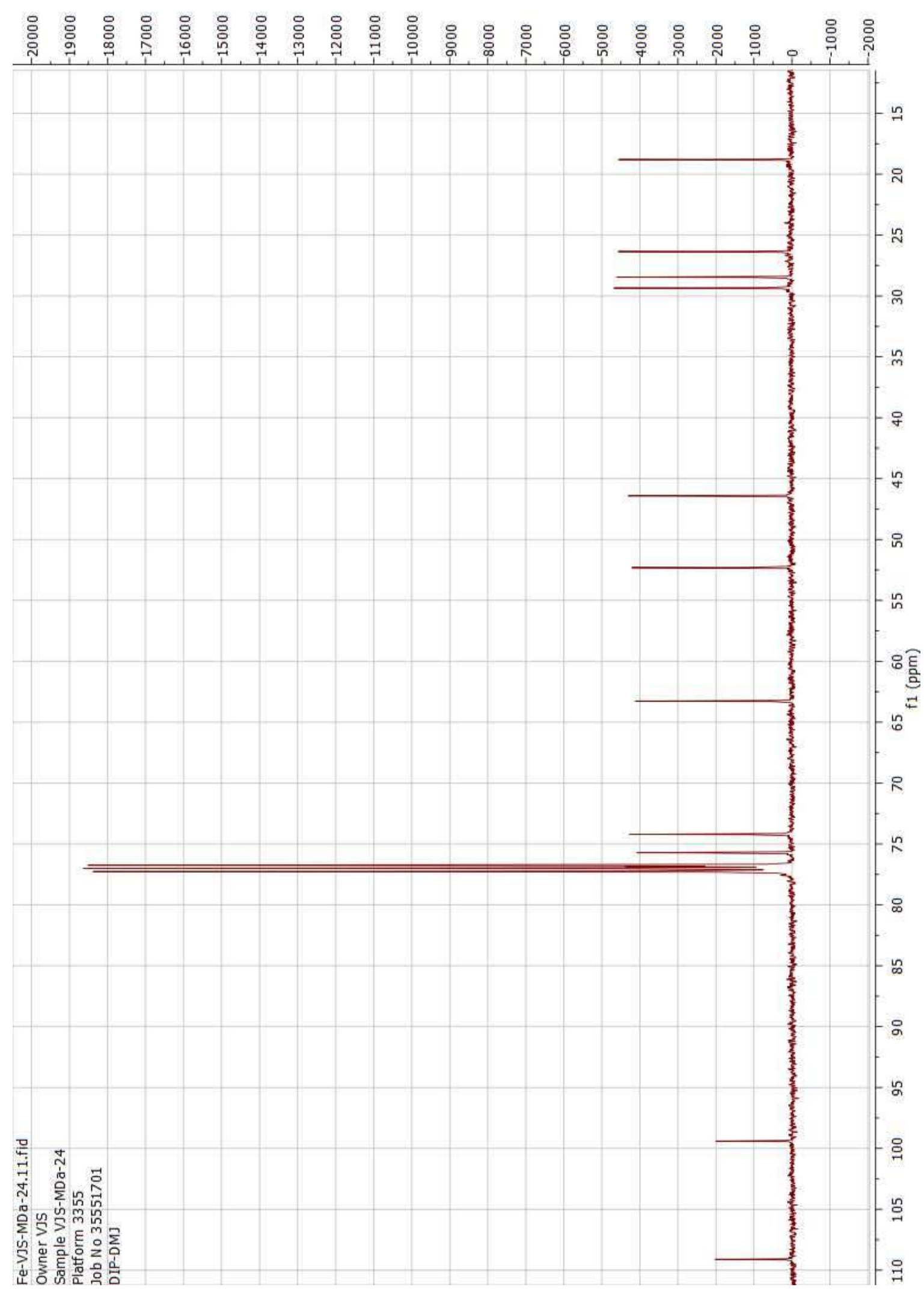

${ }^{13} \mathrm{C}$ NMR spectrum of $2\left(125 \mathrm{MHz}, \mathrm{CDCl}_{3}\right)$ 


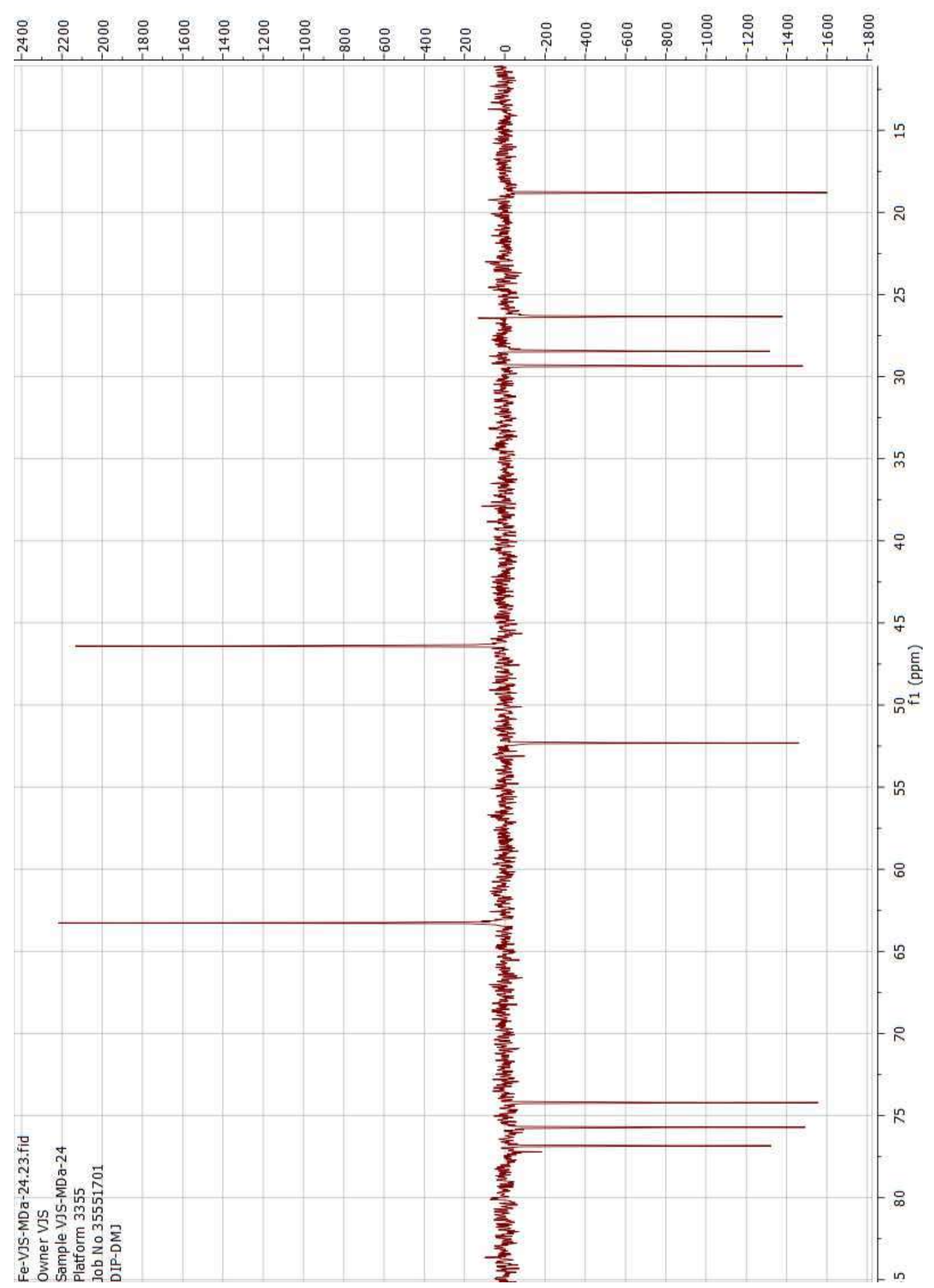

DEPT-135 spectrum of $2\left(125 \mathrm{MHz}, \mathrm{CDCl}_{3}\right)$ 


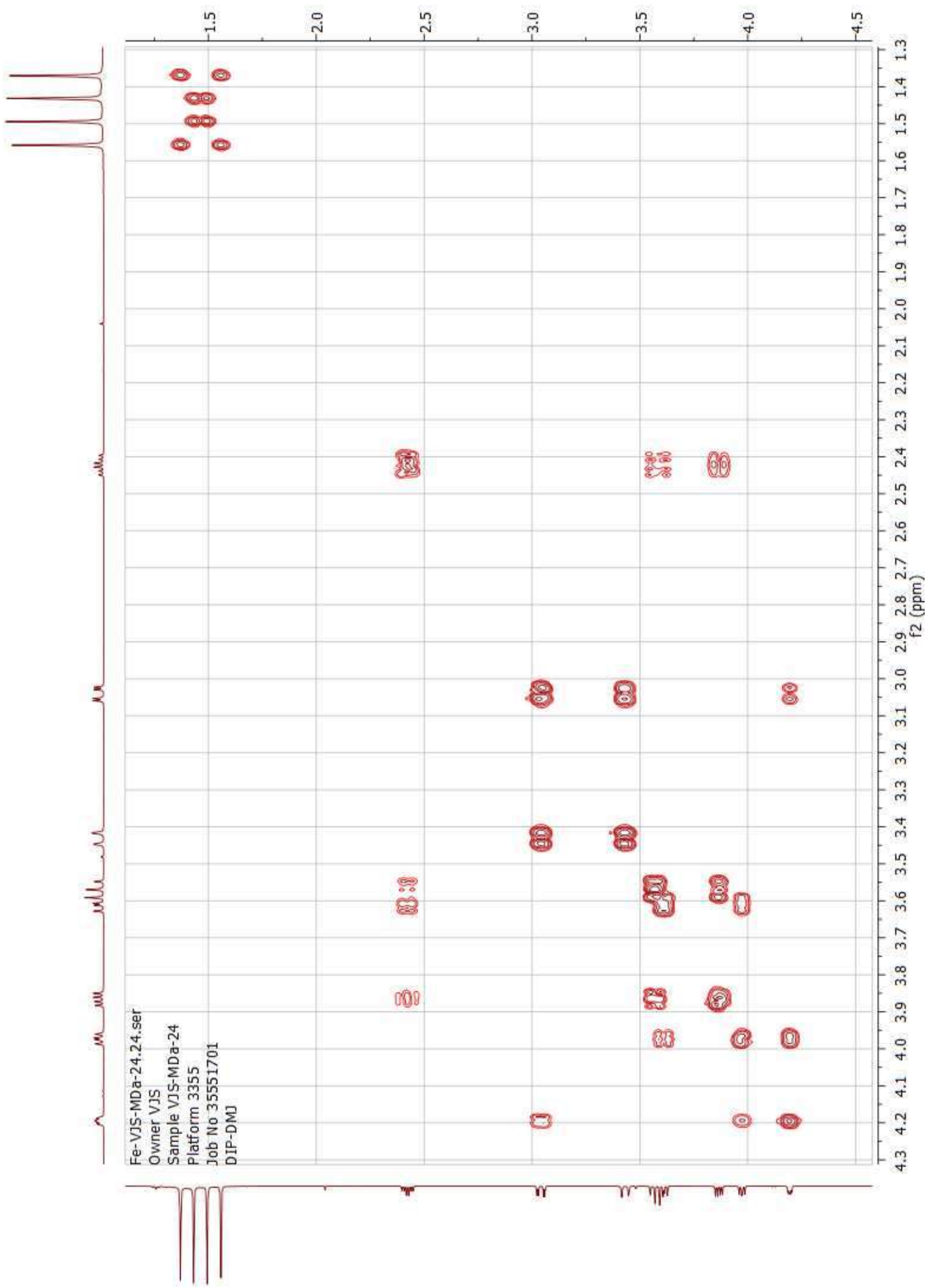

COSY spectrum of $2\left(500 \mathrm{MHz}, \mathrm{CDCl}_{3}\right)$ 
(wdd) if

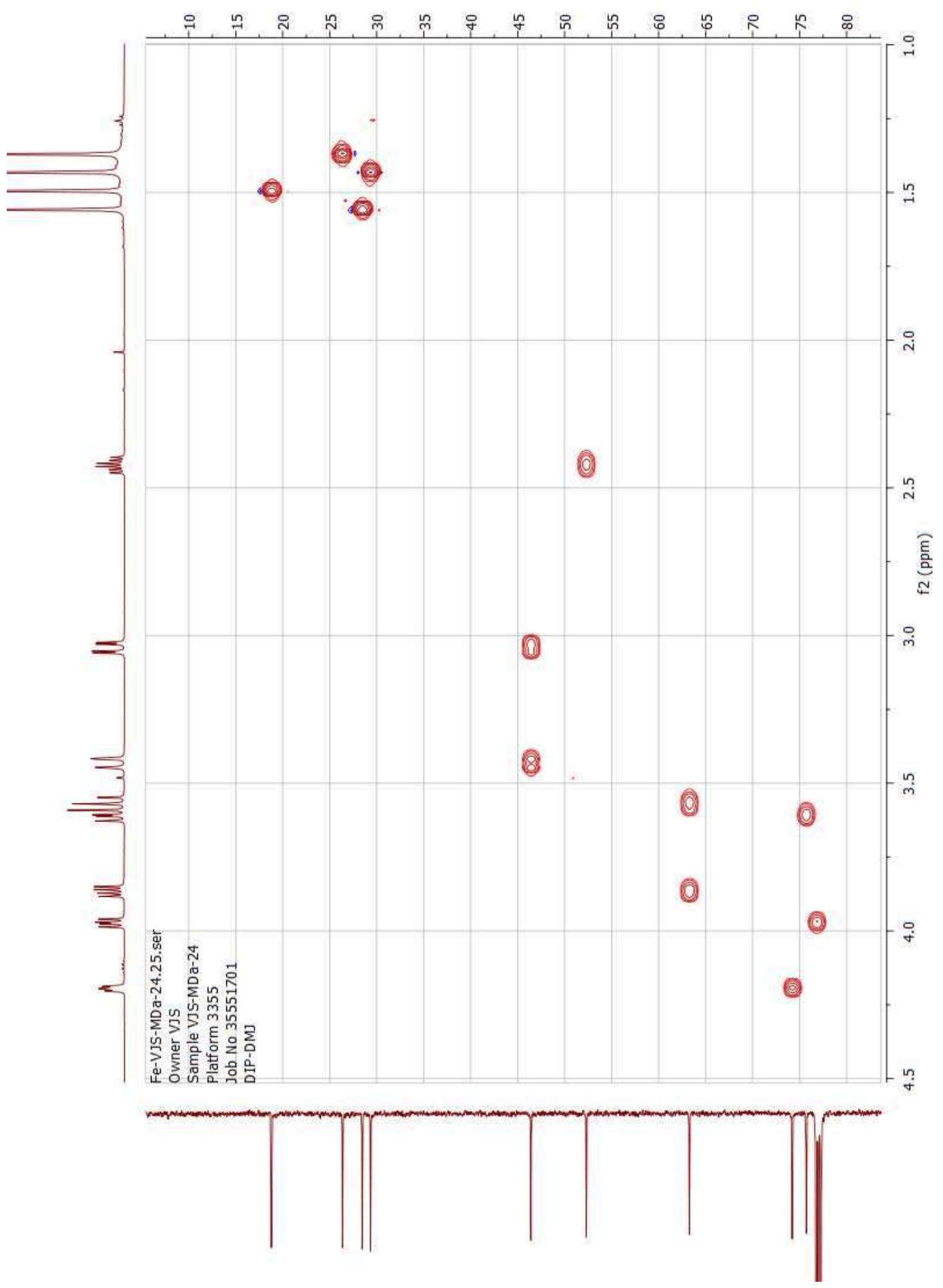

HSQC spectrum of $2\left(500 \mathrm{MHz}, \mathrm{CDCl}_{3}\right)$ 
(uidd) It

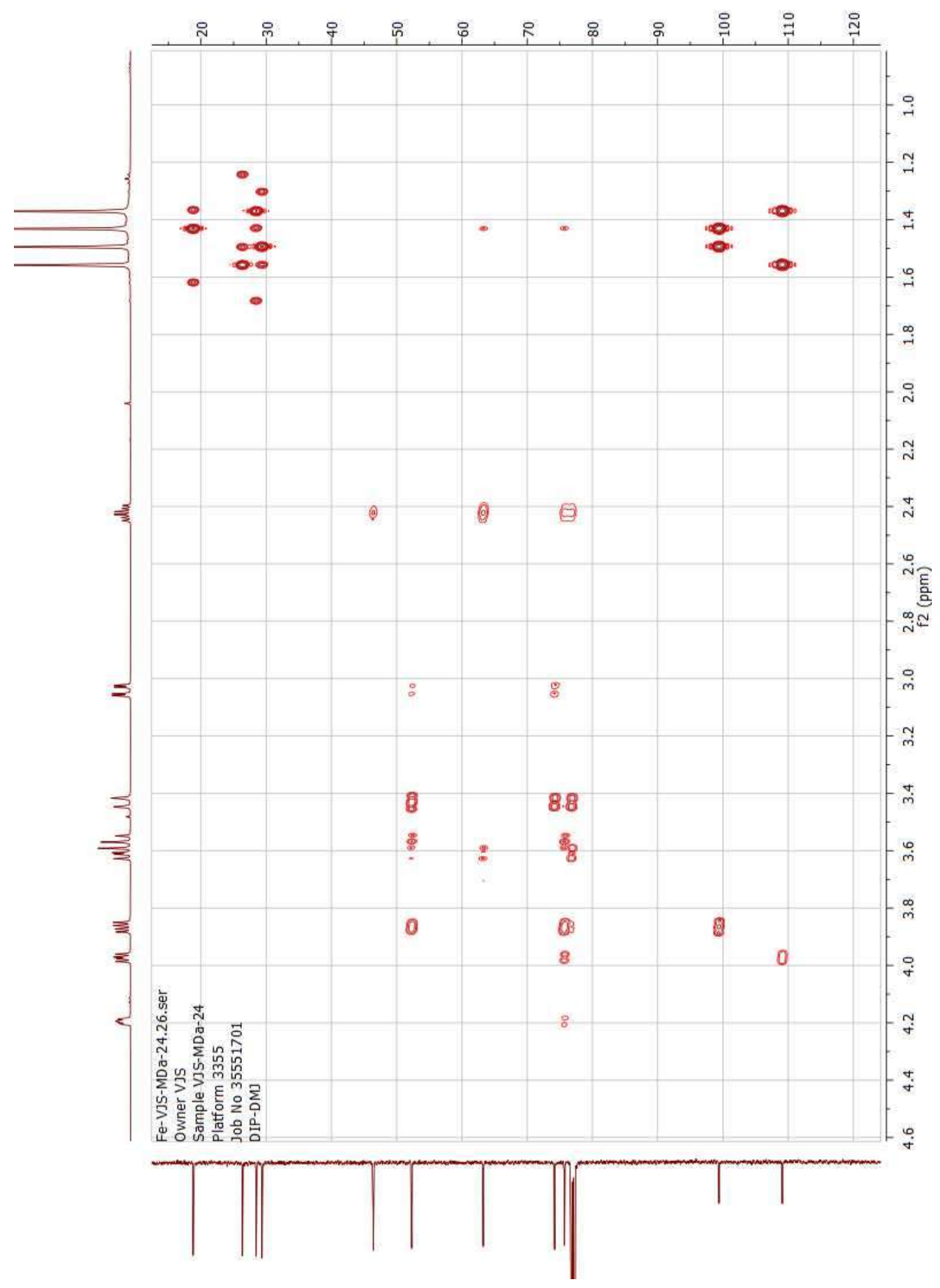

HMBC spectrum of $2\left(500 \mathrm{MHz}, \mathrm{CDCl}_{3}\right)$ 


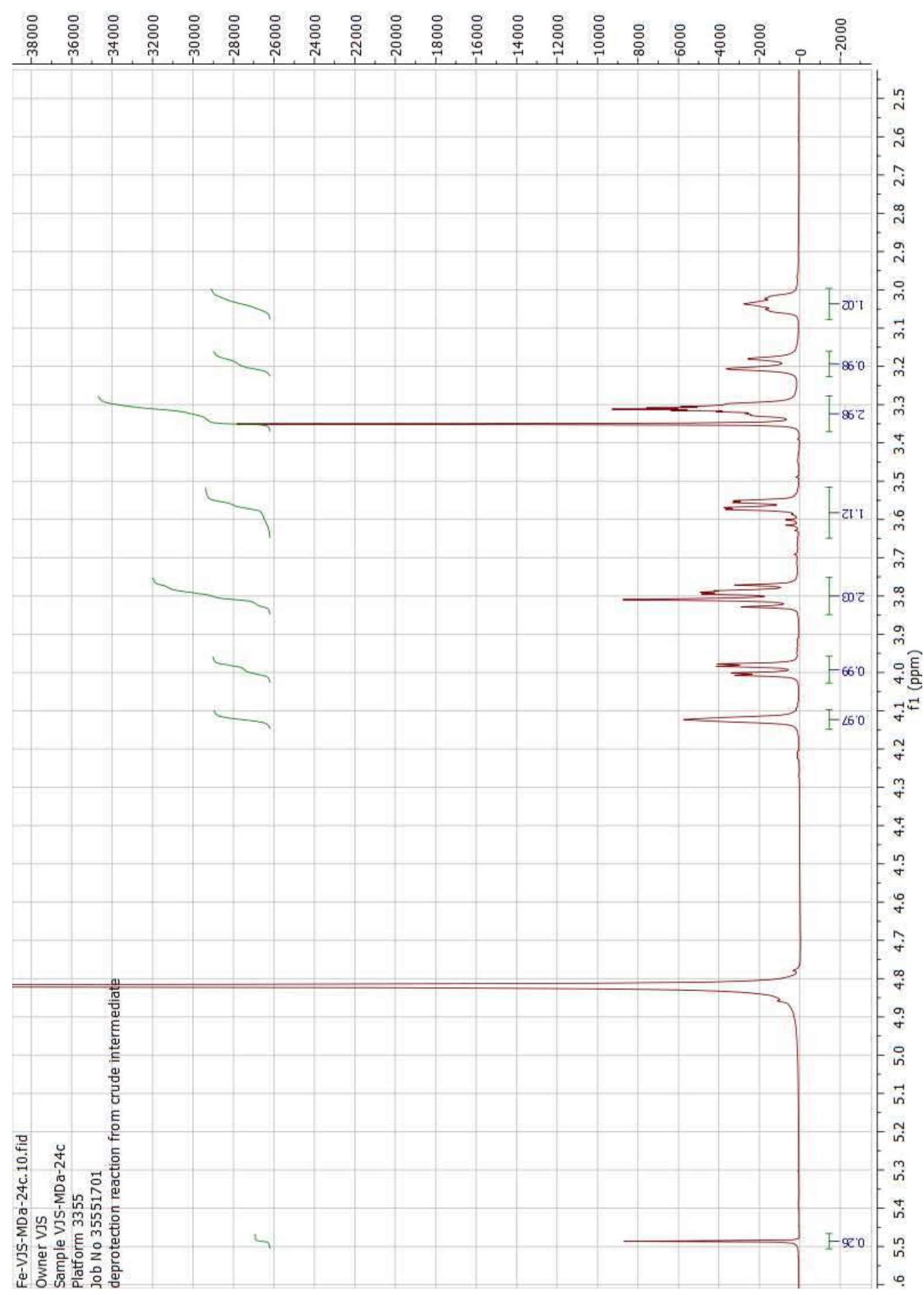

${ }^{1} \mathrm{H}$ NMR spectrum of $\mathbf{3}$ (500 MHz, MeOD) 


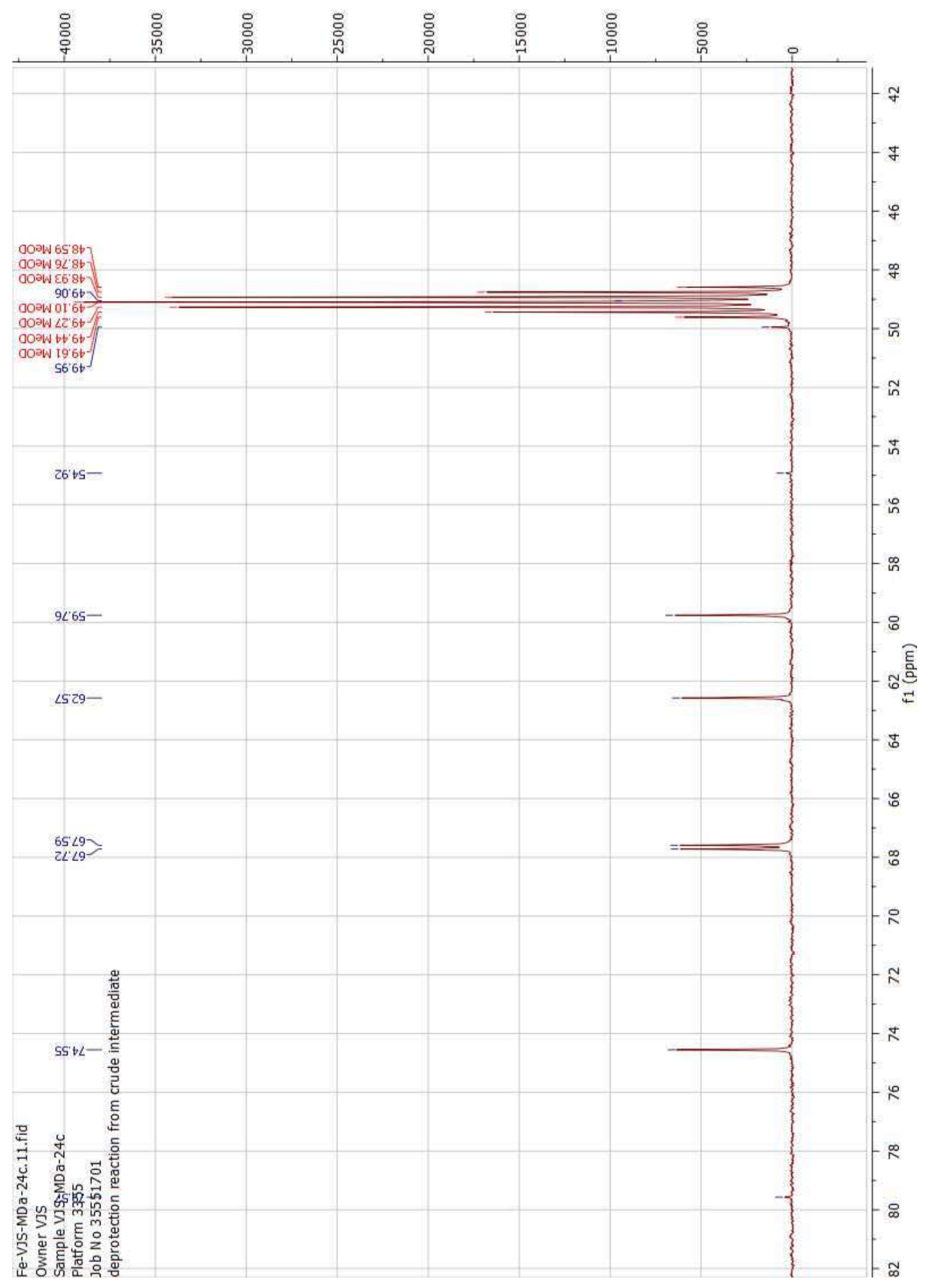

${ }^{13} \mathrm{C}$ NMR spectrum of 3 (125 MHz, MeOD) 


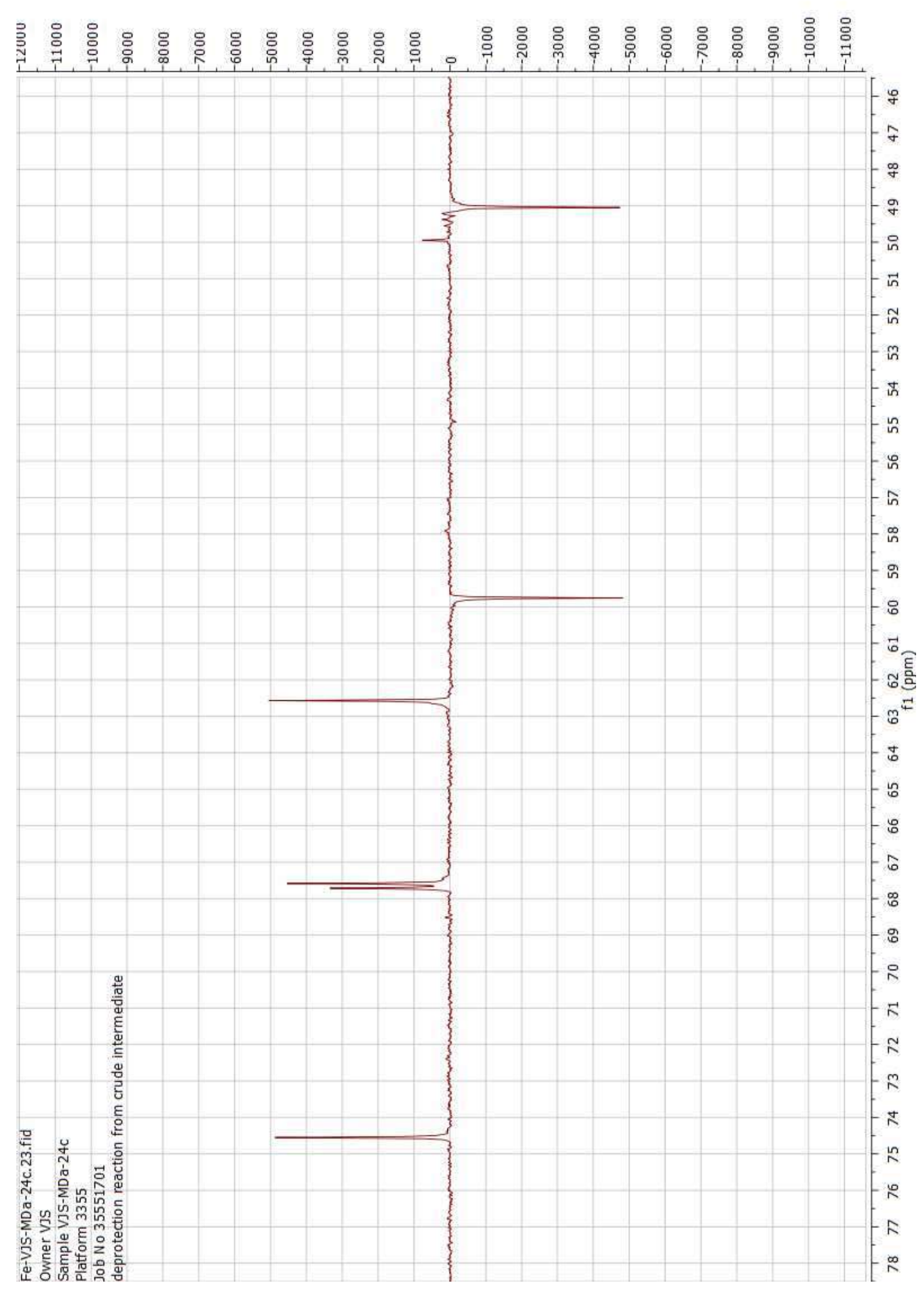

DEPT-135 spectrum of $\mathbf{3}$ (125 MHz, MeOD)

58 


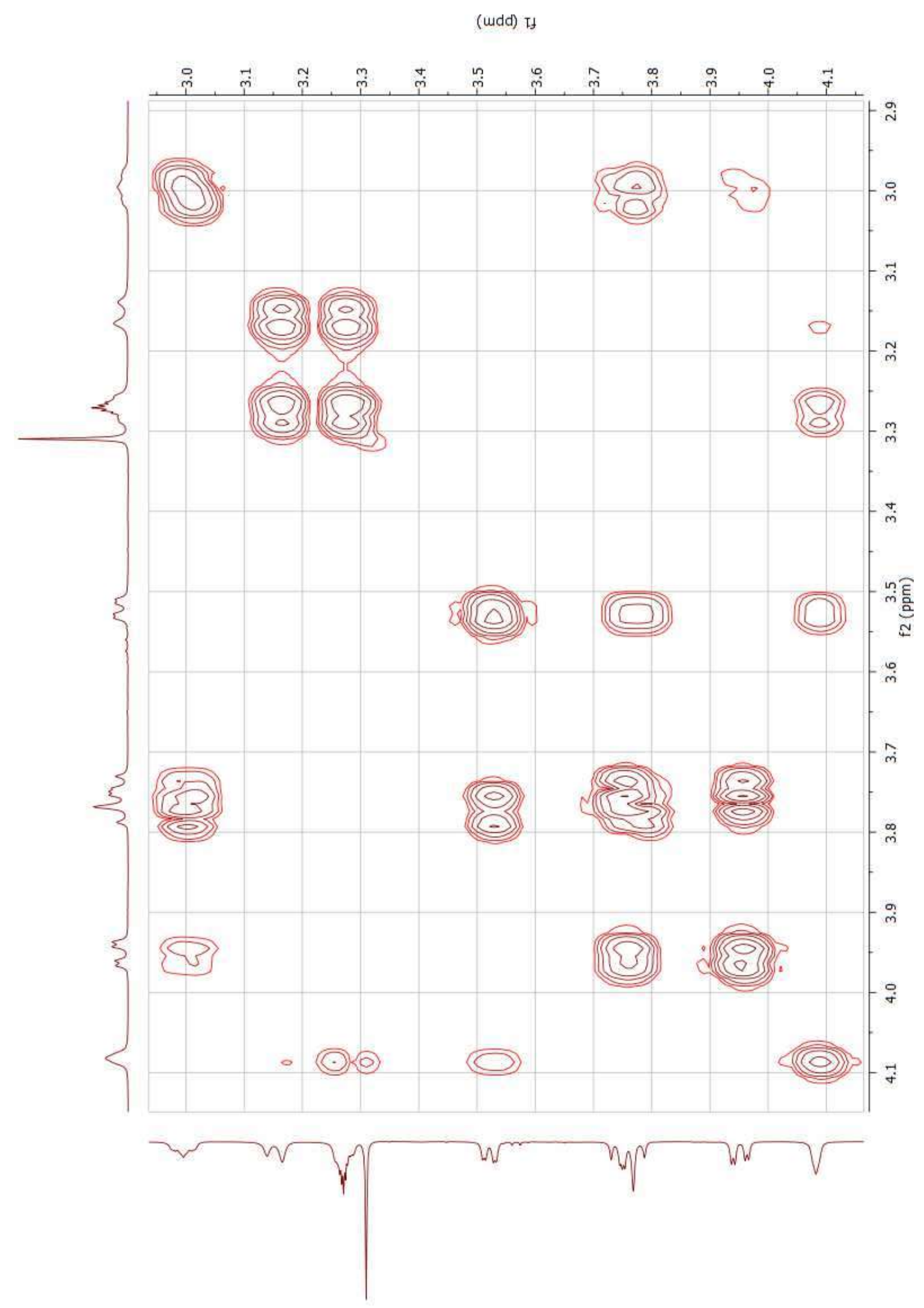

COSY spectrum of $\mathbf{3}$ (500 MHz, MeOD) 


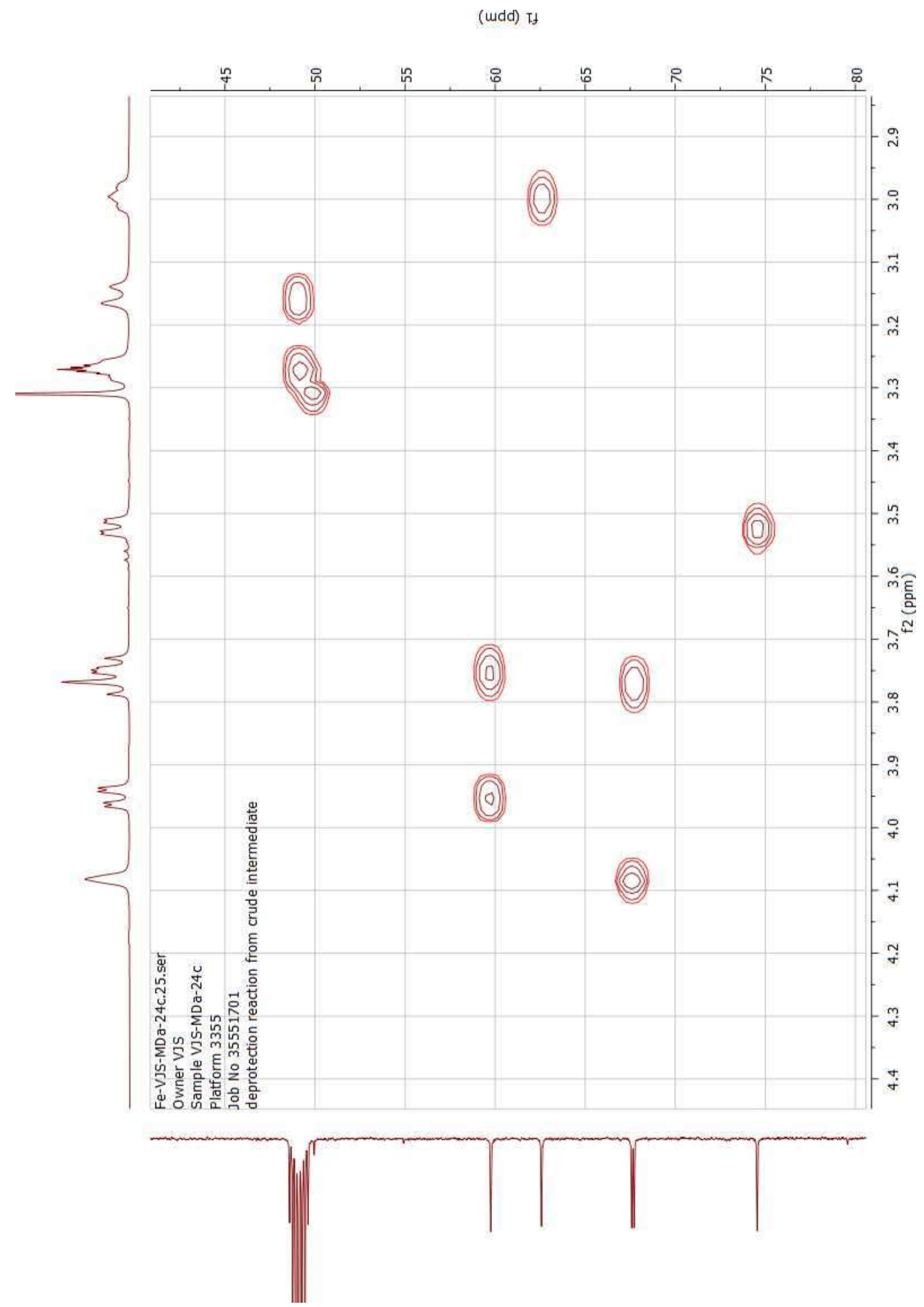

HSQC spectrum of $\mathbf{3}$ (500 MHz, MeOD) 
(udd) It

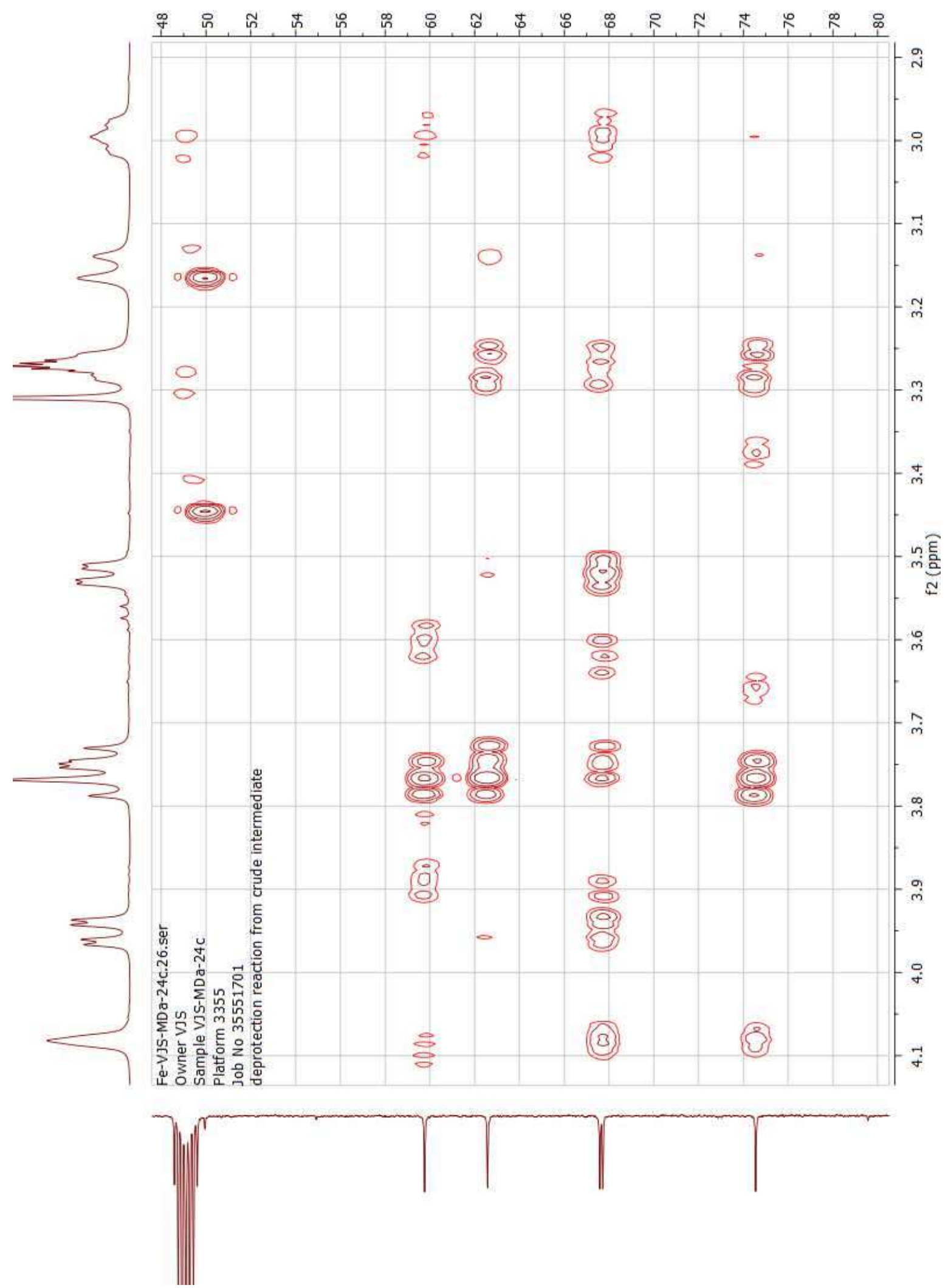

HMBC spectrum of $3(500 \mathrm{MHz}, \mathrm{MeOD})$ 


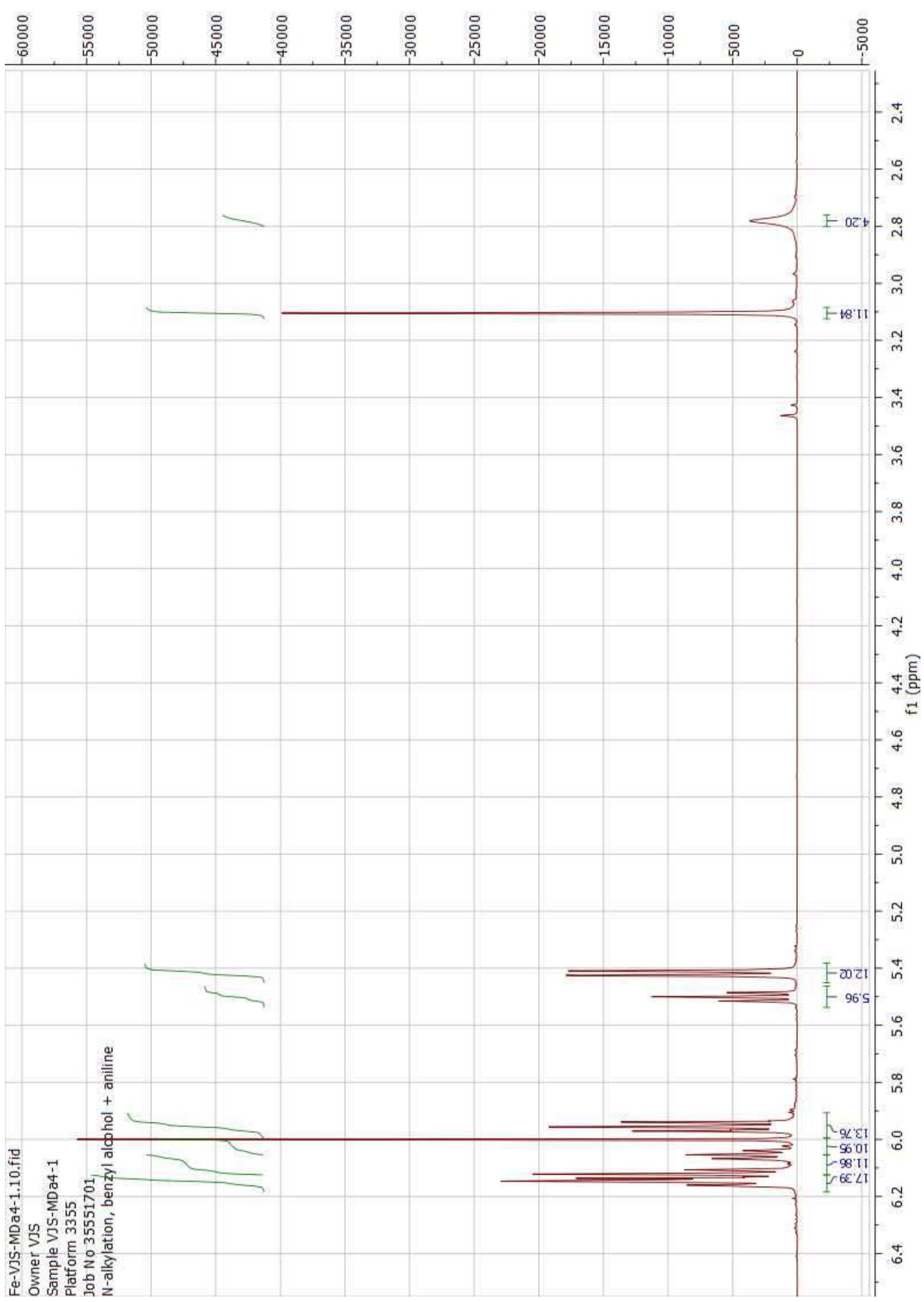

${ }^{1} \mathrm{H}$ NMR spectrum of benzylaniline (model reaction) 


\section{LCMS}
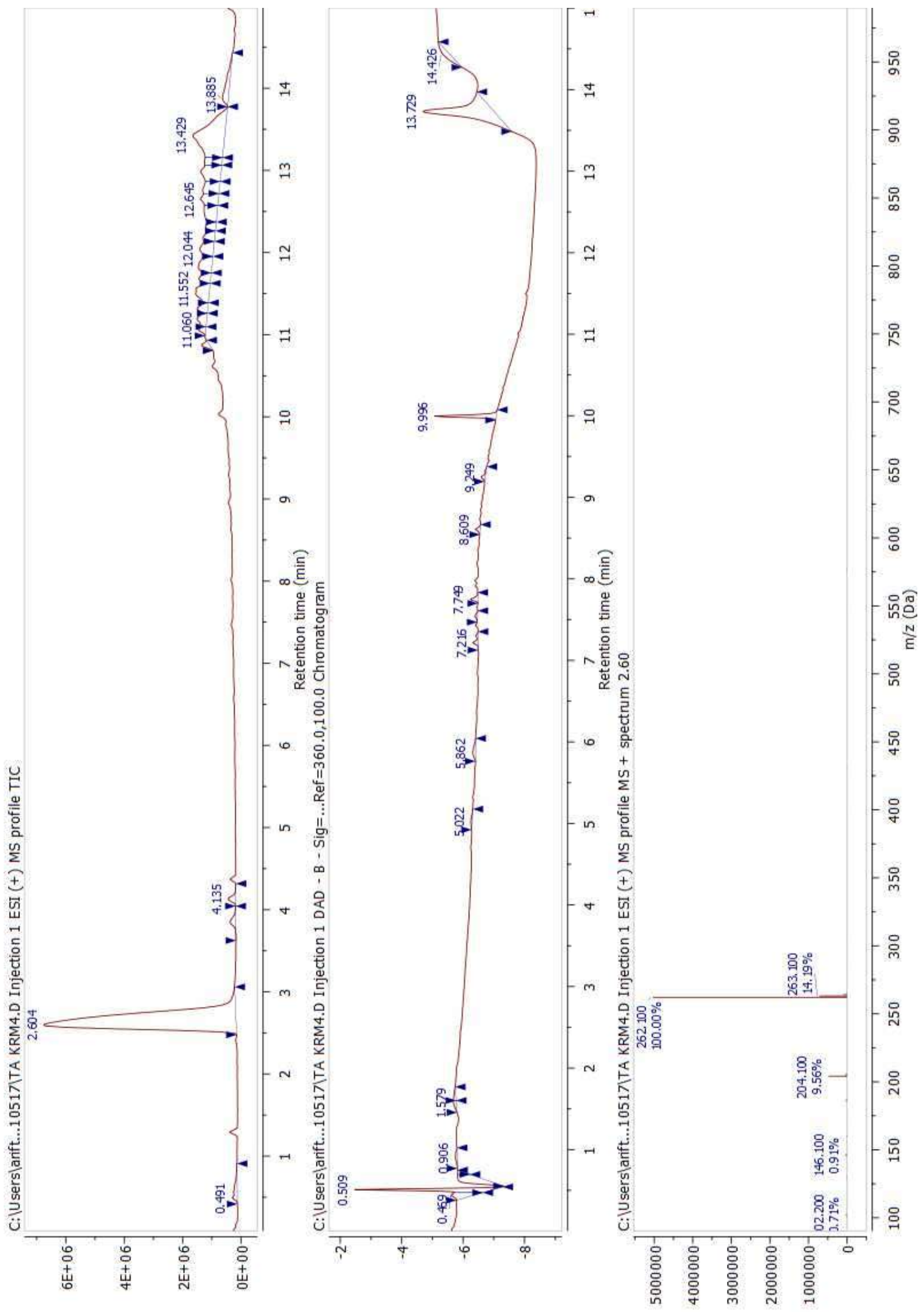

LCMS - KRM4 (1) 

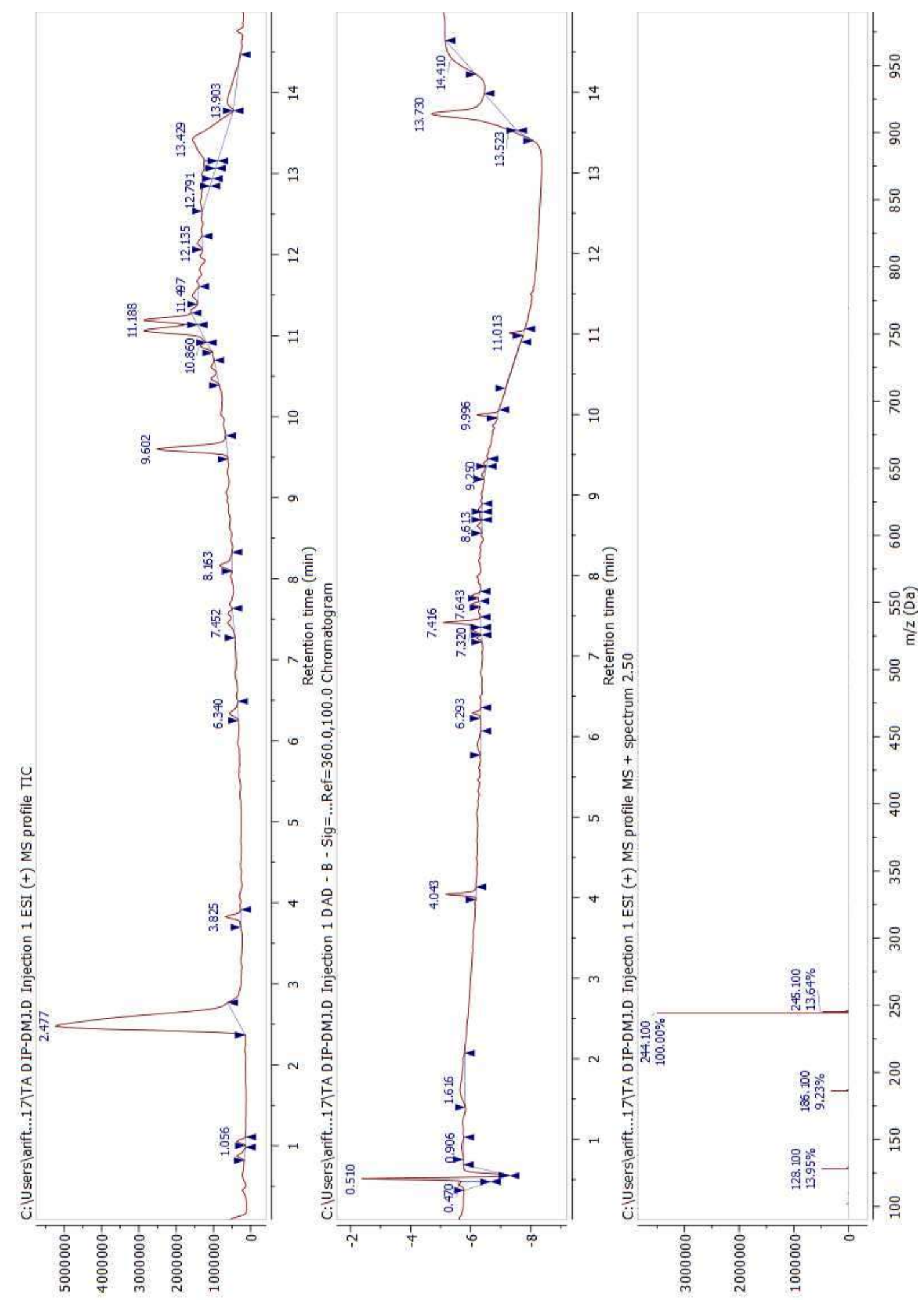

LCMS - 2 

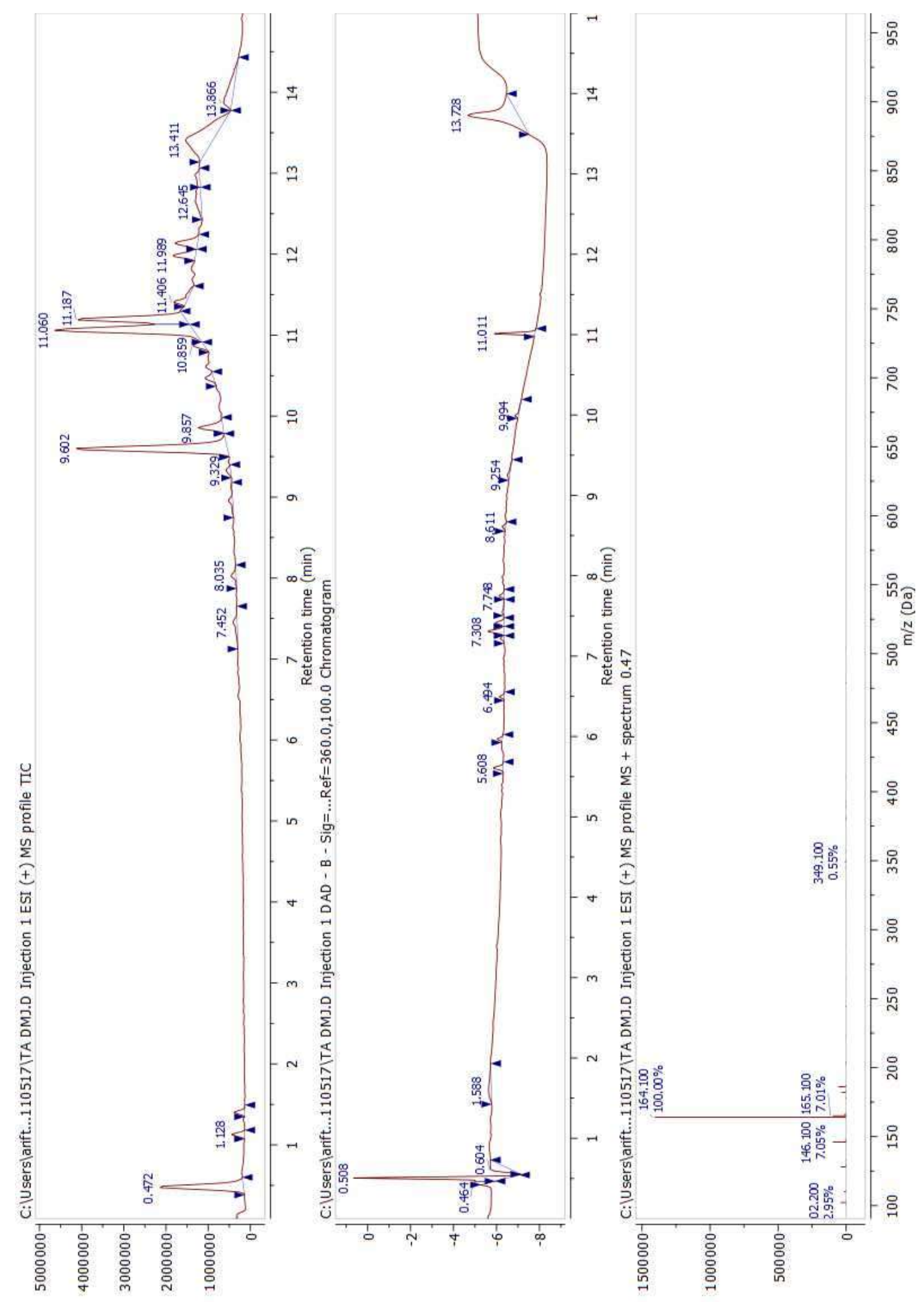

LCMS - DMJ (3) 

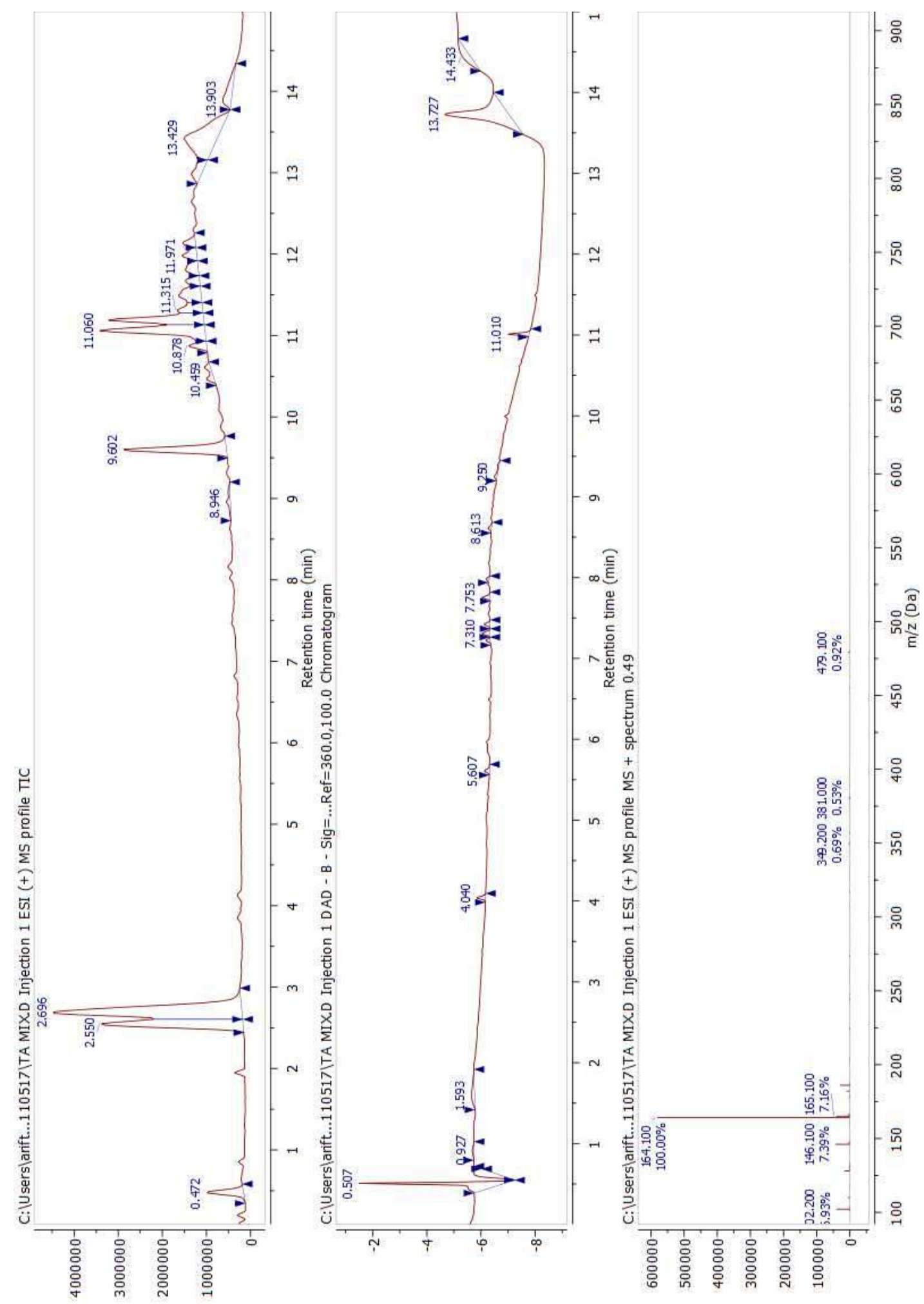

LCMS, compounds 1, 2 and $\mathbf{3}$ 


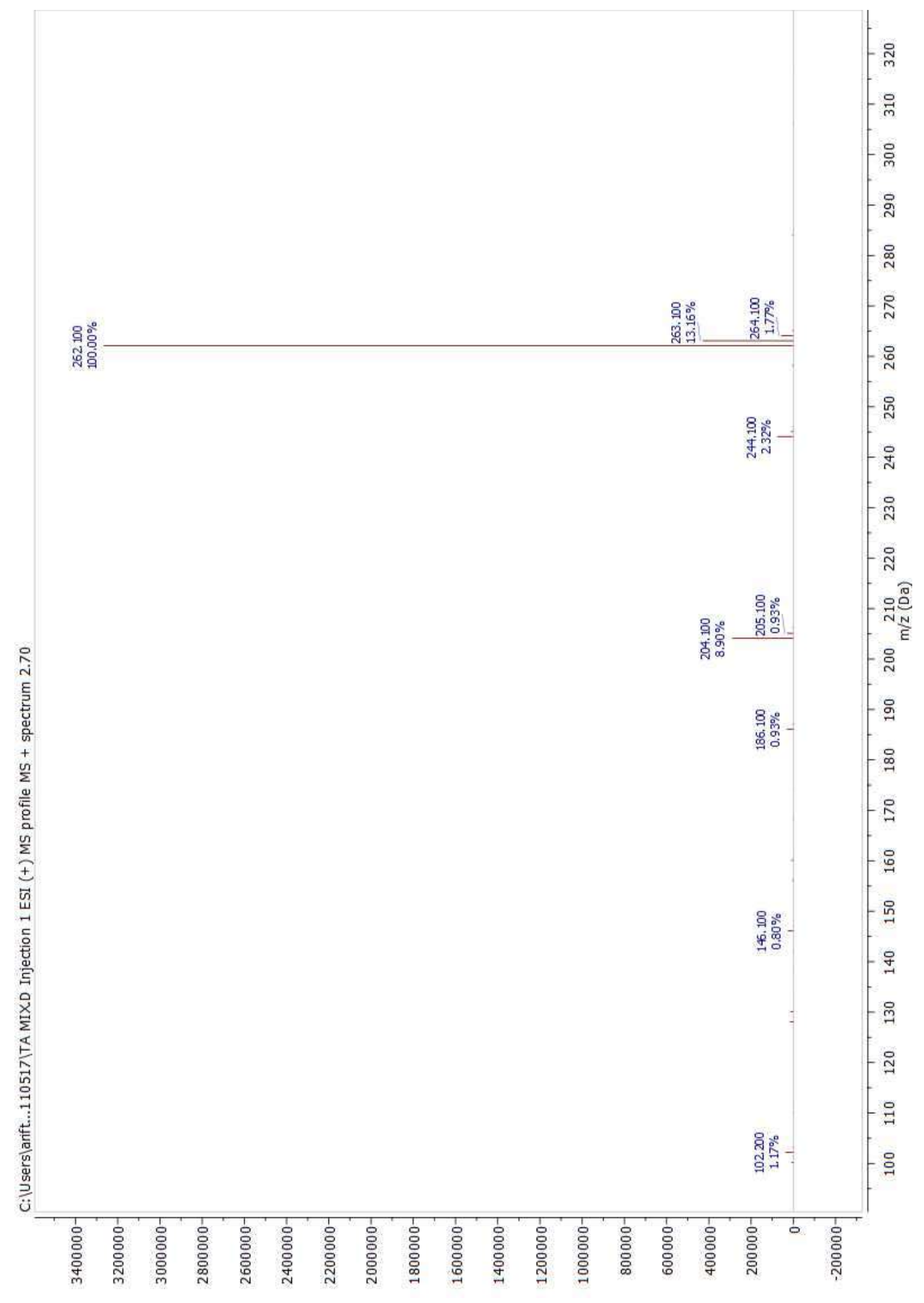

KRM4 (1) MS 


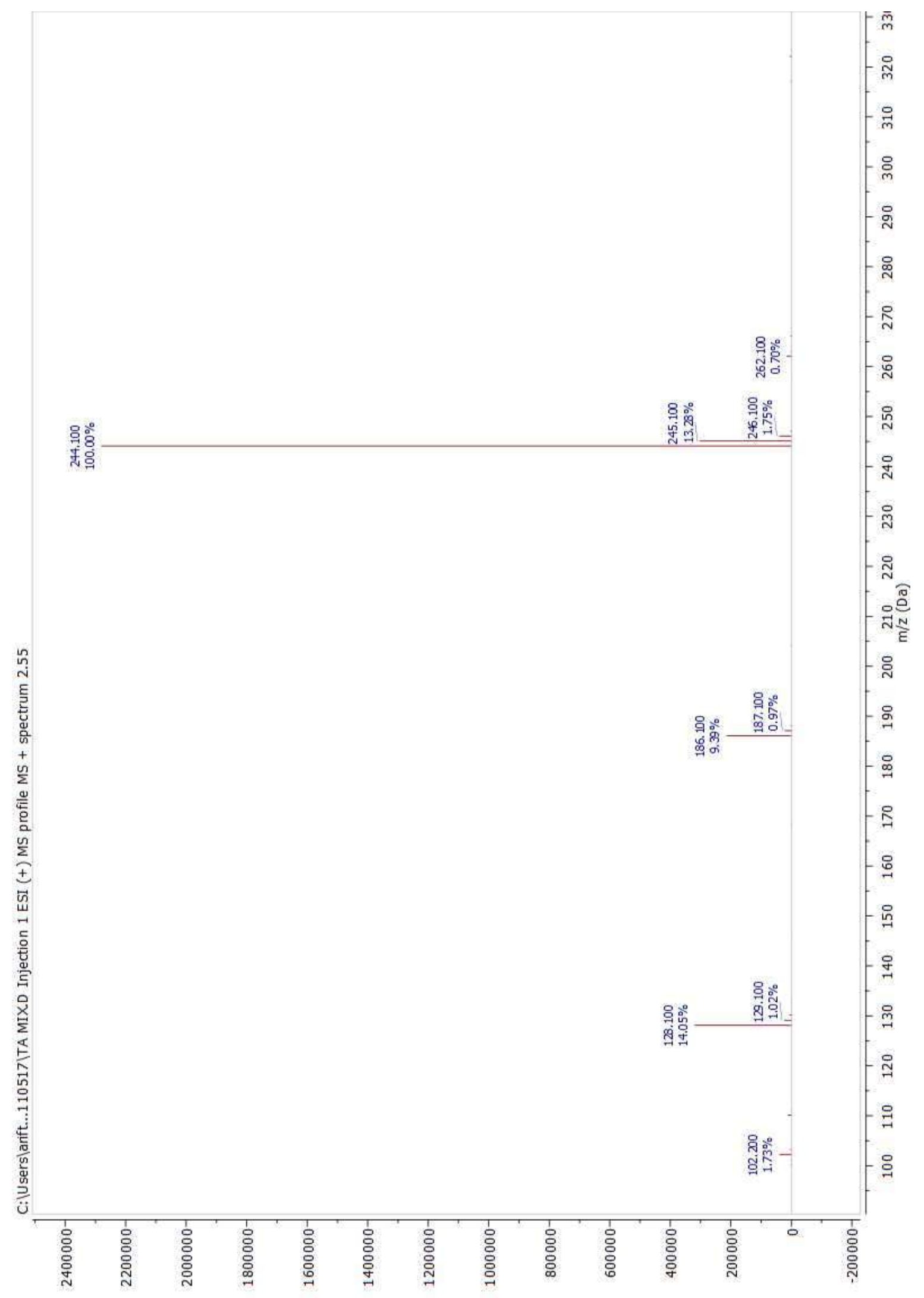

2 MS 


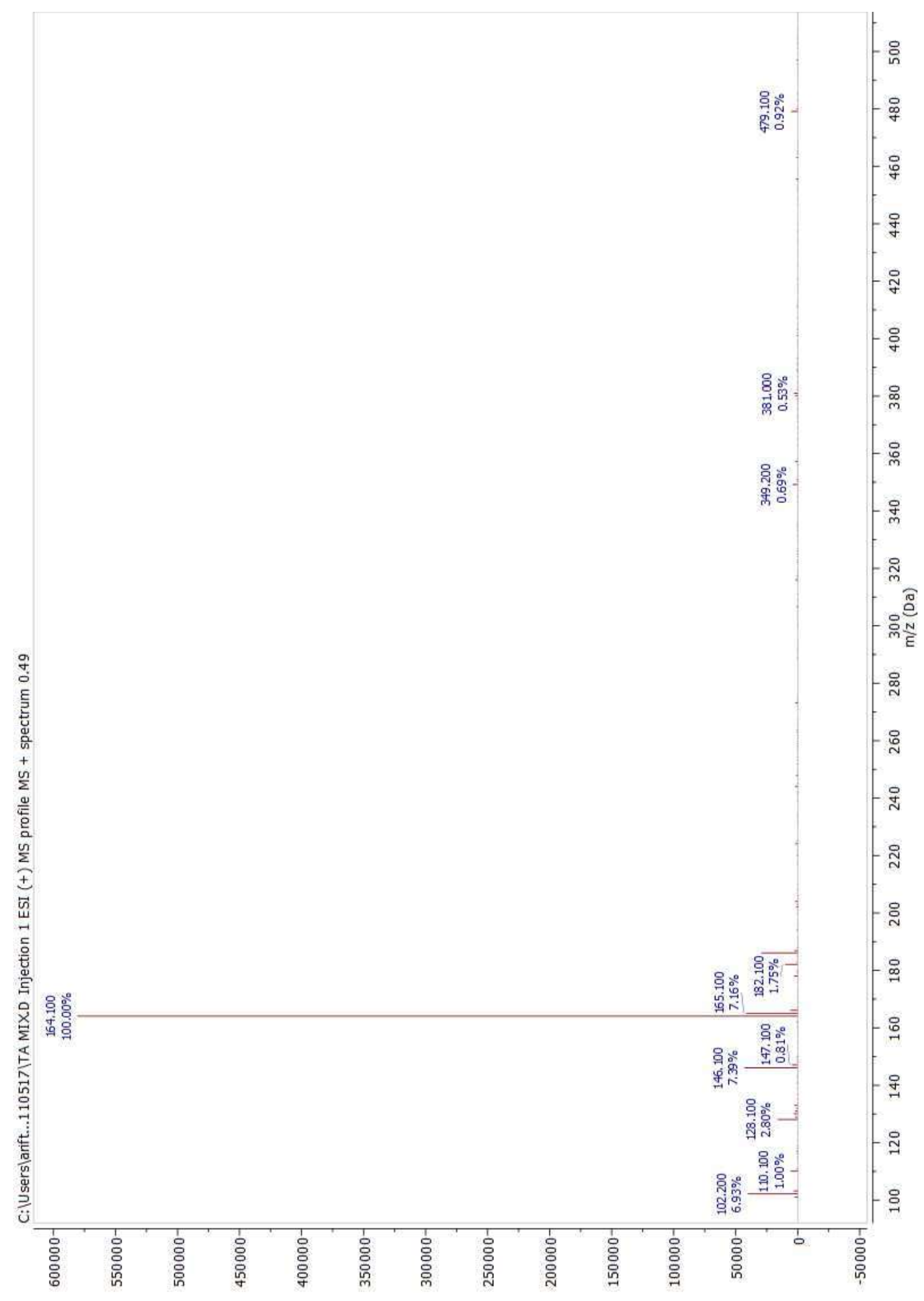

DMJ (3) MS 